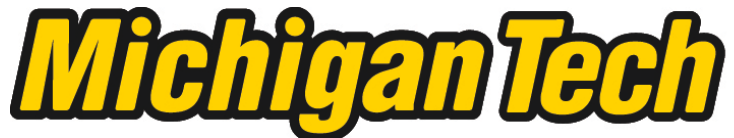 \\ Michigan Technological University Create the Future Digital Commons @ Michigan Tech
}

\section{Local Use and Management of Tasba (Senna obtusifolia) in the Traditional Food System of Sanguere Paul, North Cameroon}

Mary E. Snyder

Michigan Technological University

Follow this and additional works at: https://digitalcommons.mtu.edu/etds

Part of the Forest Sciences Commons

Copyright 2013 Mary E. Snyder

\section{Recommended Citation}

Snyder, Mary E., "Local Use and Management of Tasba (Senna obtusifolia) in the Traditional Food System of Sanguere Paul, North Cameroon", Master's Thesis, Michigan Technological University, 2013.

https://doi.org/10.37099/mtu.dc.etds/623

Follow this and additional works at: https://digitalcommons.mtu.edu/etds

8 Part of the Forest Sciences Commons 
LOCAL USE AND MANAGEMENT OF TASBA (SENNA OBTUSIFOLIA) IN THE TRADITIONAL FOOD SYSTEM OF SANGUÉRÉ PAUL, NORTH CAMEROON

By

Mary E. Snyder

A THESIS

Submitted in partial fulfillment of the requirements for the degree of

MASTER OF SCIENCE

In Forestry

MICHIGAN TECHNOLOGICAL UNIVERSITY

2013

C2013 Mary E. Snyder 
This Thesis, "Local Use and Management of Tasba (Senna obtusifolia) in the Traditional Food System of Sanguéré Paul, North Cameroon" has been approved in partial fulfillment of the requirements for the Degree of MASTER OF SCIENCE IN FORESTRY

School of Forest Resources and Environmental Science

Thesis Adviser: Dr. Catherine Tarasoff

Committee Member: Dr. Blair Orr

Committee Member: Dr. Dieter Adolphs

School Dean: Dr. Terry Sharik 


\section{TABLE OF CONTENTS}

LIST OF FIGURES.............................................. 6

LIST OF TABLES................................................ 8

ACKNOWLEDGEMENTS........................................... 9

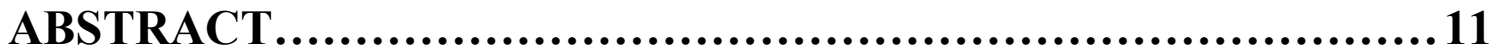

1. INTRODUCTION................................................12

2. COUNTRY BACKGROUND...................................16

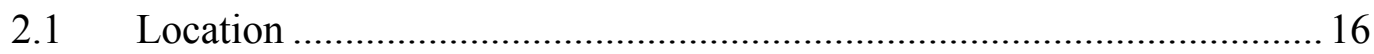

$2.2 \quad$ People

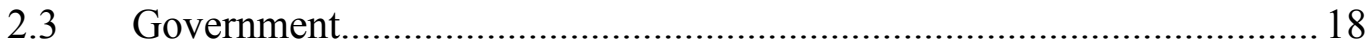

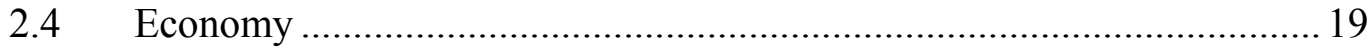

3. STUDY BACKGROUND.........................................21

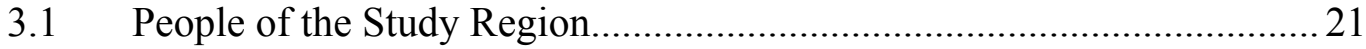

3.2 Climate, Ecosystem, and Environmental Issues ……………………......22

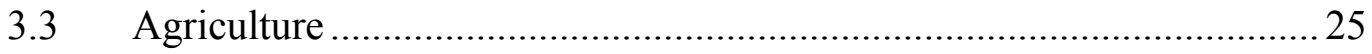

3.4 Gender Work Roles and Food Production ................................................2

3.5 Wild Plants Used as Food Sources …………………………………........ 32

3.6 Weeds as Wild Foods................................................................................ 34

3.7 Gathered Foods as Part of Livelihood Strategies........................................ 34

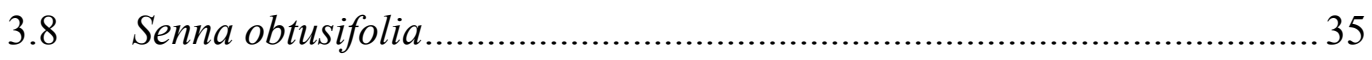

4. METHODS............................................................................38

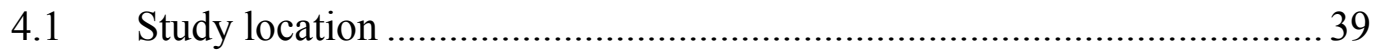

4.2 Wild food Collection and Use................................................................. 41

4.2.1 Demographic Data and Socioeconomic Clas ..................................42 


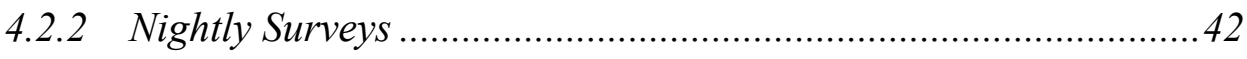

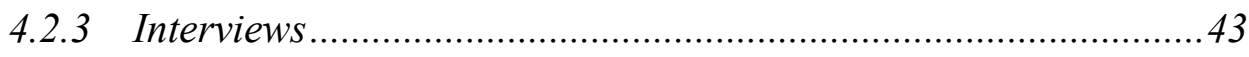

4.2.4 Field Measurements................................................................4

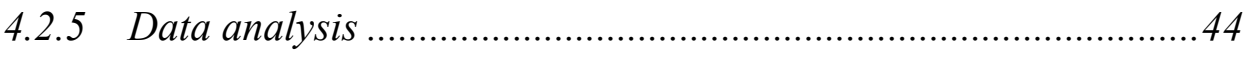

5. RESULTS AND ANALYSIS.....................................46

5.1. Results of Semi-Structured Open Interviews............................................ 46

5.2. Results of Nightly Surveys ................................................................... 48

5.3. Collection Patterns Based on Socioeconomic Conditions ..........................52

5.3.1. Likelihood of Collection Based on the Father's Job ...................53

5.3.2. Likelihood of Collection Based on the Mother's Job ....................55

5.4. Preserving (Drying) Traditional Vegetables ...............................................57

5.4.1 Likelihood of Drying Traditional Vegetable Species........................59

5.4.2. Likelihood of Drying Based on the Father's Job...........................59

5.4.3. Likelihood of Drying Based on the Mother's Job..........................61

5.5. Locations of Collecting Traditional Vegetables and Tasba........................62

5.5.1. Proportion of Vegetable Collection Locations Based on Job Type

5.5.2. Proportion of Tasba Collection Based on Job Type.......................64

5.5.3. Likelihood of Collection Based on Job ............................................66

5.6. Changes of Behavior throughout the Rainy Season .................................. 68

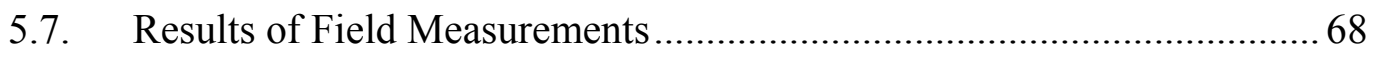

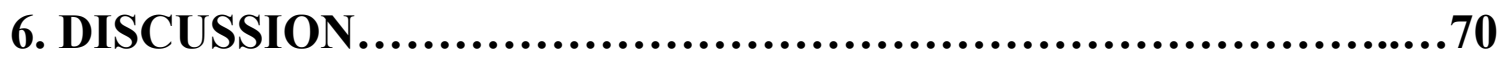

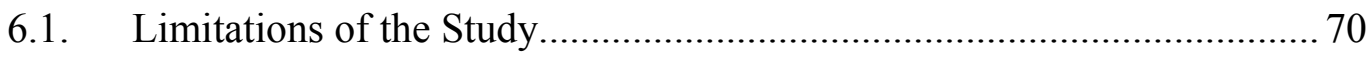

6.2. Time Saving Activities and Tasba Use ………………………................ 71

6.3. Proximity, Collection Locations, and Species Composition .....................72 
6.4. Household Income and Food Management Strategies

6.5. Seasonal Changes of Tasba Management and Tasba's Importance During the "Hungry Season"..

6.6. Importance of Tasba and En Brousse areas in the Traditional Vegetable System.

7. CONCLUSION....................................................80

8. WORKS CITED..................................................83

APPENDIX A............................................................90

APPENDIX B......................................................92

APPENDIX C............................................................93

APPENDIX D.......................................................95 


\section{LIST OF FIGURES}

Figure 1.1. Main carrefour (intersection) in Sanguéré Paul..................................... 12

Figure 1.2. Author working in the fields with women......................................... 13

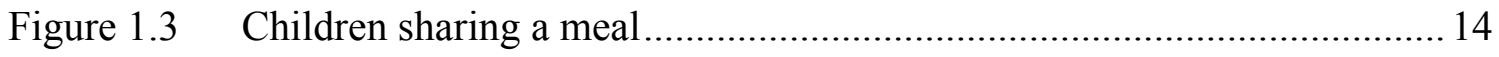

Figure 2.1. Map of Cameroon in relation to surrounding African countries .............. 16

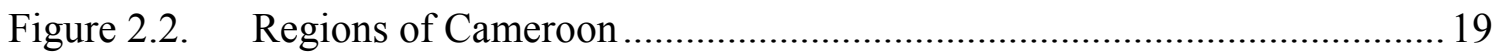

Figure 3.1. The Benue River................................................................................ 23

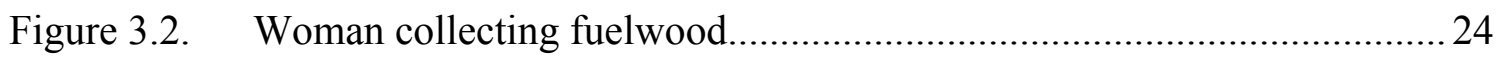

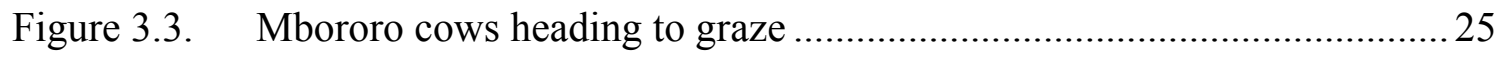

Figure 3.4. Millet farmed in the Extreme North ................................................... 27

Figure 3.5. Cotton Produced in the North Region ........................................... 28

Figure 3.6. Mbororo woman preparing couscous over the fire................................. 30

Figure 3.7. Typical Cameroonian meal, couscous and sauce (haako) ....................... 31

Figure 3.8. Women taking gardened vegetables to Garoua for sale ......................... 32

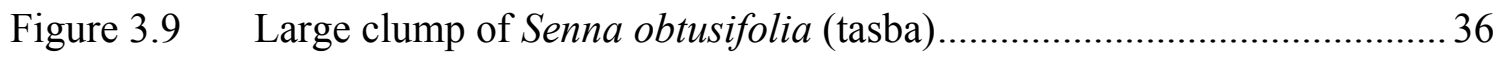

Figure 4.1 Market Area in Sanguéré Paul on a non-market day.............................. 40

Figure 4.2 Typical market day in a large market in the Grand North...................... 40

Figure 5.1 Number of days separate households reported collecting traditional vegetables.............................................................................. 49

Figure 5.2. Proportion of species collected in household surveys during the June October 2012 rainy season........................................................ 50

Figure 5.3. Distribution of preserving tasba (drying) verses eating tasba fresh ........51

Figure 5.4. Distribution of tasba collection sties the entire population ....................52

Figure 5.5. Likelihood of households in Sanguéré Paul collecting traditional plant species based on husband's job categories compared to subsistence

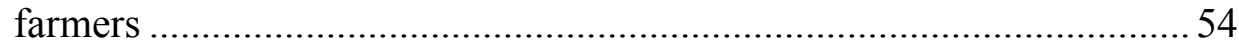

Figure 5.6. Likelihood of households in Sanguéré Paul collecting tasba based on husband's job categories compared to subsistence farmers. 
Figure 5.7. Likelihood of households in Sanguéré Paul collecting traditional vegetables based on mother's job categories compared to subsistence farmers

Figure 5.8. Likelihood of household in Sanguéré Paul collecting tasba based on mother's job categories compared to subsistence farmers. 57

Figure 5.9. Woman and children removing leaves from plants ............................58

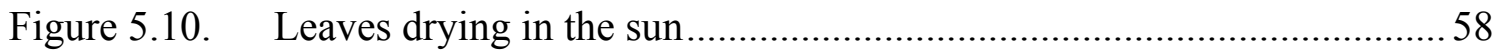

Figure 5.11. Likelihood of drying the four most common traditional vegetables compared to tasba

Figure 5.12. Likelihood of households in Sanguéré Paul to dry traditional vegetables based on different father's job categories compared to subsistence farmers 60

Figure 5.13. Likelihood of households in Sanguéré Paul to dry traditional vegetables based on different mother's job categories compared to subsistence farmers 62

Figure 5.14. Proportion of collection locations by father's job 63

Figure 5.15. Proportion of collection locations by mother's job .64

Figure 5.16. Proportion of tasba collection locations by father's job 65

Figure 5.17. Proportion of tasba collection locations by mother's job .66 


\section{LIST OF TABLES}

Table 5.1. Five most popular species mentioned in nightly surveys ........................50

Table 5.2. Likelihood of collecting traditional vegetables at different locations based on if the mother has a job other than subsistence farming ......................6 67

Table 5.3. Likelihood of collecting tasba different locations based on if the mother has a job other than subsistence farming ..........................................6 67

Table 5.4. Contingency table comparing Sunny and Shaded Cultivated and Uncultivated Sites 


\section{ACKNOWLEDGEMENTS}

I would like thank my adviser Catherine Tarasoff for her interest in my project and for helping me however possible, even while on maternity leave. I want to thank my committee member Blair Orr for helping me with ideas and guiding me through the writing process, motivating me when I may have lost focus.

I want to thank my parents John and Barbara Snyder for encouraging me to do the PCMI program in the first place, and for their support and encouragement during all my time in Cameroon. Thank you to my sisters Katie and Jamie Snyder who supported me through phone calls and letters. And a double thank you to Katie for helping me through the graduate school process, ensuring me (as a fellow graduate student) that I was not alone in my feelings and that I would get through this. Thank you to my Grandpa, Donald Longworth and my Grandma Katherine Longworth who told me they worried about me every day, but also wrote me and supported me, reminding of what a great opportunity this was encouraging to get to know and love the people of my community. Thanks to my Aunt, Sue Stempky, as well as my mother, for taking the time to come visit me and get to know my friends and my life in Cameroon.

I want to thank my friend Michael Rotter, for encouraging and inspiring me to research and explore and reminding me of my scientific abilities, and always being there to talk to me about my project, even when I was across the world and he was working on his own project. Also, thank you to Kevin Bentley who called me most holidays and birthdays, read my letters and really listened to what I was saying. Thank you to my PCV 
friends, notably Nuru West, Jennifer Baskerville, Dori Bahir and Melissa Persaud for helping me stay sane when I was under times of stress. Thank you to Trevor Taylor and Meghan Pollack for letting me use their photos to help tell my story.

Thank you to my officemates Brian Barbre, Noah Goyke, Kyle Fredrickson and Brian Pattullo for listening to me, supporting me and distracting me enough to keep me sane during the writing process. I enjoyed getting to know you boys this semester.

Last but certainly not least I want to thank the women of my community, especially Tabitha and her children. You welcomed me into your family and showed me strength and kindness like I have never known before, I could not have done this without your friendship. 


\begin{abstract}
The purpose of this study is to examine the importance of the wild edible weed tasba (Senna obtusifolia) in Sanguéré Paul, Cameroon by examining how households use and manage the plant. This study found that local management of tasba is minimal compared to other traditional vegetables. Tasba was collected most frequently from en brousse or the communal, fallowed land which is often too degraded for traditional field crops to grow. Women subsistence farmers were closely involved with tasba as they are the ones responsible for food production within the family. Socioeconomic differences between women affects how they manage tasba and other vegetables to form a livelihood strategy to achieve food security within the family. Modifications and changes in management and use of tasba are influenced by time, proximity and income based on her perspective, preferences and resources available. Overall, tasba is an integral part of the traditional food system in Sanguéré Paul, and can play a role in the uncertain ecological and social setting of northern Cameroon.
\end{abstract}




\section{CHAPTER 1: INTRODUCTION}

I served as an Agroforestry volunteer in the town of Sanguéré Paul from December 2010 to November 2012 (Figure 1.1). Upon arrival, the women in my village welcomed me into their homes and their lives, and I began work with them and learn from them (Figure 1.2). I spent time with my women neighbors and noticed how much they did, how hard they worked, and how much they knew. They took care of themselves, their children, their husbands, and performed most household tasks in stride, often without recognition or reward. Women in Sanguéré Paul were timid and lacked confidence but I thought they were remarkable.

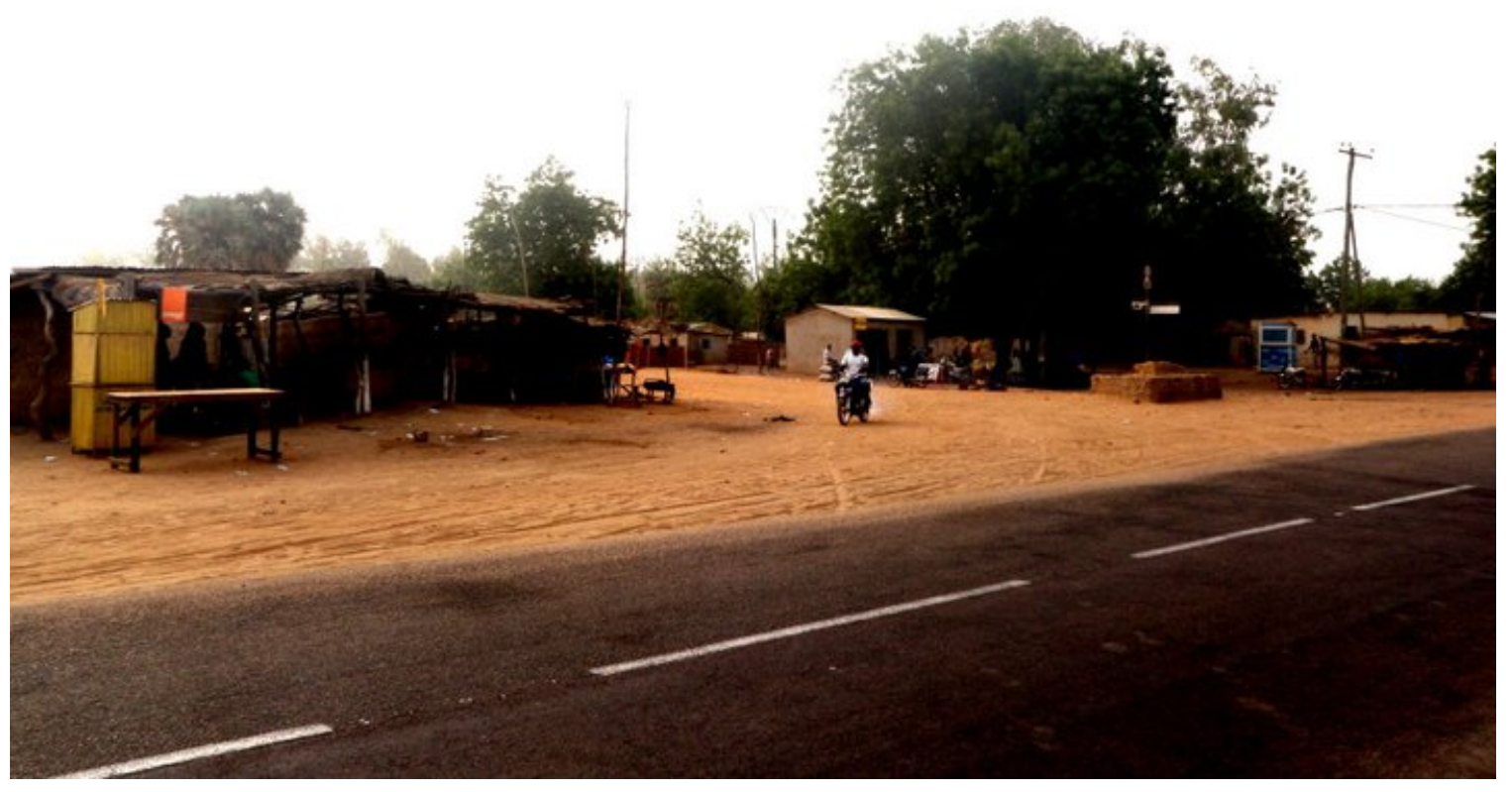

Figure 1.1: Main carrefour (intersection) in Sanguéré Paul. Photo Credit: Mary Snyder 


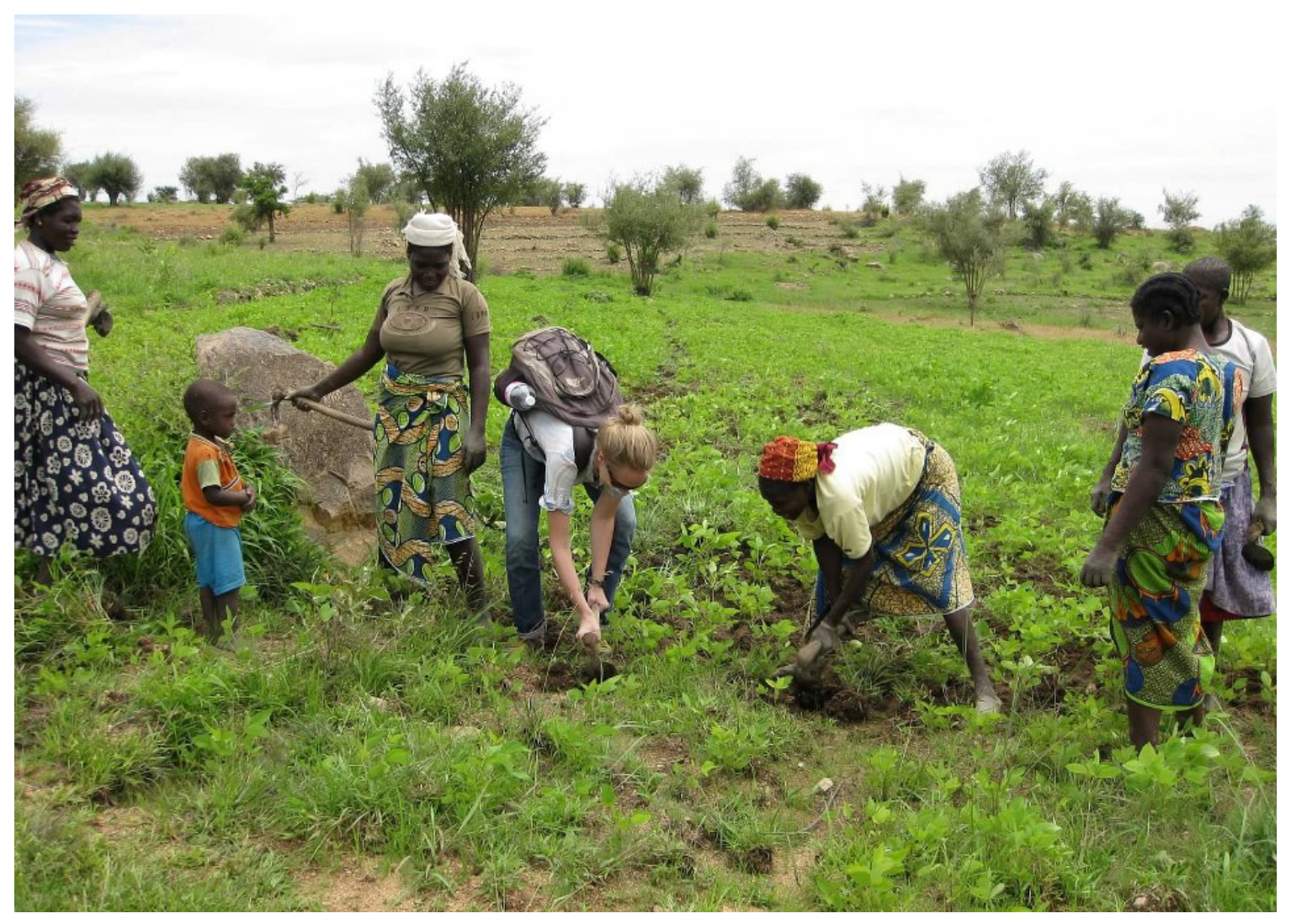

Figure 1.2: Author working in the fields with women. Photo Credit: Mary Snyder

When I was visiting my friends we were often eating and preparing food as this is normal protocol for visiting guests and family in Cameroon (Figure 1.3). I began to notice that these women were building their livelihoods and supporting their families with limited resources. I wanted learn what they were eating, where they were getting their food from, how they were supporting their family in such a tough environment, and I wanted document and study these women-driven traditional food systems. I developed this study on the edible weed tasba (Senna obtusifolia) to learn how this plant fit into the traditional food system of the region. This purpose of this thesis is to examine the 
importance of the wild edible weed tasba in Sanguéré Paul, Cameroon by examining how households use and manage the plant.

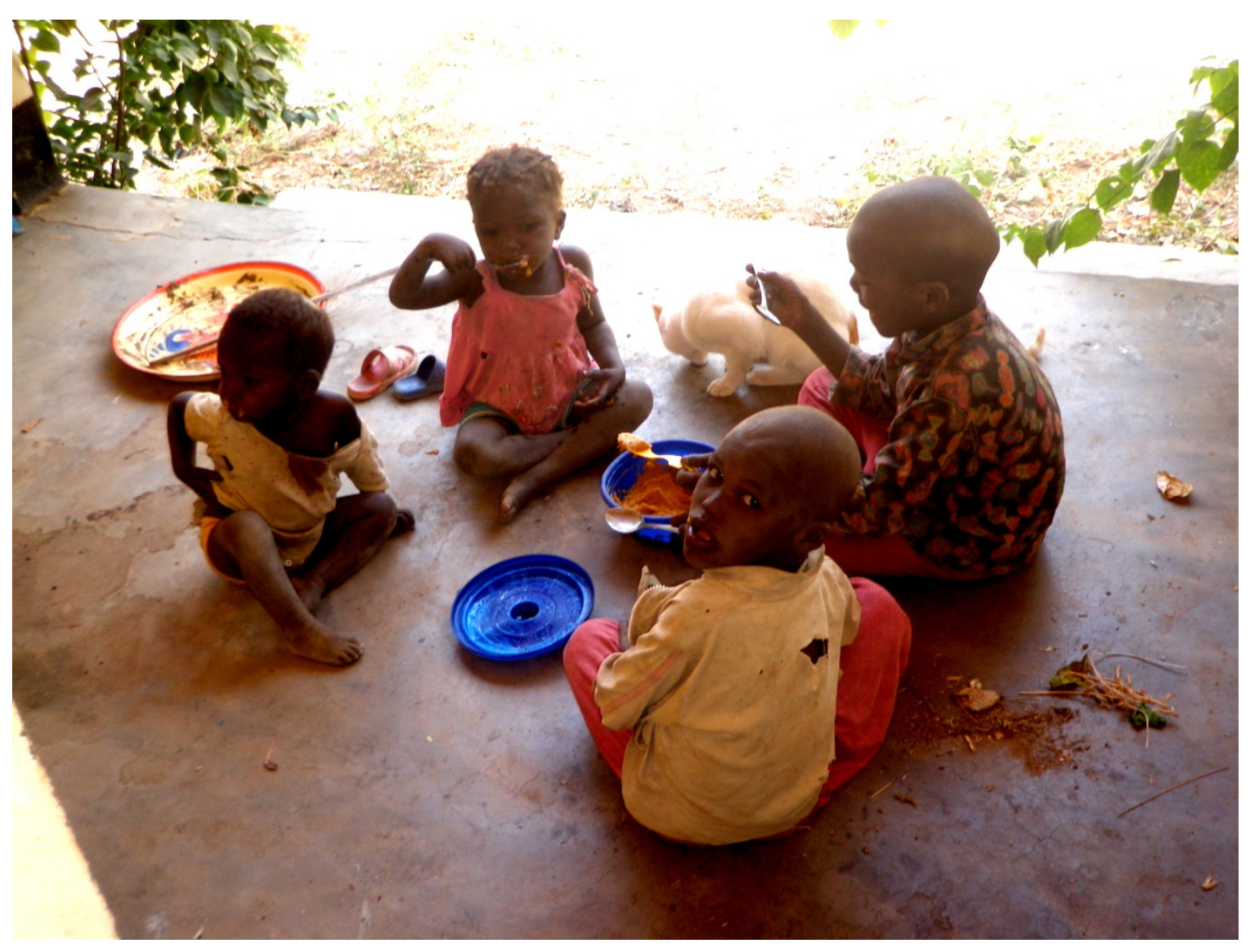

Figure 1.3: Children sharing a meal. Photo credit: Mary Snyder

Chapter Two provides a background of Cameroon as a whole, highlighting the diverse ecological and cultural ranges within the country. Chapter Three presents a background of the study area focusing on the ecology and agricultural sector of north Cameroon, and then looks at how wild foods and weeds fit into the traditional food system. Chapter Four presents the methodology of the paper and the results are presented and analyzed in Chapter Five. Chapter Six offers a discussion on the local management 
and use of tasba and the social and ecological issues which affect the livelihood strategies which women use to manage this plant, as well as key agro-ecological settings for collection. Finally, Chapter Seven offers a conclusion on the future of this plant in a changing social and climatic environment. 


\section{CHAPTER 2: COUNTRY BACKGROUND}

\subsection{Location}

The Republic of Cameroon is located in Central Africa on the western side of the continent. It is bordered by seven countries, Equatorial Guinea, Nigeria, Chad, Central African Republic, Republic of the Congo and Gabon as well as the Bight of Bonny in the Atlantic Ocean with 402 kilometers of coastline (Figure 2.1). The total area of Cameroon is $475,440 \mathrm{~km}^{2}$ which makes it slightly larger than the state of California (CIA 2013).

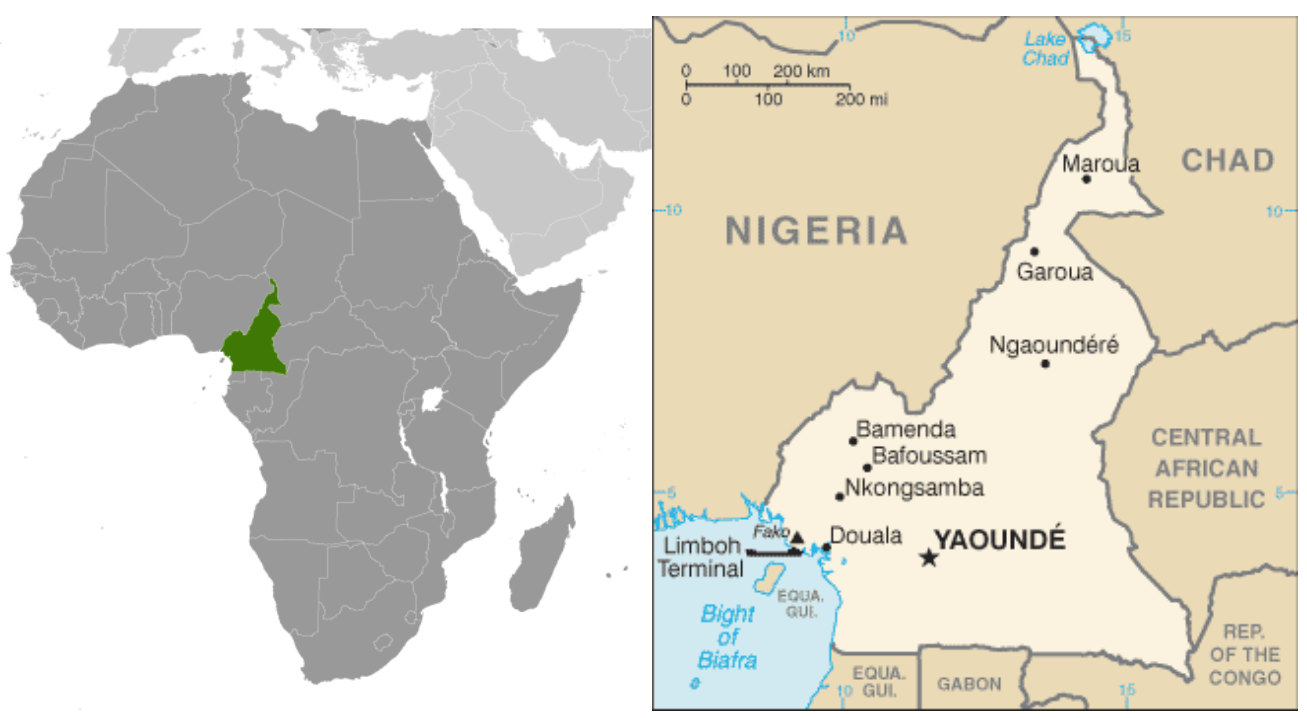

Figure 2.1: Map of Cameroon in relation to surrounding African countries (CIA 2013). Map Courtesy of CIA

Cameroon has a diverse range of ecological zones ranging from savannah in the north, the Western Highlands in the western regions and humid forest in the south and eastern regions. The climate is as varied as its landscape. The north is a semi-arid zone characterized by high temperatures and a single rainy season. The southern area can 
generally be divided into two climatic categories. The bimodal rainforest zone has two rainy seasons (2634-3198 $\mathrm{mm}$ of rain per year) and a short dry season. This zone is located in the western and southern areas, including Douala and Kribi (Tingem et al. 2008). Farther inland towards Yaoundé, the capital, is the monomial tropical zone which has only one rainy season $(<1660 \mathrm{~mm}$ per year) and a longer dry season (Molua 2006; Tingem et al. 2008). The highest point, Mount Cameroon, is an active volcano and reaches 4,095 $\mathrm{m}$. The lowest elevation is sea level along the Atlantic Ocean (CIA 2013).

\subsection{People}

The estimated population in July 2012 was $20,129,878$ with $58 \%$ of the total population residing in urban settings. The growth rate is approximately $2.1 \%$ annually (CIA 2013). The official languages of Cameroon are English and French, but there are over 250 local languages spoken (Lodhi 1993). There are approximately 300 ethnic tribes residing in Cameroon. The largest tribes are the Bamiléké in the west, Fulbé in the north, Béti and Bassa in the south and the Baka in the east (Anon. 2008).

The primary religions include Christian (40\%), Muslim (20\%) and traditional beliefs or animists (40\%) (US State Department 2005). Christians are found in highest concentrations in the southern and western regions with Catholics in Francophone regions and Protestants in Anglophone regions. Muslims are found in all major cities, and in the northern regions where the Fulani ethnic group is prominent. Traditional beliefs are practiced throughout all the regions, but are most often concentrated in rural areas (US State Department 2005). 


\subsection{Government}

Cameroon is divided into 10 regions (the largest administrative division): two Anglophone (Northwest and South West) and eight Francophone regions (Extreme North, North, Adamaoua, Central, Littoral, West, South, and East) (Figure 2.2). The political capital Yaoundé, located in the Central region, has 1.7 million inhabitants (CIA 2013).

Cameroon gained independence from France in 1960 and Ahmadou Ahidjo was appointed the first president (CIA 2013). In 1982 the current president Paul Biya was elected (CIA 2013). Cameroon is a republic with both a president and prime minister. The president has the power to appoint and dismiss the prime minister, cabinet members, treasury members, judges, governors, prefects, and subprefects, whereas mayors and other local officials are elected through municipal elections (CIA 2013). The most recent presidential election took place in November 2011 . With $78 \%$ of the votes Paul Biya was re-elected to another seven-year term (CIA 2013). Municipal elections were held in February 2013.

In the past Cameroon has faced problems with corruption. It was ranked as the most corrupt country in 1998 by Transparency International. In 2012 it received a transparency score of 26 (scale 0-100, with lower values more corrupt), indicating continued concerns of corruption (Transparency International 1998; 2012) 


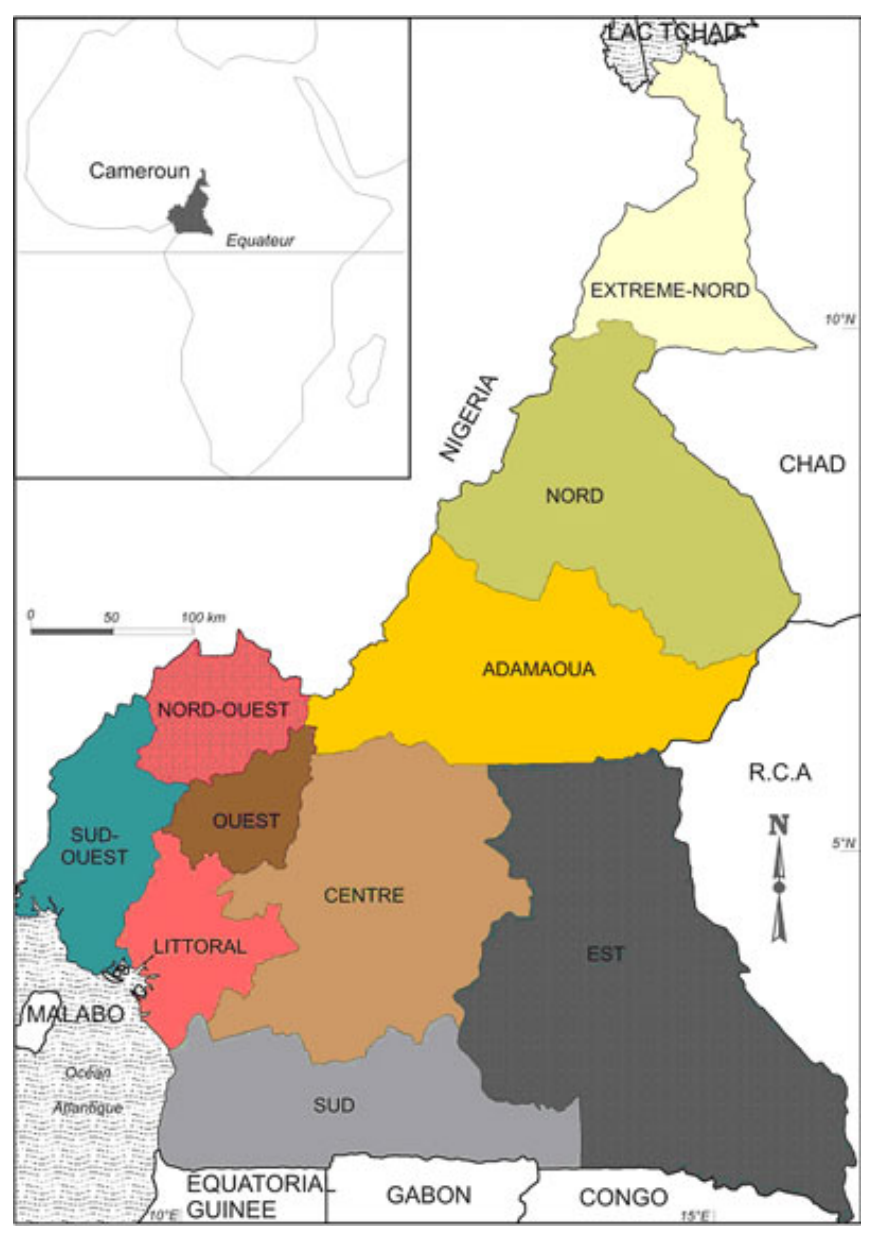

Figure 2.2: Regions of Cameroon (FAO 2007). Map Courtesy of FAO.

\subsection{Economy}

Because Cameroon has a diverse range of ecological systems, it also has a diverse range of economic opportunities. In both the north and the south, Cameroon is an agricultural society with both small-scale household subsistence farming and large-scale exports. Approximately $19-35 \%$ of the GDP comes from agricultural products, $22-31 \%$ from industry and mining and 36-39\% from services (CIA 2013; Moula and Lambi 2006). 
Seventy percent of the population is in the agricultural sector, $13 \%$ in industry and $17 \%$ in services (CIA 2013). The southern area of Cameroon has rich soils, vast rainforests and abundant natural resources and supports the major cash crops of the country such as oil palm, bananas, cocoa, rubber, plantains, and coffee (CIA 2013). The poor business environment discourages foreign investment (Tignem et al. 2008; CIA 2013).

Forty-eight percent of the population lives below the poverty line (CIA 2013). The malnutrition rate for the country is $35.8 \%$ but it is higher in the North (45\%), where it is related to the poor economic opportunities (UNICEF 2011). 


\section{CHAPTER 3: STUDY BACKGROUND}

The North region as well as the Extreme North and Adamawa regions of Cameroon comprise what is sometimes referred to as the "Grand North." While the southern region is dominated by tropical forests, fertile soil and high rainfall, the Grand North has a short rainy season and infertile soils and is a savanna ecosystem. Because of the differences in natural resource distribution, most development and economic opportunities have been concentrated in the south, and inhabitants of the North, Extreme North, Adamawa and East Regions lack basic access to potable water and health care resources (Lynch 1991; UNICEF 2011).

\subsection{People of the Study Region}

The North region has a population of 1,968,481 (2005 estimate) and population density of approximately 25.5 people per $\mathrm{km}^{2}$, compared to the national average of 40 people per $\mathrm{km}^{2}$ (Institut National de la Statistique 2011). The north region is situated between the densely populated Extreme North region ( 90.8 people per $\mathrm{km}^{2}$ ) and the more sparsely populated Adamawa region (13.9 people per $\mathrm{km}^{2}$ ) (Institut National de la Statistique 2011). Garoua, the capital of the North region, has a population of approximately 230,000 (Cerdan et al. 2004).

Garoua has a high population growth rate $(5.1 \%)$ that can be attributed to immigration from the densely populated Extreme North as well as refugees from Chad, Central African Republic and Nigeria (Mayaka 2002; MINPAT 1993). Because of this large influx of people, Garoua is a place of high ethnic diversity. However, the Grand 
North in general is influenced by the dominant Muslim Fulani [Fulbé] ethnic tribe.

Fulfulde, the language of the Fulani is used as the market language in the North, Extreme North and Adamawa regions and the traditional Fulani leadership system of lamidos still holds great importance (Mayaka 2002).

\subsection{Climate, Ecosystem and Environmental Issues}

The North region of Cameroon is part of the larger Sudano-Sahelian savanna ecosystem. Species of acacia trees are prevalent, notably Acacia senegal which produces gum arabic, as well as Balanites aegyptica (date tree), Tamarindus indica (tamarind), and Butyrospermum paradoxum (shea butter tree) are also important and widespread (LimLi et al. 2011).

In the Sudano-Sahelian savannah, there is one rainy season in the North which occurs from approximately June-October and varies from 600-1000 $\mathrm{mm}$ of rain per year. Rainfall is often sporadic and unpredictable and leads to a series of droughts and floods as it did most recently in 2011(drought) and 2012 (floods) (FAO 2013; IFRC 2012; Limli et al. 2011; Molua and Lambi 2006). Daily temperatures vary from $25-34^{\circ} \mathrm{C}$. The highest temperatures fall in the dry months of March-April (Tingem et al. 2008). The variability and unpredictable nature of rainfall and temperatures in the region affect the growing season and yields of plants. These stresses increase the vulnerability of the food systems and reduces food security for the population (FAO 2013; Gregory et al. 2005).

The Benue River has a port in Garoua and serves as a major basin for the North Region. Tributaries or mayos flow into the Benue River from inside Cameroon and 
surrounding Chad and Nigeria and also from the Adamawa Plateau and the Bamenda Highlands (Molua and Lambi 2006). The Benue River eventually flows into Nigeria to join with the Niger River (Molua and Lambi 2006). The Benue River serves as an important source of water as well as a fishing resource for the people of Garoua and the surrounding areas (Figure 3.1).

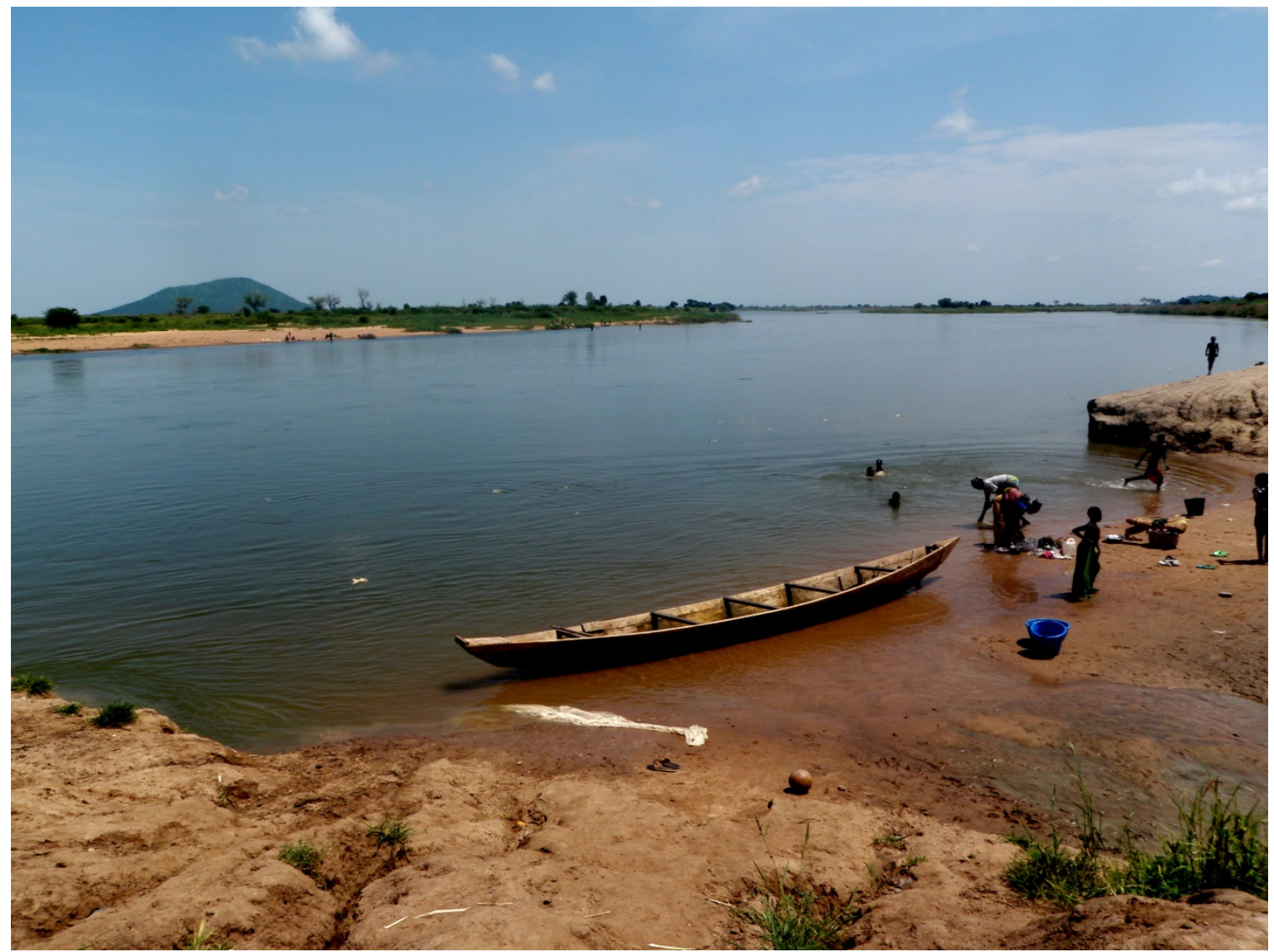

Figure 3.1: The Benue River. Photo credit: Mary Snyder

One of the most pressing ecological issues in North Cameroon is desertification. This issue is compounded by deforestation for fuelwood and construction materials, erosion due to vegetation removal and fire, and soil depletion due to overuse of chemical 
fertilizers, overgrazing, and over-cultivation (Figure 3.2) (Emmanuel Neba 2010). This pattern of changing landscape is intensified by increasing population densities and land scarcity (McGregor 1995). Farmer-grazer conflicts are also common between the nomadic (and semi-nomadic) Mbororo herders and permanent agricultural residents (Figure 3.3).

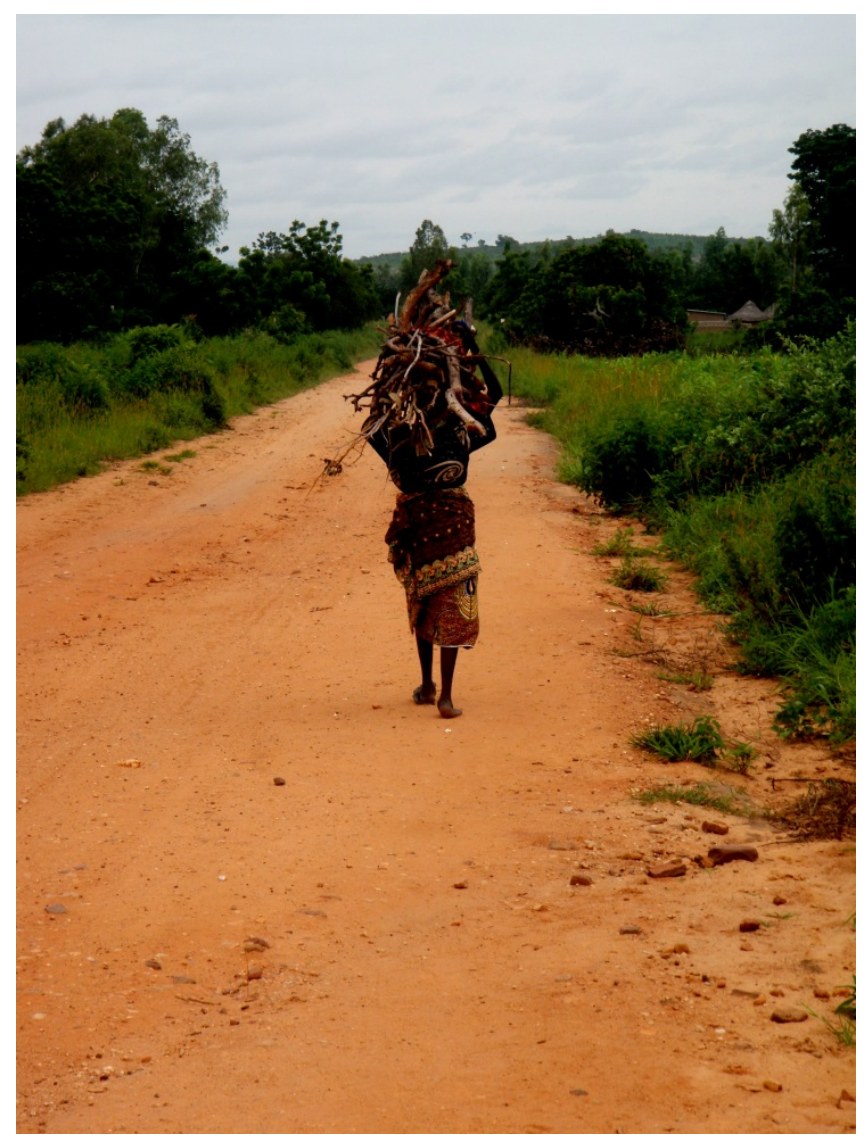

Figure 3.2: Woman colleting fuelwood. Photo credit: Mary Snyder 


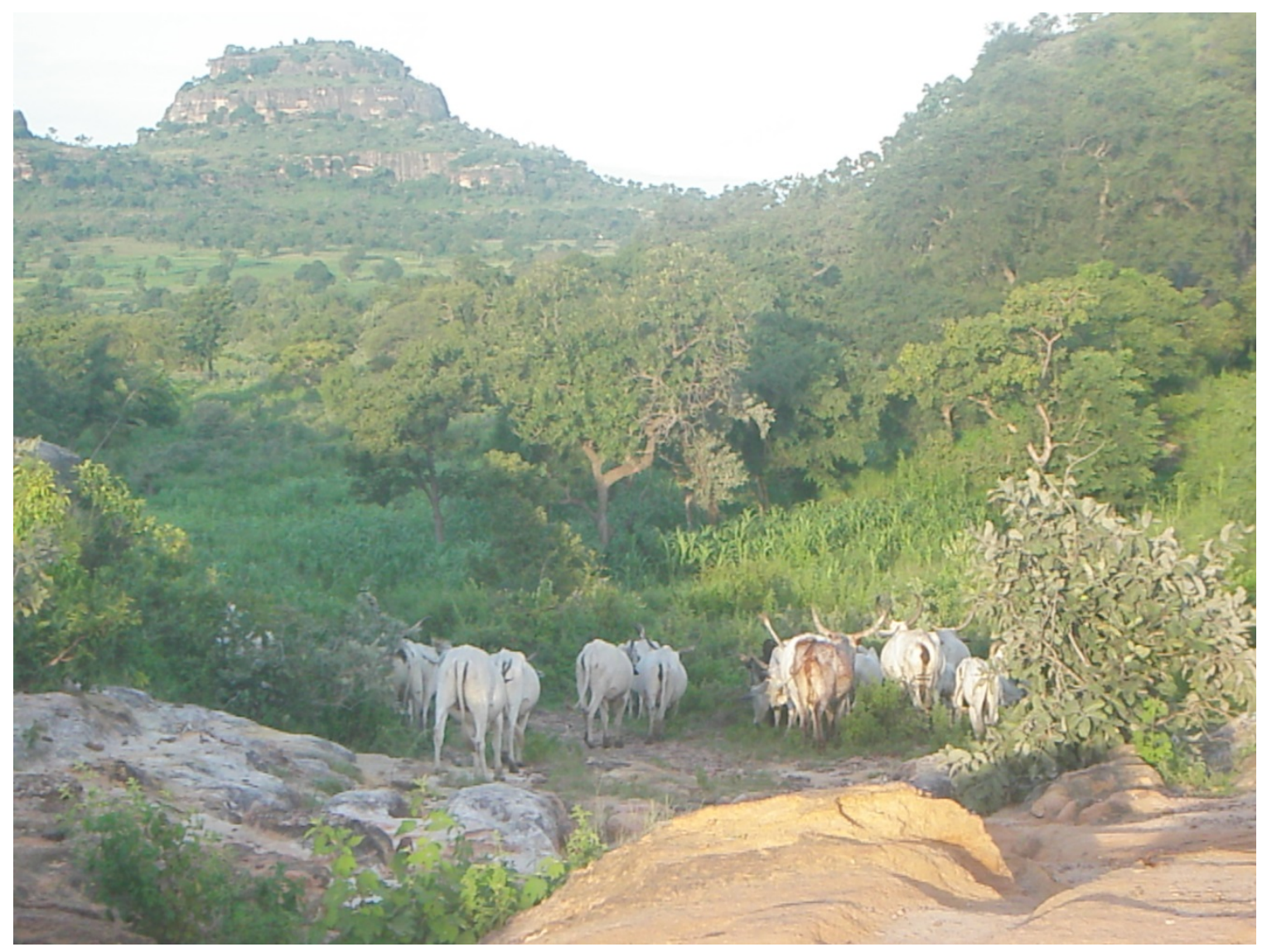

Figure 3.3: Mbrorro cows heading to graze. Photo credit: Mary Snyder

\subsection{Agriculture}

Consistent with national averages, approximately $70 \%$ of the population of North Cameroon is involved in the agricultural sector (Kenga et al. 2003). The primary form of farming is upland cereal small-scale, rain-fed subsistence farming (Beets 1990). The average farm size in northern Cameroon is 1.5-3.1 hectares, divided into quarter hectare plots (Kenga et al. 2003). Land tenure is complicated and uncertain as it often follows traditional regimes where land is owned and distributed by the chiefs (laamiido, lawan and jaagordo) which can make land distribution uneven (Hansen 2003; Kenga et al. 
2003). Typically, the labor force is comprised solely of family members and therefore a critical limiting factor on expansion and productivity for small-scale farmers is the lack of an available workforce (Kenga et al. 2003).

Major crops grown in the region include cereals such as maize (Zea mays), millet (Pennisetum glaucum) and sorghum (Sorghum bicolour) as well as groundnut [peanuts] (Arachis hypogaea) and other minor species such as sesame (Sesamamum indicum), cowpea (Vigna unguiculata), beans (Phaseolus spp.), yams (Dioscorea spp.) and soybeans (Glycine max) (Figure 3.4). Millet and sorghum have lower water requirements than maize and therefore become increasingly frequent farther north (Kenga et al.2003). Dry season sorghum, known locally as Muskuwaari, is grown in areas that have clay soils and are susceptible to inundation during the rainy season. Muskuwaari can contribute to food security since these clay areas cannot be farmed during the typical planting season (Kenga et al. 2003).

Groundnut, another important food crop that is grown throughout the Grand North, is prepared in a variety of ways including ground into a paste. Known as pot d'arrachide, the paste is used in many of the sauces that are prepared for meals. Cotton (Gossypium spp.) is the major cash crop grown in the area, comprising $30 \%$ of the cultivated land area (Figure 3.5) (Nana and Havard 2002). 


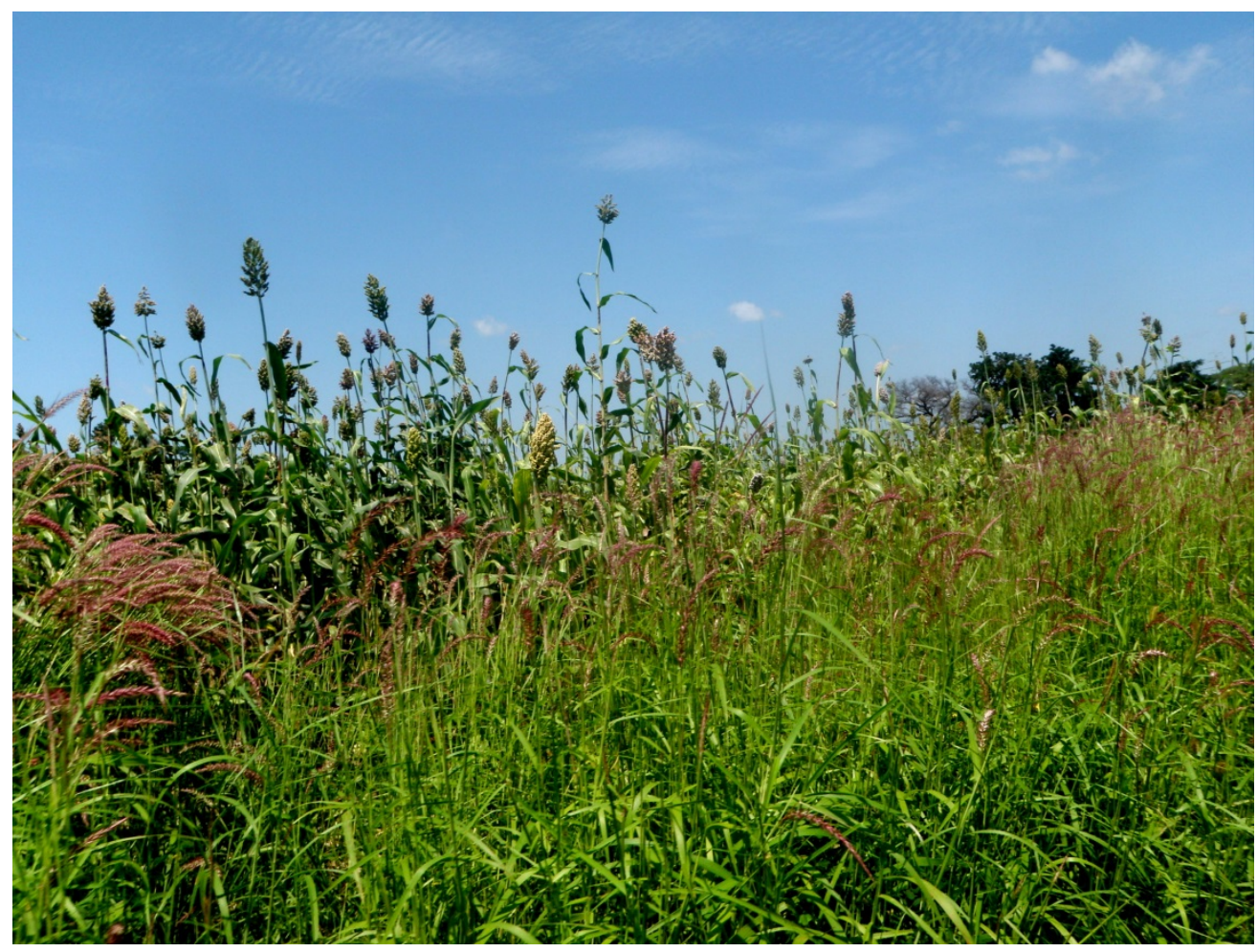

Figure 3.4: Millet farmed in the Extreme North Region. Photo credit: Mary Snyder 


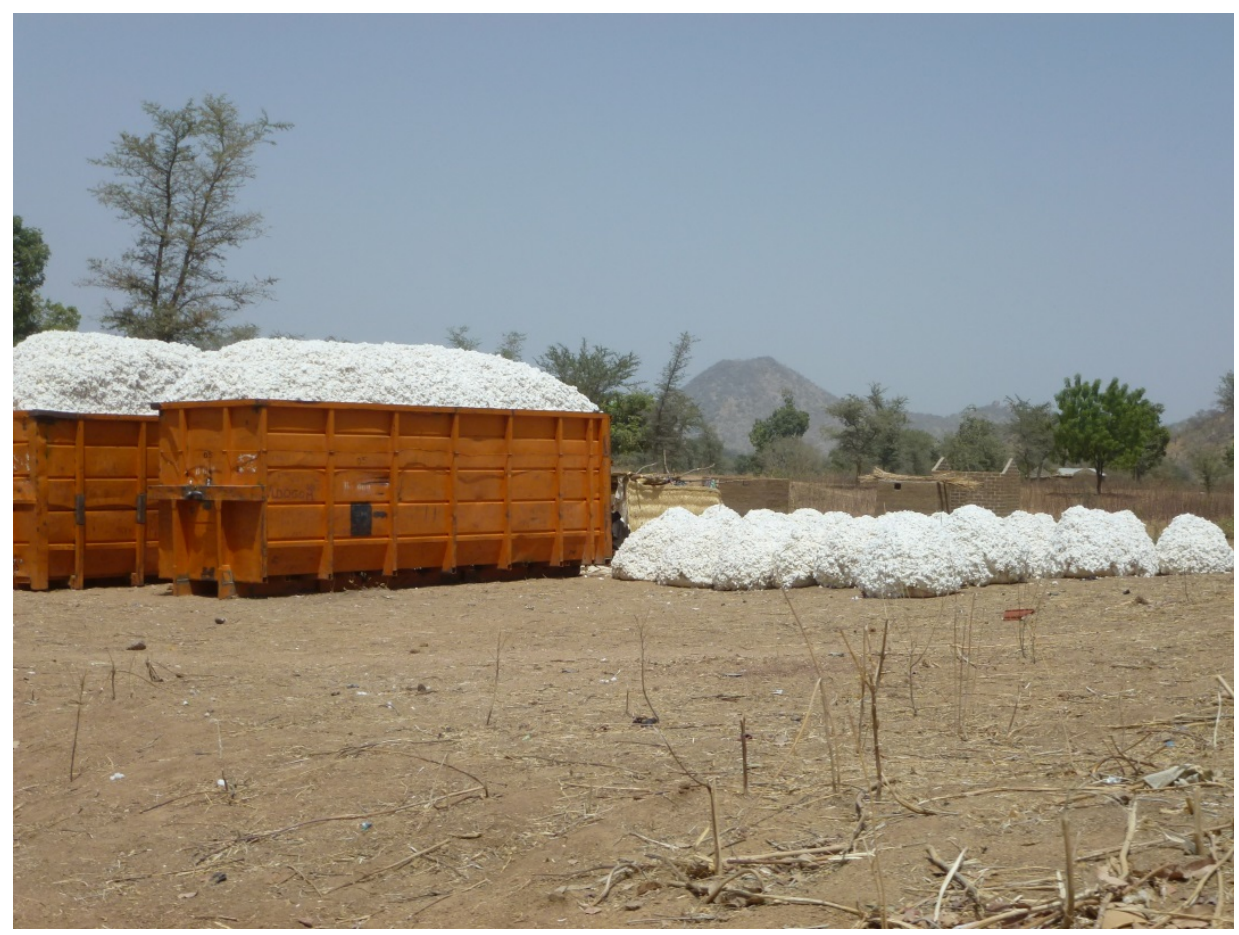

Figure 3.5: Cotton produced in the North Region. Photo Credit: Trevor Taylor

Animal husbandry is also important in the North Region. While moving throughout the seasons to take advantage of annual grass species, the Mbororo people herd cows and gain income through raising and selling large cattle herds and their products (Moritz et al. 2002). The Mbororo herders are a clan of the dominant Fulbé ethnic tribe (Moritz et al. 2002). Many farmers raise cows, goats, sheep, chickens, ducks and other small animals (Kenga et al. 2003). Small-scale animal husbandry is often a responsibility of women within the household (FAO 2011).

The majority of the technical assistance for farmers comes in two forms: the Société de Développeent de Coton du Cameroun (SODECOTON) and L'Institut de Recherche Agricole Pour le Developpement (IRAD). Often this guidance is not 
accessible to women and other small-scale subsistence farmers. Although women are a major part of the agricultural labor force, they have unequal opportunities in technical assistance and information, resource provisions (including microfinance opportunities), decisions making, land tenure, and capital. Therefore, women often have lower social status within the community (Fon 2011; Saito et al. 1994)

\subsection{Gender Work Roles and Food Preparation}

Within Northern Cameroon, as in many agricultural societies, specific crops are known as "men’s crops" or "women's crops." Typically, the men farm cash crops such as cotton and maize and women are responsible for food crops such as groundnuts, millet and sorghum. However, women are becoming increasingly involved with cash crops (FAO 2011). Women account for approximately half of the agricultural labor force in sub-Saharan Africa, although estimates are as high as 60-80\% (FAO 2011).

Women have many other roles within the household in addition to the production

of food cereal crops and small-scale animal husbandry. Women are often responsible for fuelwood and water collection, cereal grinding, seed preparation and storage, and food preparation (Saito and Weidemann 1990; FAO 2011). The typical meal in northern Cameroon consists of a cereal staple (usually maize, sorghum or millet, but also rice or cassava) ground into a flour and mixed with water over a fire to provide a porridge like mixture (known as couscous) which serves as the base of the meal (Figure 3.6). The other part of the meal, the sauce, known as haako in Fulfulde (translates to leaf in 
English), contributes substantially to the nutrition, diversity, variety and enjoyment of a meal (Figure 3.7).

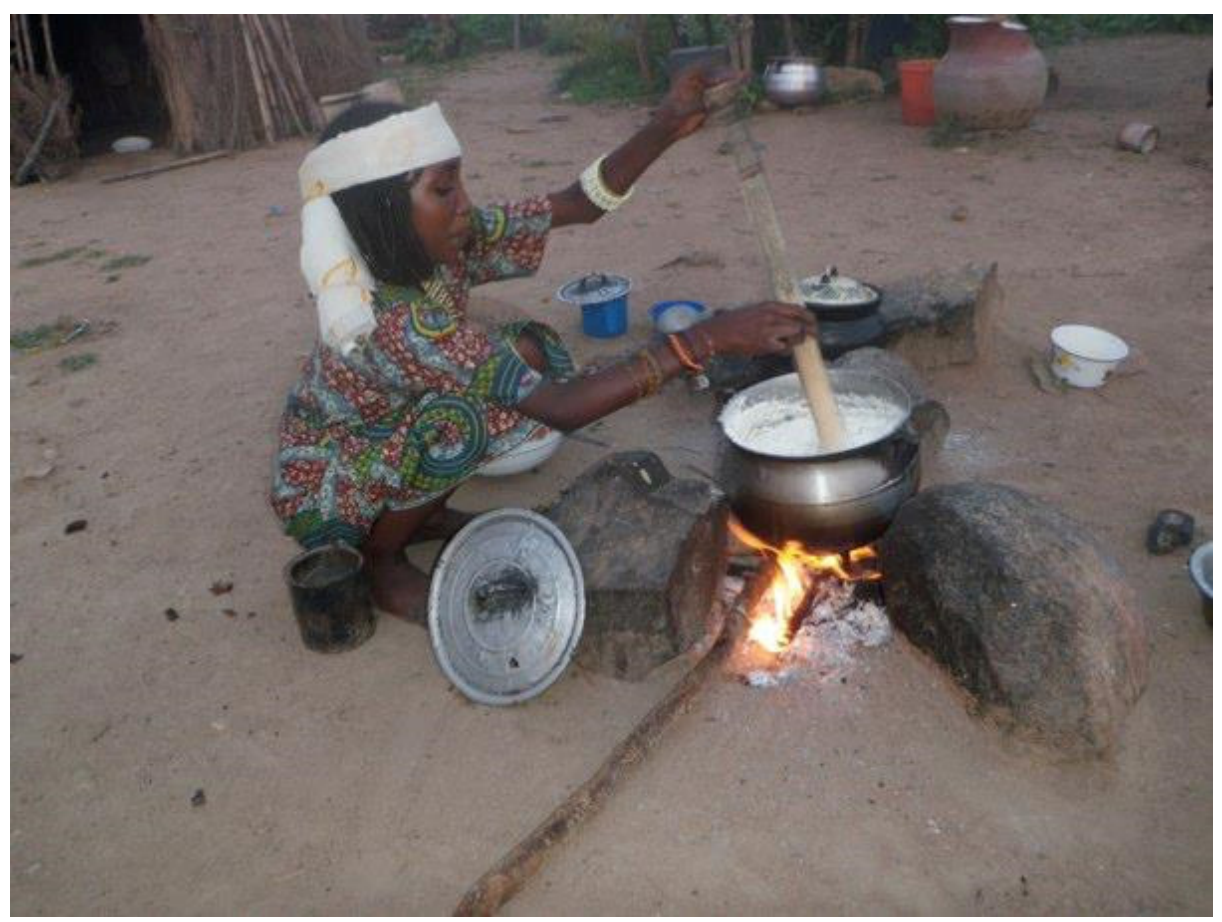

Figure 3.6: Mbororo woman preparing couscous over the fire. Photo credit: Meghan Pollak 


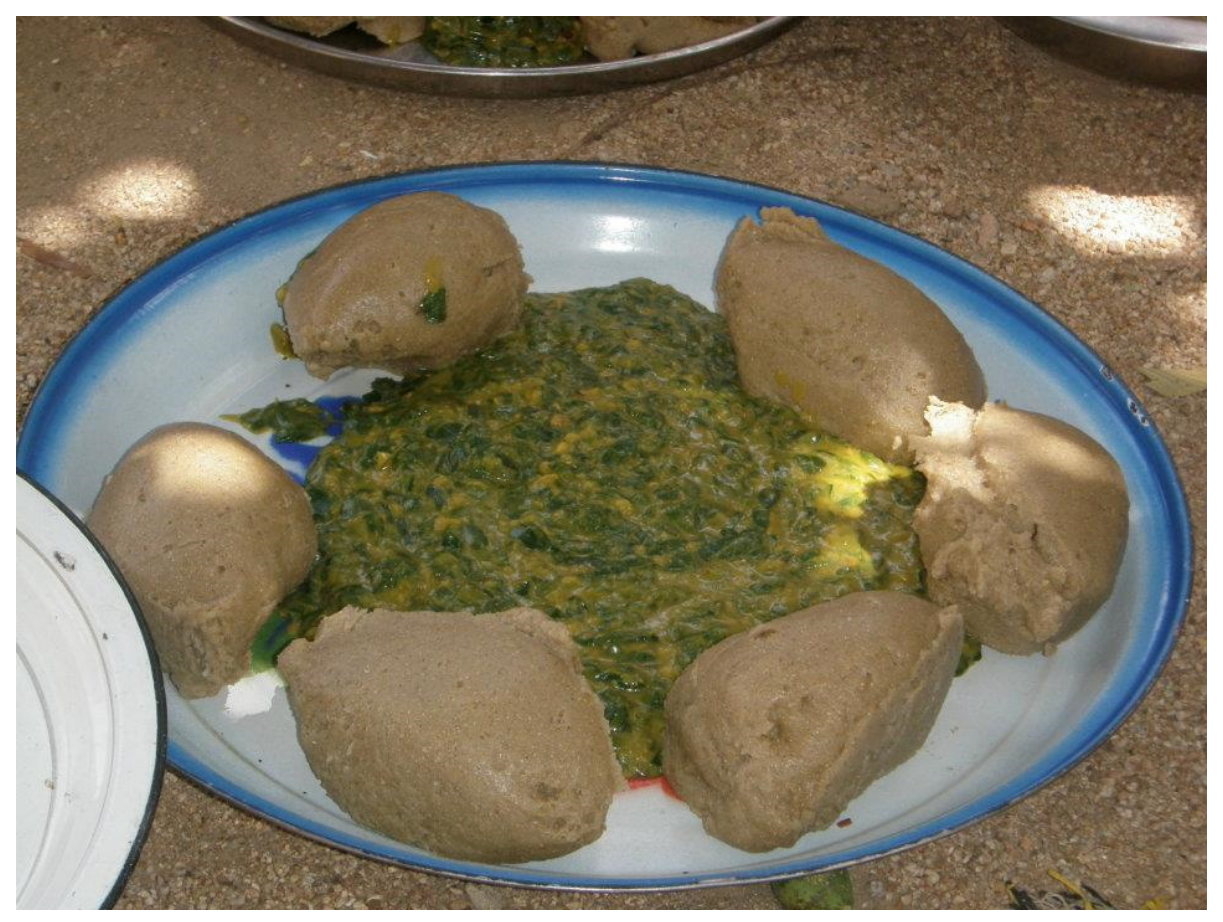

Figure 3.7: Typical Cameroonian meal, couscous and sauce (haako). Photo credit: Meghan Pollak

In the literature, the plants which are in these sauces have been referred to as traditional vegetables, leafy vegetables, and indigenous vegetables and their importance has been well documented in developing countries as part of the traditional food systems. Traditional food systems are defined by Kuhnlein and Receveur (1996) as systems which are "composed of items from the local, natural environment that are culturally acceptable". The vegetables used in these systems can range in production scales. In Cameroon, some species such as folere [roselle] (Hibiscus sabdarifa), gombo [okra] (Abelmoschus esculentus) and gubudo (Cerathoteca sesamoides) are produced in both large commercial gardens and in smaller homegarden plots for markets and household use (Figure 3.8) (Iyebi-Mandjek 1997). 


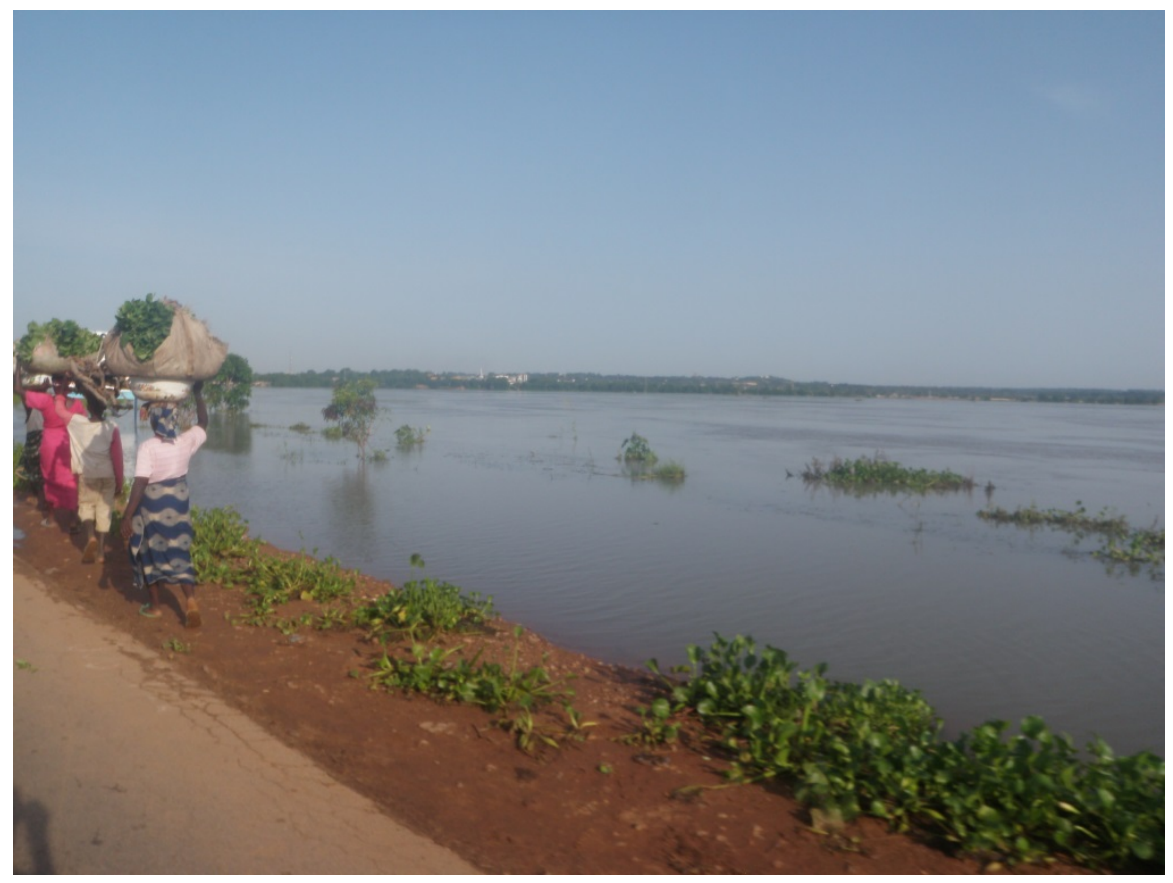

Figure 3.8: Women bringing gardened vegetables to Garoua for sale. Photo Credit: Mary Snyder

\subsection{Wild plants Used as Food Sources}

Some species used in sauce preparation are fully domesticated, cultivated species, while other species are semi-cultivated and others are wild plants, collected from fields and communal lands. Collected wild foods are important to the lives people living in rural areas in many places in Africa as well as Latin America and Asia (Campbell et al. 1997; Delang 2006; Shackleton et al. 2002; Shackleton 2003; Vainio-Mattila 2000; Zinyama et al. 1990). Wild foods are routinely used in diets, during the "hungry season" (the time when food reserves are low, and the new crops are not yet ready for harvesting) as well as in times of both acute food shortages and famine (Harris and Mohammad; 2003; Tabuti 2007; Zinyama et al. 1990). Populations, particularly the rural poor, use 
wild plants as a source of income and for security against times of uncertainty (Shackleton et al. 1998 Gockowski et al. 2003).

Wild plants consumed and utilized by local populations are also gaining recognition for the role they play in conserving indigenous knowledge (Balemie and Kebebew 2006; Shava 2005) and biodiversity (Thrupp 2000). The nutrition of wild plants as part of a traditional diet has been studied, showing that often these traditional vegetables contain important vitamins and they are often more nutritious than their domesticated equivalents (Becker 1983; Gockowski et al. 2003; Yang and Keding 2009). Production, preservation and commercialization of wild food plants is important in rural and peri-urban economies and there is potential to expand and strengthen these market systems at the production and market level (Mahyao et al. 2008). Wild plants are a valuable resource in current and potential local food security (Modi et al. 2006), particularly for vulnerable populations. Wild plants also have a potential role in women's empowerment and rural development by providing a source of employment and income through the collection and sale of these food species in local communities (Pasternak et al. 2009).

The extent to which wild plants are used depends on a range of socioeconomic (e.g. wealth and urbanization) and ecological conditions (e.g. rainfall and elevation) which affects vegetation growth and species diversity (Campbell et al. 1997; Cocks et al. 2008; Shackleton et al. 1998; Shackleton and Shackleton 2006). 


\subsection{Weeds as Wild Foods}

In agricultural systems weeds are typically viewed as a burden and removed to increase productivity of desired crops. However, "weedy" is a relative term and the significance is determined by those defining it (Radosevich et al. 1997). A species which is considered a weed in one environment may be a targeted wild food in another. In Africa and other parts of the world, many of the wild plants used in traditional diets are considered weedy species. Weedy species can be considered some of the most important wild plants by local populations (Cruz-Garcia and Price 2012; High and Shackleton 2000). The economic importance of these species has also been recognized (VieyraOdilon and Vibrans 2001).

Changes in land use can alter the composition of the vegetation and the wild plants available. Landscapes with high agricultural intensity, highly degraded areas and areas with diminishing communal or fallowed land often favor weedy species over nonweedy species (McGregor 1995; Scoones et al. 2004). The change in collection and availability of wild species, in turn, changes the dependence on cultivated vegetable sources (Campbell et al. 1997; McGregor 1995).

\subsection{Gathered foods as part of livelihood strategies}

Food is managed at the household level based on the resources and capital available to the family, to achieve food security (De Haan and Zoomers 2005). Depending on a variety of socioeconomic (wealth, education, family composition, ethnicity, and occupation) and environmental conditions (rainfall, available crops and 
food sources), a household performs a variety of actions to form a robust livelihood strategy so the family can survive. Changes in resource availability can change opportunities within a livelihood strategy, which therefore affects household food security.

\subsection{Senna obtusifolia}

Senna obtusifolia has a wide ecological range and therefore has a wide variety of common names including sicklepod in the United States, Java bean in Australia, kawal in Sudan and tasba in Cameroon (Binggeli 2005;Dirar 1984; Parsons and Cuthbertson 2001). Tasba has a wide distribution and is a common weed in agricultural systems but is also common to pastures, roadsides and unused overgrown and degraded areas (Binggeli 2005; Parsons and Cuthbertson 2001). It has be documented as a weed in 67 countries and 26 crops including groundnut, soybeans, sugarcane (Saccharum officinarum), cotton, sorghum, maize and taro (Colocasia esculenta) (Binggeli 2005; El Hadj et al. 2005).

Tasba is in the family Fabaceae, subfamily Caesalpiniodeae (Binggeli 2005). Tasba is an annual or a short lived perennial that can reach heights of 1.8-2.1 m (Parsons and Cuthbertson 2001). The alternate compound leaves are evenly pinnate. Three pairs

of oppositely positioned, obovate, leaflets comprise the leaf (El Hadj et al. 2005; Parsons and Cuthbertson 2001). Flowers are yellow and found most often in pairs (although they can be found individually) towards the axils of the leaf. The flowers are composed of five petals approximately 1-1.5 cm long (Figure 3.9) (Parsons and Cuthbertson 2001). 
The brownish-green seedpod is curved (sickle-shaped) and approximately $10-15 \mathrm{~cm}$ long (El Hadj et al. 2005; Parsons and Cuthbertson 2001).

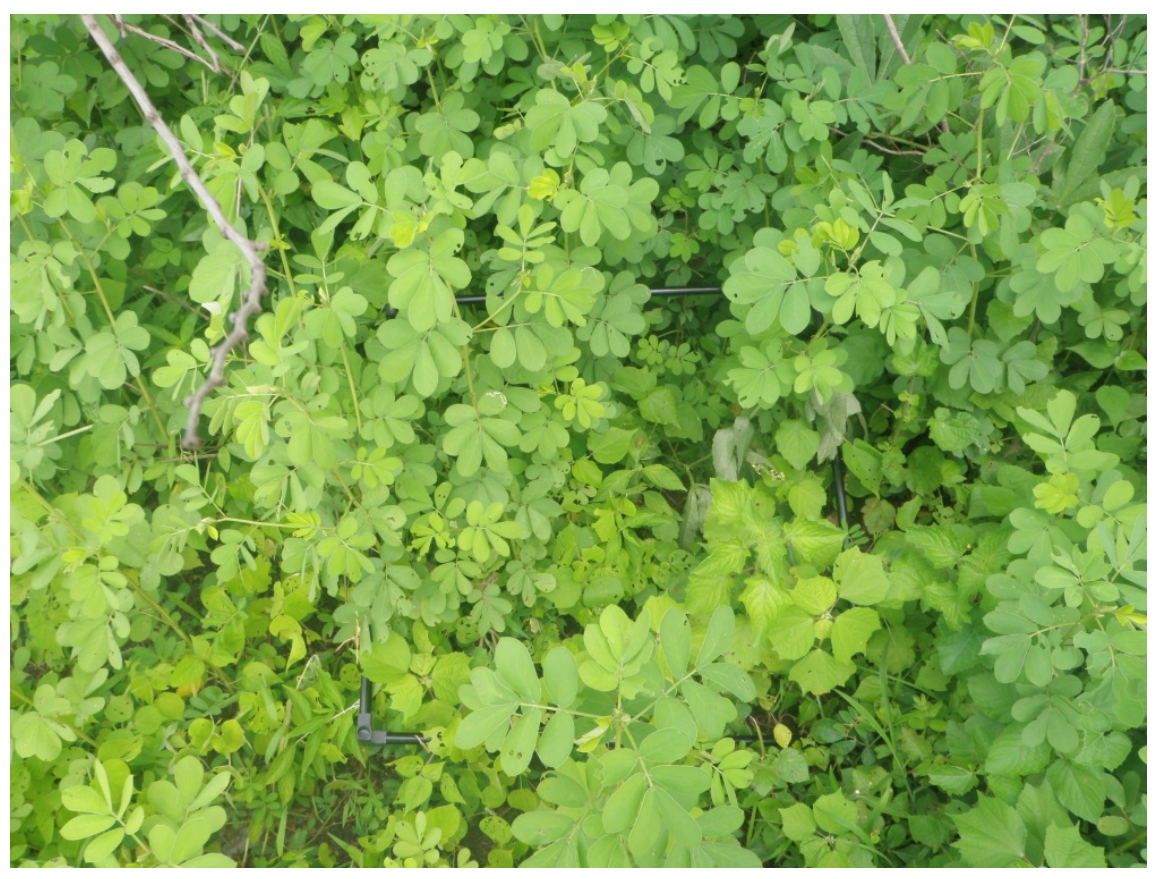

Figure 3.9: Large clump of Senna obtusifolia (tasba). Photo credit: Mary Snyder

Senna obtusifolia is "weedy" in nature and therefore can tolerate a wide range of environmental conditions and out compete other species. It thrives in temperatures of 25$32^{\circ} \mathrm{C}$ and rainfall between 640-4290mm (1520mm optimal) (Binggeli, 2005; Holm et al. 1997). Senna obtusifolia can grow in soils with a pH range of 4.6-7.9 (Murrary et al. 1976). This plant grows best in fertile soils but can grow in a wide variety of soils including well-aerated, sandy soils (Binggeli 2005). In some references it is listed as not able to fix nitrogen (Binggeli 2005), but a study in Senegal showed that Senna obtusifolia had mycorrhizal colonization (Duponnois et al. 2001). 
Although it is considered a problematic weed in many areas including Australia and the United States, it has been documented as a food source parts of Africa including Sudan, Niger and Senegal (Becker 1983; Dirar 1984; Abasse et al. 2006; Dunlop et al. 2006). Senna obtusioflia is an important source of protein as well as vitamins A and C in many traditional diets (Dirar 1984; Pasternak et al. 2009; Sudi et al. 2011). It has also been studied for its potential as a mulching material in gardens, animal feed during dry seasons, as well as a potential species for domestication and improving degraded lands (Awodoyin and Sola 2005; El Hadj et al. 2005; Pasternak et al. 2006; Pasternak et al. 2009).

Although much research has been done on the importance of traditional food systems in general, little work has been done to study the role of specific plants within the system. Research often mentions the importance of documenting traditional food systems for the conservation of indigenous knowledge as well as to serve as reference point for policy decisions and development goals concerning food security and women's empowerment (High and Shackleton 2000; Pasternak et al. 2006). This purpose of this paper is to examine the importance of the wild edible weed tasba in Sanguéré Paul, Cameroon by examining how households use and manage the plant. Patterns of use, preservation methods and patterns and collection patterns will be examined as well as collection locations and changes in usages over the growing season. This information will be used to identify key groups of interest as well as important environmental locations and significant harvesting periods. 


\section{CHAPTER 4-METHODS}

This study was conducted while I served as a Peace Corps Volunteer in Sanguéré Paul between December 2010 and November 2012. The first year of service was spent gaining trust, learning about the environment, the community and the people. Within the second year of service a study plan was formulated regarding the traditional wild edible plants that women were collecting from homegardens and from en brousse, (the unmanaged land which is generally fallowed land, land between fields, or uncultivatable land).

Data was collected primarily between the months of June and October 2012, during one rainy season, in the village of Sanguéré Paul in the North Region of Cameroon. The work was predominantly done alongside of women, as they are chiefly responsible for leaf collection and meals within the household. However, men's opinions were also sought out when applicable to provide a different point of view.

As a Peace Corps Volunteer, my study participants were my friends, my neighbors and fellow community members. This means I was living with them, interacting with them and learning from them. In Cameroon, as in many other places in the world, this also means eating with them. The women in my community were generally warm and accepting and always wanted to feed me, and fortunately for me, this meant observing and tasting the plants I was studying.

Once I had gained sufficient knowledge on the practice of collecting plants for food, I decided it was important to narrow the study to one specific plant, so I could 
develop a more focused study on one specific plant, rather than a broad survey of traditional food plants. I decided on the plant known locally as tasba because it is easy to identify, widely used, uncommon in the literature and also something I personally had eaten.

\subsection{Study Location}

This data for this study was collected in the village of Sanguéré Paul $\left(9^{\circ} 16^{\prime} 42.23 \mathrm{~N}, 1327^{\prime} 41.40^{\circ} \mathrm{E}\right)$, located in the North Region of Cameroon. This small town of about 3000 permanent inhabitants is located $10 \mathrm{~km}$ southeast of Garoua, the capital of the North Region. Sanguéré Paul is slightly atypical to the Grand North where the population of Sanguéré Paul is primarily Christian, including the village lawan (chief). However, both Muslim and Christian populations exist in the village, including a small Mbororo neighborhood. The village has many different ethnic tribes but the lawan and his family are the Mboum ethnicity.

A branch of the governmental agricultural research station, L'Institut de Recherche Agricole Pour le Développement (IRAD) is located on the periphery of town. The research station provides technical support, access to improved seed varieties, local employment, and is also are a major landowner in the area. The village is situated on a main highway which connects Garoua to Ngoundere and thus access to the markets of Garoua is readily available. There is a small local market on Wednesdays (Figure 4.1), however compared to other markets in the area, the market in Sanguéré Paul is not considered large, and little external produce is sold (Figure 4.2). 


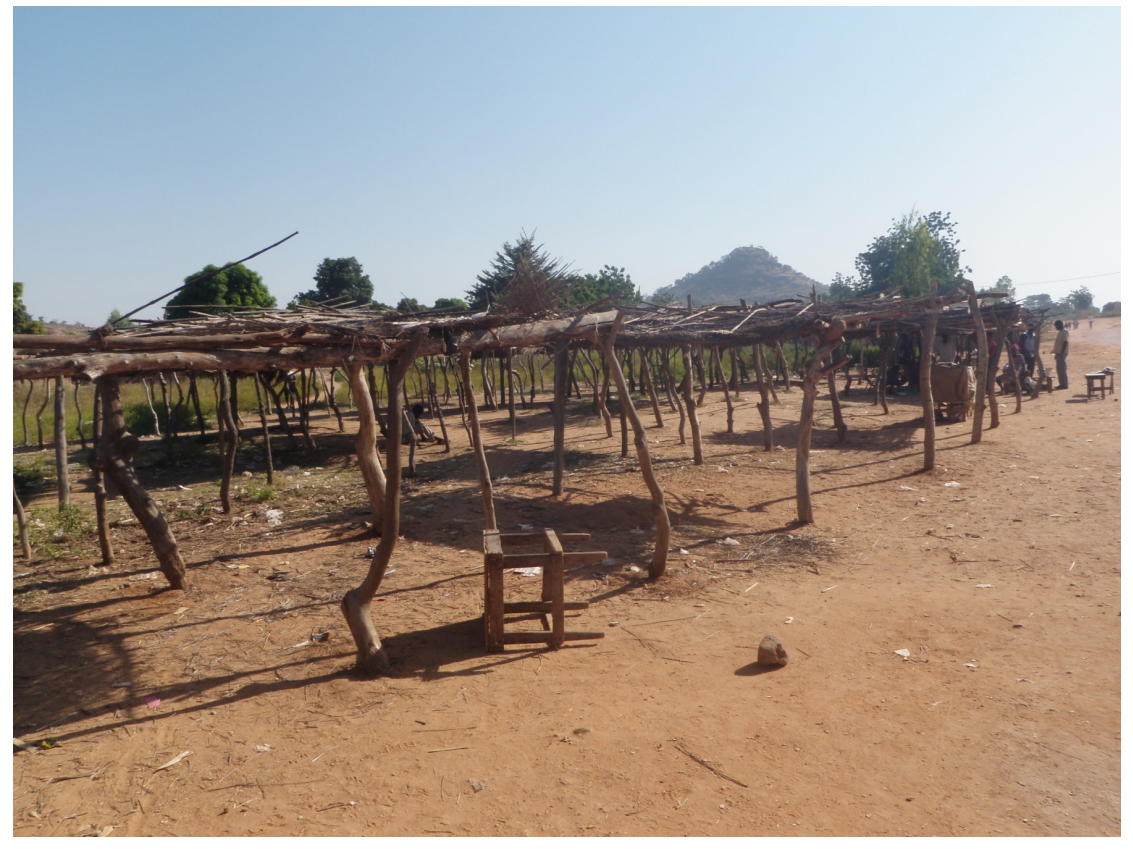

Figure 4.1: Market area in Sanguéré Paul, on a non-market day. Photo credit: Mary Snyder

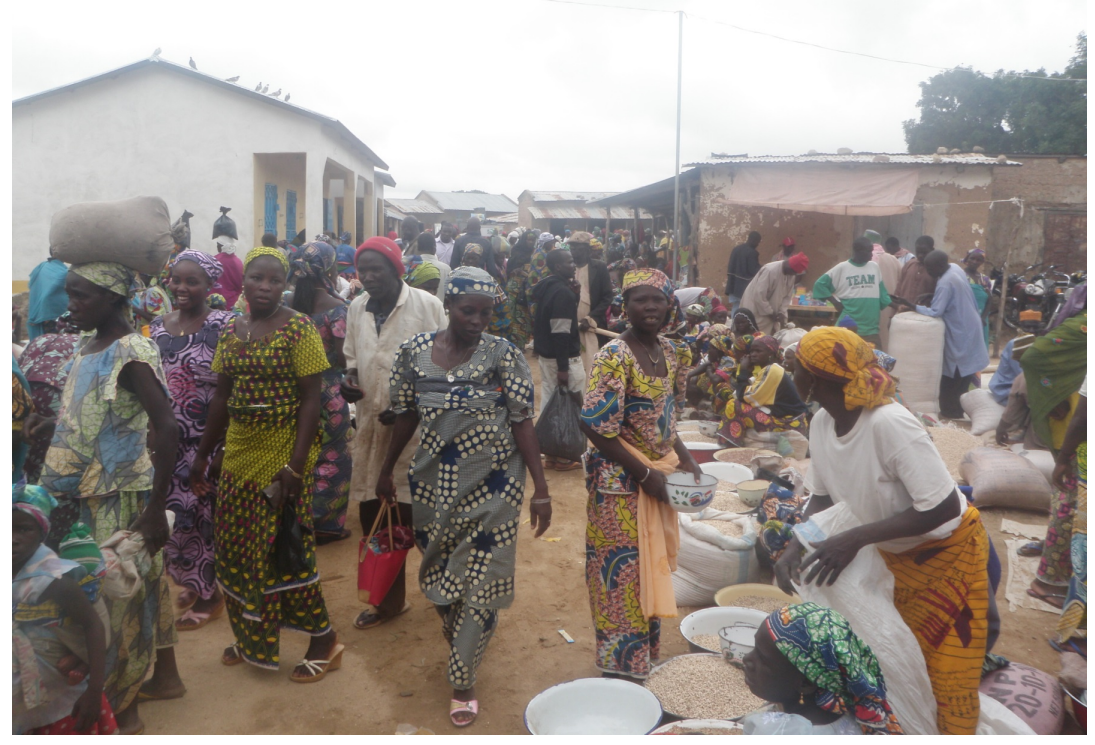

Figure 4.2: Typical market day in a large market in the Grand North. Photo credit: Mary Snyder 
Crops planted in Sanguéré Paul are the same as in the rest of the region, primarily maize, sorghum, millet, groundnuts, and cotton. Dry season millet is generally not grown in the area since the soil is too sandy.

\subsection{Wild Food Collection and Use}

A series of surveys, interviews, participant observation and key informants were used to determine the collection, consumption, preparation, management, and preservation strategies of the wild food plant tasba. Much of the qualitative information was gained through participant observation. Bernard (1995) indicates that participant observation includes "observation, natural conversations, structured, semi-structured and unstructured interviews, checklists, questionnaires, and other unobtrusive methods". These methods were all used in some capacity. Key informants were used to clarify and expand on ideas which were discovered in participant observation and interviews. These individuals were people who were easy to communicate with, knowledgeable about the goals of the study, and were concerned that the correct information was conveyed (Bernard, 1995).

This study was approved by the Michigan Technological University Institutional Review Board (Approval number: M0927). Twenty one families were chosen from a variety of socioeconomic conditions for the study. Three of the families were not used throughout the entire study due to disinterest and unforeseen circumstances such as injuries, births and relocation which prohibited the continuation of survey data. 
However, their point of view is accounted for in the study as they participated in the participant observation portion of the study.

\subsubsection{Demographic Data and Socioeconomic Class}

Initially, demographic data was collected from each household to identify the number of people within the household, neighborhood (quartier), father's job, mother's job, house material, roof material, ownership of a motorcycle, livestock (species and number) and the presence of a compound wall (Jenkins and Scott 2007). Each family was also given socioeconomic ranking (scale 1-4 with 4 being a higher ranking) based on the methods described in Hargreaves et al. (2007).

\subsubsection{Nightly Surveys}

Nightly surveys were conducted throughout the rainy season when the participating households returned from their fields or work and had presumably already collected any plants they were going to that day. The primary focus was to get an understanding of what plants they had collected that day and how they were utilizing them. The survey was kept simple to ensure consistent results and not to bother households routinely with complicated questions. Therefore, the following three questions were always asked:

1. What plants were collected today?

2. Where were they collected from and

3. Were the plants eaten, dried or sold? 


\subsubsection{Interviews}

Semi-structured open ended interviews were conducted in person with selected families and key informants to gain specific comparable information about tasba and how it is perceived within the community (Bernard 2002). If the respondents did not know French, the interviews were performed in Fulfulde, with the help of a translator. The interviews were conducted towards the end of the study to avoid biasing future nightly surveys because the interview involved many specific questions about tasba. The structured interviews were performed opportunistically because they were conducted during a busy harvesting period and therefore a specific schedule was difficult to arrange. Interviews were continued until a degree of "saturation" was reached and no new information was being discovered (Guest et al. 2006). Informal interviewing was also used throughout the study to gain knowledge about the plant in a more opportunistic, less structured manner.

Although I conducted the interviews at the end of my Peace Corps service, some of the women still appeared bashful and insecure during the interviews. Occasionally interviews with women were to help the women feel more comfortable. Distractions which could be considered threatening or intimidating such as male supervision or unneeded outside observers were removed. The ideas expressed by timid women were often confirmed by other women who were interviewed, but not with the same enthusiasm and depth. The best interviews were conducted with people within my community with whom I was closest to, as they were comfortable with me and wanted to 
help me and share information with me. They elaborated on more ideas and spoke more freely.

The foci of the interview was to gain qualitative data on the abundance of tasba, collection locations, collection periods, management efforts enforced on tasba, preparation techniques, alternative uses, drying periods and techniques as well as history of tasba within the community.

\subsubsection{Field Measurements}

Field measurements were taken at 35 sites located in and out of cultivated land (homegardens and fields), to determine if cultivation tasks (weeding, hoeing, applying pesticides or fertilizers) affected the abundance of tasba. The methods described by Daubenmire (1959) were used to get a percent cover estimate of tasba in 35 sites with different management practices, and ecological conditions (Daubenmire 1959). Sun availability and slope were recorded at each site. Percent cover of tasba, bare ground, grasses and sedges, and other plants were recorded.

\subsubsection{Data Analysis}

Data was analyzed using JMP (JMP, Version 7. SAS Institute Inc., Cary, NC, 1989-2007). Using logistic regression, the likelihood of collecting and drying traditional plants and specifically tasba were compared across different job categories. Results of a $\mathrm{p}<0.05$ were considered significant. Logistic regression was also used to compare collection locations for households where the mother had a job verses households where the mother was a subsistence farmers. The same was done for father's jobs. Logistic 
regression was also used to look at collection and drying throughout the rainy season, to see if households were more or less likely to collect or dry vegetables throughout the season. T-tests were run to test the differences in tasba percent cover in cultivated verses uncultivated sites. Fisher's exact test was used to test the contingency between shaded sites and uncultivated sites. 


\section{CHAPTER 5-RESULTS AND ANALYSIS}

\subsection{Results of Semi-Structured Open Interviews}

Every family surveyed was familiar with tasba as a food source; it was a harvested at least once by each family surveyed in the nightly surveys. It was primarily recorded as being brought from a field or en brousse, the uncultivated land. Women and children were always the plant collectors. Both male and female participants said collecting tasba was the "woman's job." However, in special circumstances such as with widowers, the men will collect. When asked, men answered that they were capable of identifying and preparing the common plant species. No one said that they planted tasba; folere, gombo and gubudo were mentioned the most often as planted either in homegardens or intercropped in their fields, as these are more domesticated garden species. The top five plants that were reported as collected as sauce species were folere, laalo, gubudo, gombo and tasba.

The year this information was collected was a poor season for tasba as indicated by interviews, key informants and observation. Villagers were not sure why. Some attributed it to an above average rainfall, while others to the drought the previous year. One key informant attributed the reduction in tasba availability to the increase in chemical herbicides used, and another to the diminishing uncultivated land for tasba to grow in. Older villagers who grew up in the Grand North said that they ate tasba as a child, but there were varied comments on the changing availability of the plant. One 
person indicated that a market for tasba has grown over the years so there is increased demand but there was uncertainty about the abundance overall.

Responses about the environment women find tasba in were varied. Women know where to look for tasba. The majority of the women asked said that tasba does not "like" sandy soil, and can be found in fertile areas, often where there is a lot of cow manure and under trees where the leaves have fallen. The women indicated that they most often find tasba in areas of sufficient moisture, but not in areas that are inundated. Tasba will grow around all kinds of other plants, and is not known to be especially prevalent around any other wild or cultivated plant.

Tasba is prepared by removing the leaves from the stem, rinsing them with water one or two times and adding them to boiling water in a marmite. Natron is added to change the texture and reduce acidity. If the sauce is too watery, water will be removed to achieve the correct consistency. Next, the pot d'arrachide is mixed in as well as salt, Maggie cubes (monosodium glutamate) and other desired condiments. This was the standard way of preparing tasba, mentioned by several village women during the interviews. Alternative recipes can be used depending on the moyens or means at the moment of preparation. Dried fish and white beans are often added when available. Tasba may be mixed with other leafy species such as laalo and in times of hardships or when pot d'arrachide is not available, tasba can be prepared without it.

Informants did not mention many alternative uses for tasba. One mentioned that the seeds can be ground and put in soup to help treat worms, but this was not confirmed 
by any other women. One child indicated that the stems can be used as kindling after the leaves have been removed. These results were not confirmed by any other respondents.

The women said that tasba is sold in the market. Most often it is sold dried. The most popular time for dried tasba is in March and April, in the peak dry season when many of the other sauce species are finished and it is still too dry to plant and other reserves have been used up. This is also when tasba is the most expensive. During March or April, one tasse or bowl (the typical selling quantity) can cost 100-150XAF (CFA) and at its cheapest in September the same tasse is sold for 50-100 XAF (CFA) (100XAF=0.196USD, xe Currency Converter www.x-rates.com accessed March 26, 2013). One women often brought species such as gubudo, haako gabai (Amaranthus spp.) and folere to Garoua to sell. When asked why she did not bring tasba, she said that she can plant the species that she brings to Garoua, since she cannot plant tasba, so she saves that species for her family.

\subsection{Results of Nightly Surveys}

The households surveyed collected and ate a variety of traditional vegetables. Of the days surveyed, traditional plants were collected 509 of the 618 survey occurrences (75\%) (Figure 5.1). 


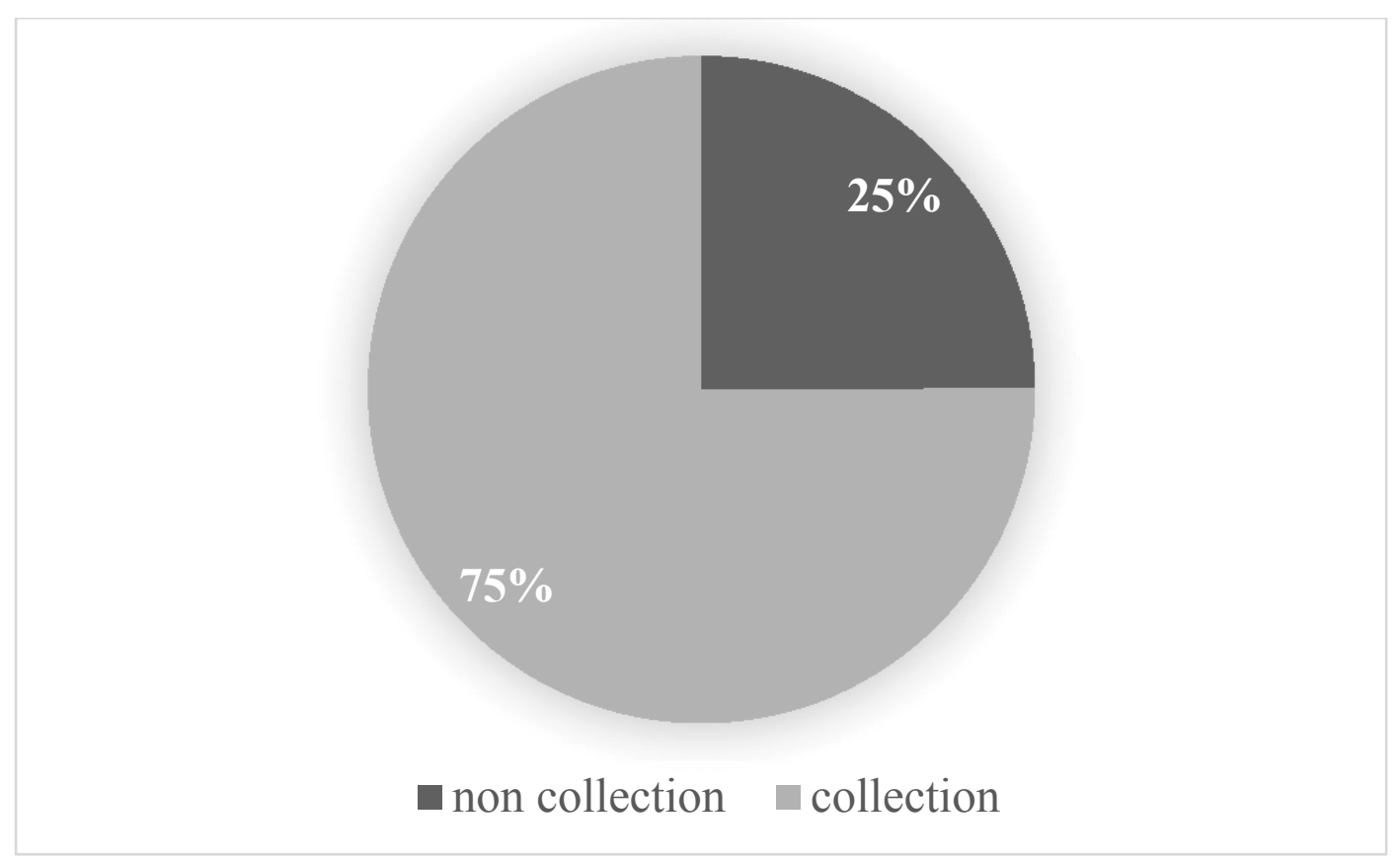

Figure 5.1: Number of days separate households reported collecting traditional vegetables from June-October 2012. ( $\mathrm{n}=618)$

Five plants (folere, tasba, gubudo, laalo and gombo) (Table 5.1) accounted for $84 \%$ of survey responses, ten species compromised the minor species category representing the other $16 \%$ of the plants mentioned, including leaves of some cultivated plants such as cassava (Manihot esculenta) leaves, melon leaves and cowpea leaves (Figure 5.2). Tasba was the second most popular plant collected, accounting for $20 \%$ of the responses. Folere was the most popular plant with $26 \%$ of the responses. 
Table 5.1: Five most popular species mentioned in nightly surveys. Reference name is what each plant was referred as most often by the respondents within the community and how they will they are referred to in this study (Iyebi-Mandjek 1997; Noer n.d.; Parsons and Cuthbertson 2001)

\begin{tabular}{cccc}
\hline $\begin{array}{c}\text { Reference } \\
\text { Name }\end{array}$ & $\begin{array}{c}\text { Fulfulde } \\
\text { Name }\end{array}$ & Other names & Scientific Name \\
\hline Folere & hologo & $\begin{array}{c}\text { roselle (English), folere } \\
\text { (French) }\end{array}$ & Hibiscus sabdarifa \\
Tasba & tasba & sicklepod (English) & Senna obtusifolia \\
Laalo & laalo & jute mallow (English) & Corchorus spp. \\
Gubudo & gubudo & false sesame (English) & Ceratotheca sesamoides \\
Gombo & baskooje & gombo (French), okra & Abelmoschus esculentus \\
& & (English) & \\
\hline
\end{tabular}

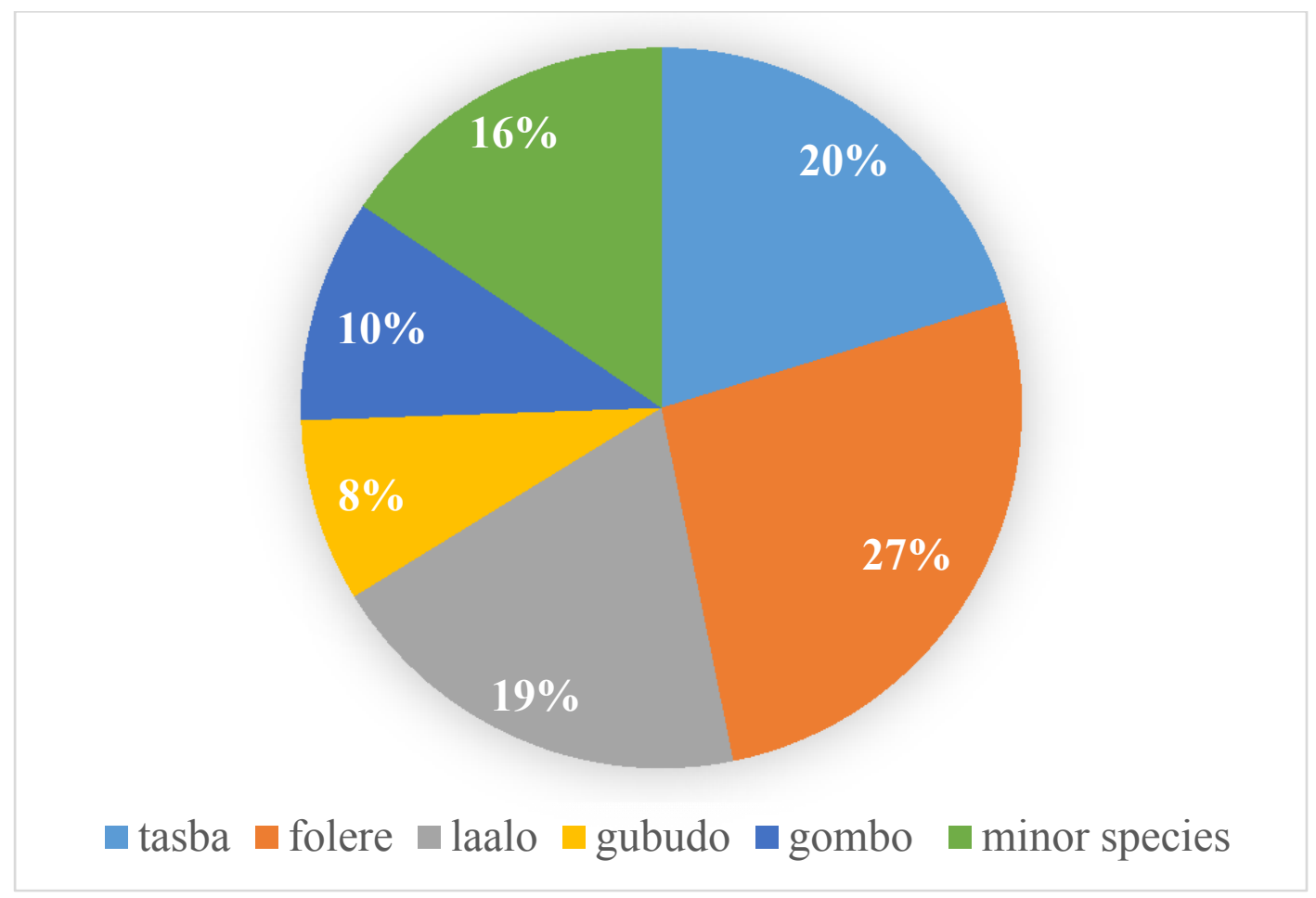

Figure 5.2: Proportion of species collected in household surveys during the June-October 2012. $(\mathrm{n}=509)$ 
When collected, tasba was eaten fresh $41 \%$ of the time or dried and saved for later, $59 \%$ of the time (Figure 5.3 ).

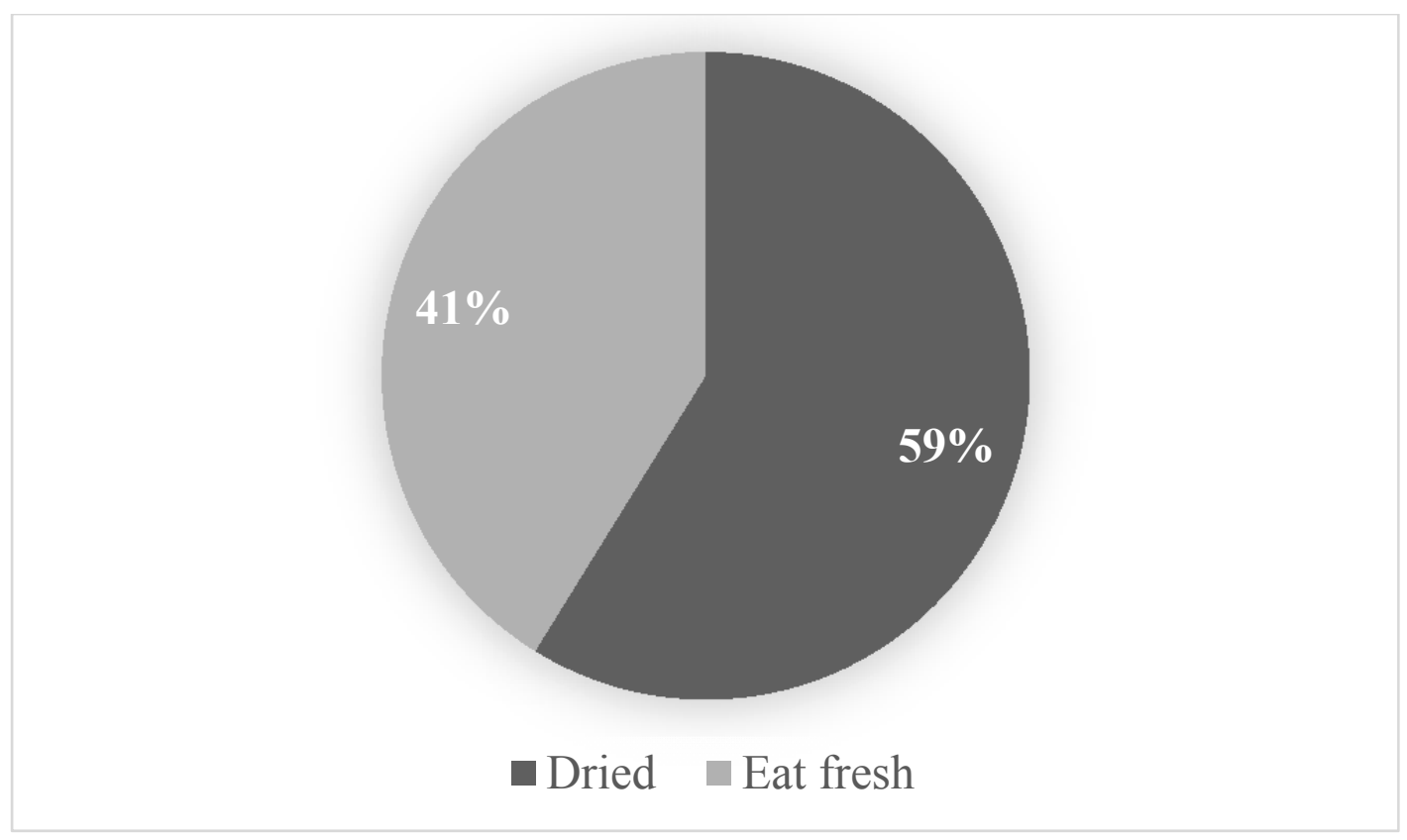

Figure 5.3: Distribution of preserving tasba (drying) verses eating tasba fresh. $(n=103)$

Traditional vegetables were collected from three places; homegardens, in and around fields and en brousse. Vegetables were also shared between families and neighbors and sold formally in markets and informally between neighbors. Some species were cultivated in homegardens, around the perimeter of fields as well as open spots between crops in the fields. Gombo, folere and gubudo were popular cultivated species, often collected from homegardens and fields. In the interviews, many women mentioned planting these species around their house and fields. 
When households collect tasba, $66 \%$ of the time they collected it en brousse, $21 \%$ of the time they collected it in or around fields and $14 \%$ of the time it was from a homegarden (Figure 5.4). No woman indicated that they planted tasba, although one informant from the Adamouwa said that since it is not common in her region, she would like to bring some seeds to the Adamouwa to plant. Generally tasba is used as a wild weed species. Women will sometimes weed around it in fields to promote growth and production, but it is not cultivated on the same level as other traditional vegetables such as gubudo and folere.

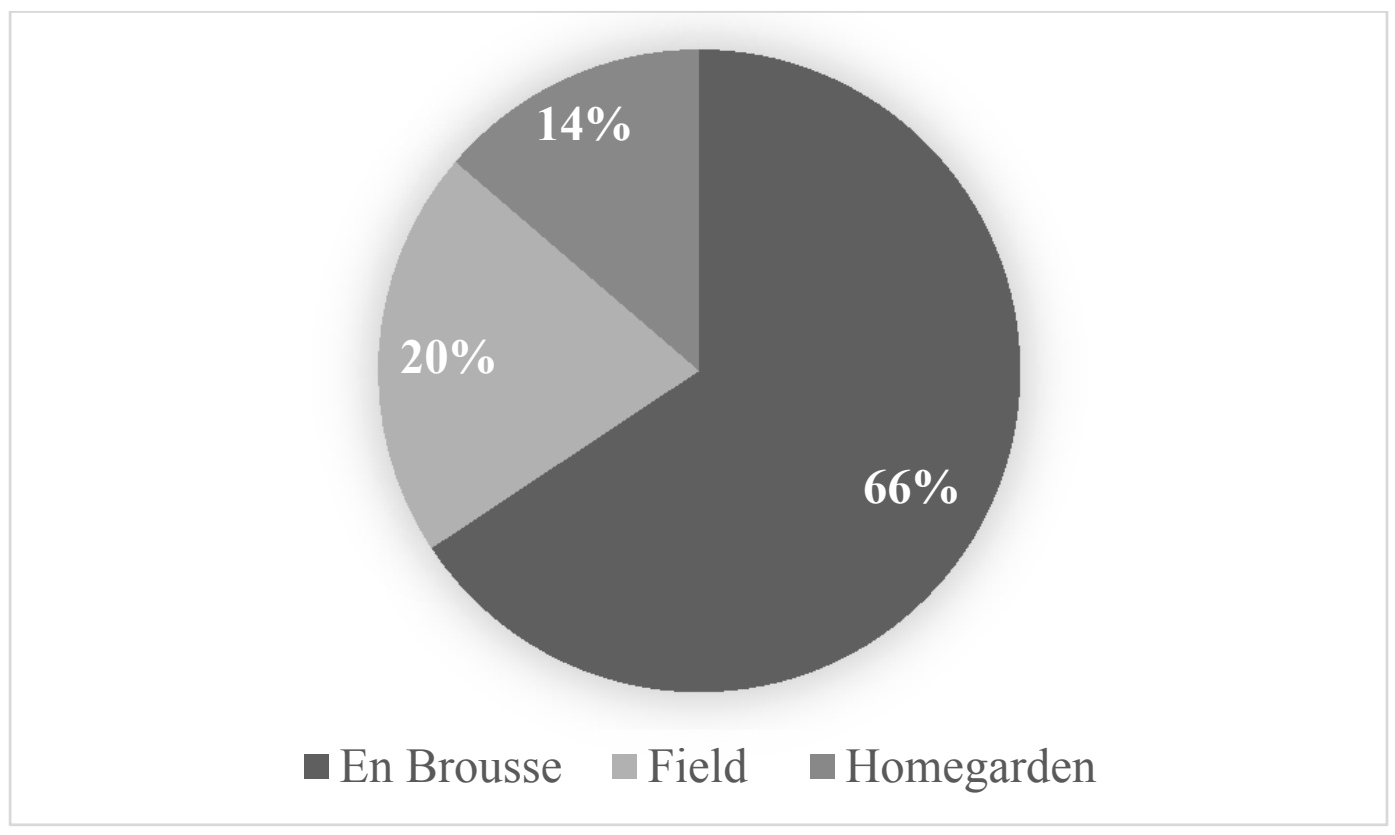

Figure 5.4: Distribution of tasba collection sites throughout the entire population. $(\mathrm{n}=103)$

\subsection{Collection Patterns Based on Socioeconomic Conditions}

Logistic regression was used to compare the likelihood of collection between families with different socioeconomic characteristics. Even though many statistics on 
socioeconomic conditions (e.g. house and roof material, animals at the household, presence or absent of motorcycle) were collected, the mother and fathers jobs were the strongest indicator of family behavior when to collecting and using wild vegetables. The father and the mother's jobs also were closely related to the socioeconomic ranking and it was strongest factor affecting status within the community, so comparisons were run for job types to compare collection behavior across different household situations. Since Sanguéré Paul is traditionally a farming community, the different jobs were compared to subsistence farming to look at the effect of job status on collection patterns.

\subsubsection{Likelihood of Collection Based on Father's Job}

Households are approximately half $(0.57)$ times as likely $(\mathrm{p}=0.003)$ to collect traditional vegetables if the husband has a job other than a subsistence farmer. When analyzing specific job categories, households where the father worked for private industry were 0.21 as likely to collect vegetables than household where the father is a subsistence farmer $(\mathrm{p}<0.01)$ (Figure 5.5). When the father worked for government, the household was 0.62 as likely to collect as famers $(\mathrm{p}=0.04)$. Families where the father was absent $(\mathrm{p}=0.11)$, a herder $(\mathrm{p}=0.16)$ or held a village job $(0.08)$ did not collect traditional vegetables significantly more or less than subsistence farmers. 


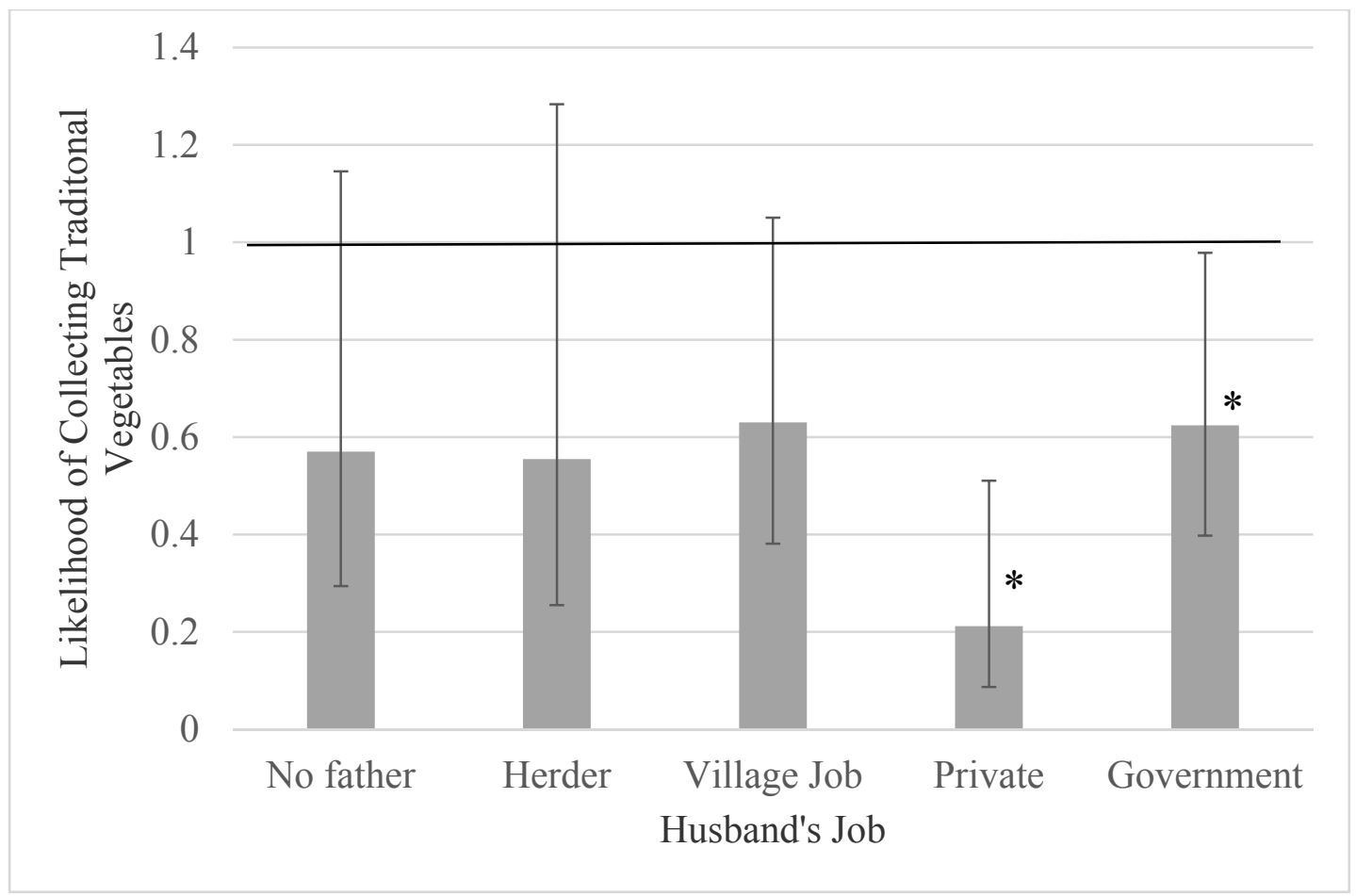

Figure 5.5: Likelihood of households in Sanguéré Paul collecting wild plant species based on husband's job categories compared to subsistence farmers. If error bar includes 1 , there is no significant difference between indicated job and substance farmers' collection patterns. Asterisks indicates significance at $\alpha=0.95$.

In contrast, households where the father had a job did not collect tasba more or less than households where the father was a subsistence farmer $(\mathrm{p}=0.09)$. However, when analyzed by job categories, households where the father works for the government, women were twice as likely to collect tasba specifically $(p=0.009)$ than households where the father was a farmer (Figure 5.6). If there was no father $(\mathrm{p}=0.32)$, if the father was a herder $(p=0.69)$ had a village $(p=0.21)$ or private job $(p=0.20)$, the household did not collect tasba significantly more or less than farmers. The most significant difference in the collection of tasba appears when comparing households where the father worked for a private institution compared to household where the father works for the government. 
Households where the father worked for a government institution were $6.06(p=0.02)$ times more likely to collect tasba than household where the farmer works for a private institution.

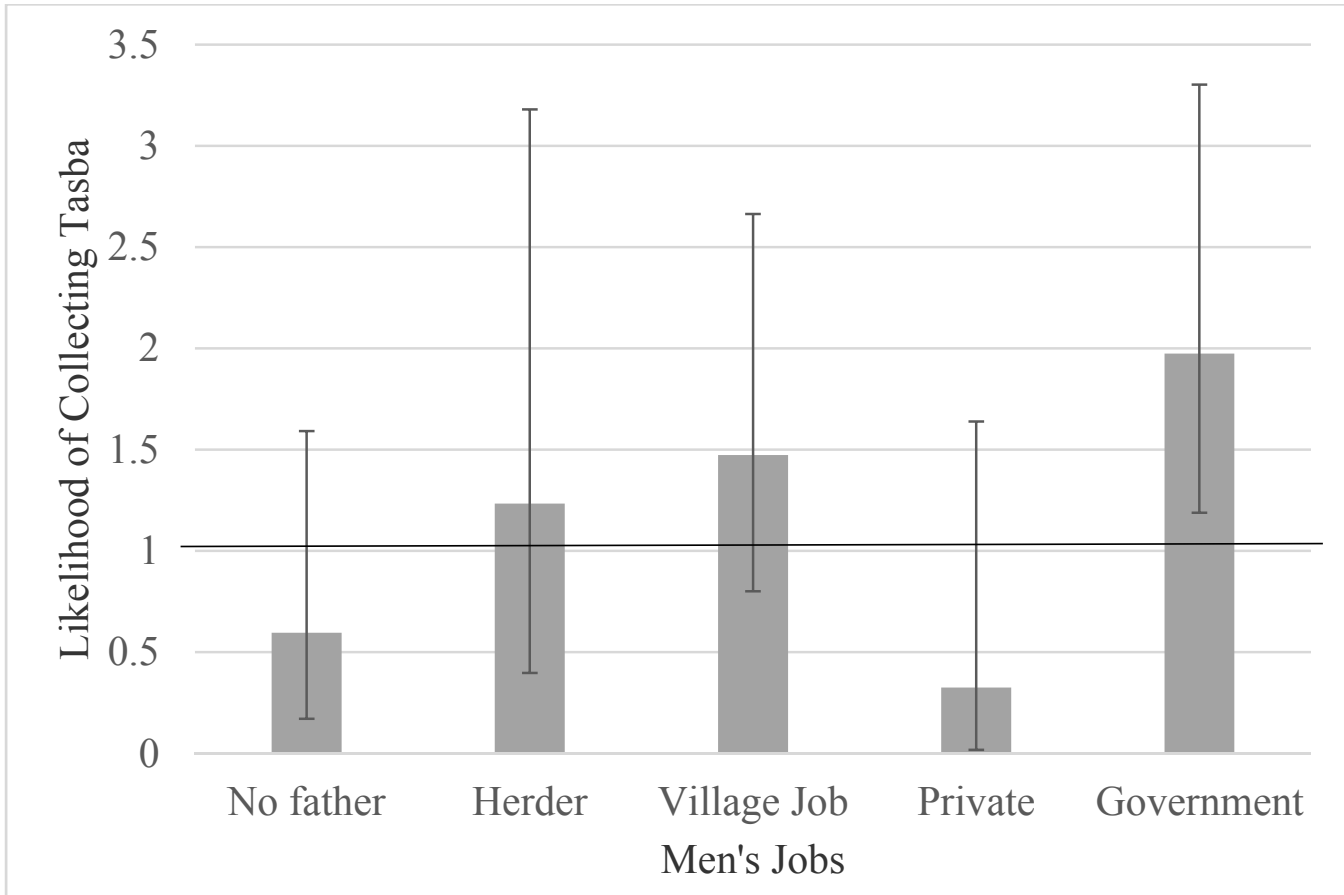

5.6: Likelihood of households in Sanguéré Paul collecting tasba based on father's job categories compared to subsistence farmers. If error bar includes 1 , there is no significant difference between indicated job and substance farmers' collection patterns. Asterisks indicates significance at $\alpha=0.95$.

\subsubsection{Likelihood of Collection Based on Mother's Job}

The households where the mother held a job other than subsistence farmer did not collect or grow traditional vegetables significantly more or less than those where the mother was a subsistence farmer $(\mathrm{p}=0.10)$ (Figure 5.7). However, in households where the mother held a job other than subsistence farming, they were half (0.59) times as likely to collect tasba specifically $(\mathrm{p}=0.02)$. When analyzed by job categories, households 
where the mother was a herder $(\mathrm{p}=0.62)$, seamstress $(\mathrm{p}=0.37)$ or stayed home $(\mathrm{p}=0.85)$ did not collect tasba significantly more or less than households where the mother was a subsistence farmer ( $>00.05)$ (Figure 5.8). However, households where the mother was a market vendor were half as likely to collect to tasba as subsistence farmers ( $\mathrm{p}=0.005)$.

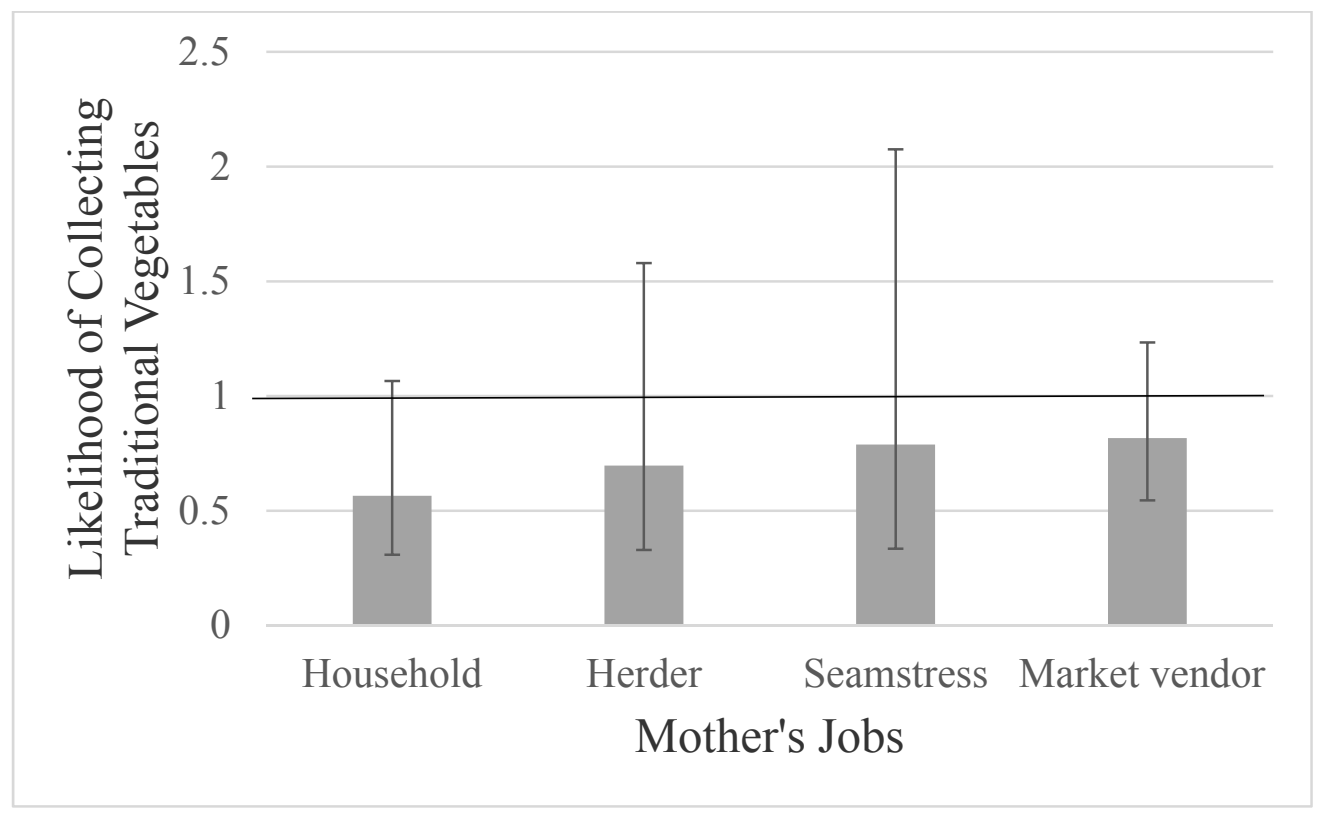

Figure 5.7: Likelihood of households in Sanguéré Paul collecting traditional vegetables based mother's job categories compared to subsistence farmers. If error bar includes 1 , there is no significant difference between indicated job and substance farmers' collection patterns. Asterisks indicates significance at $\alpha=0.95$. 


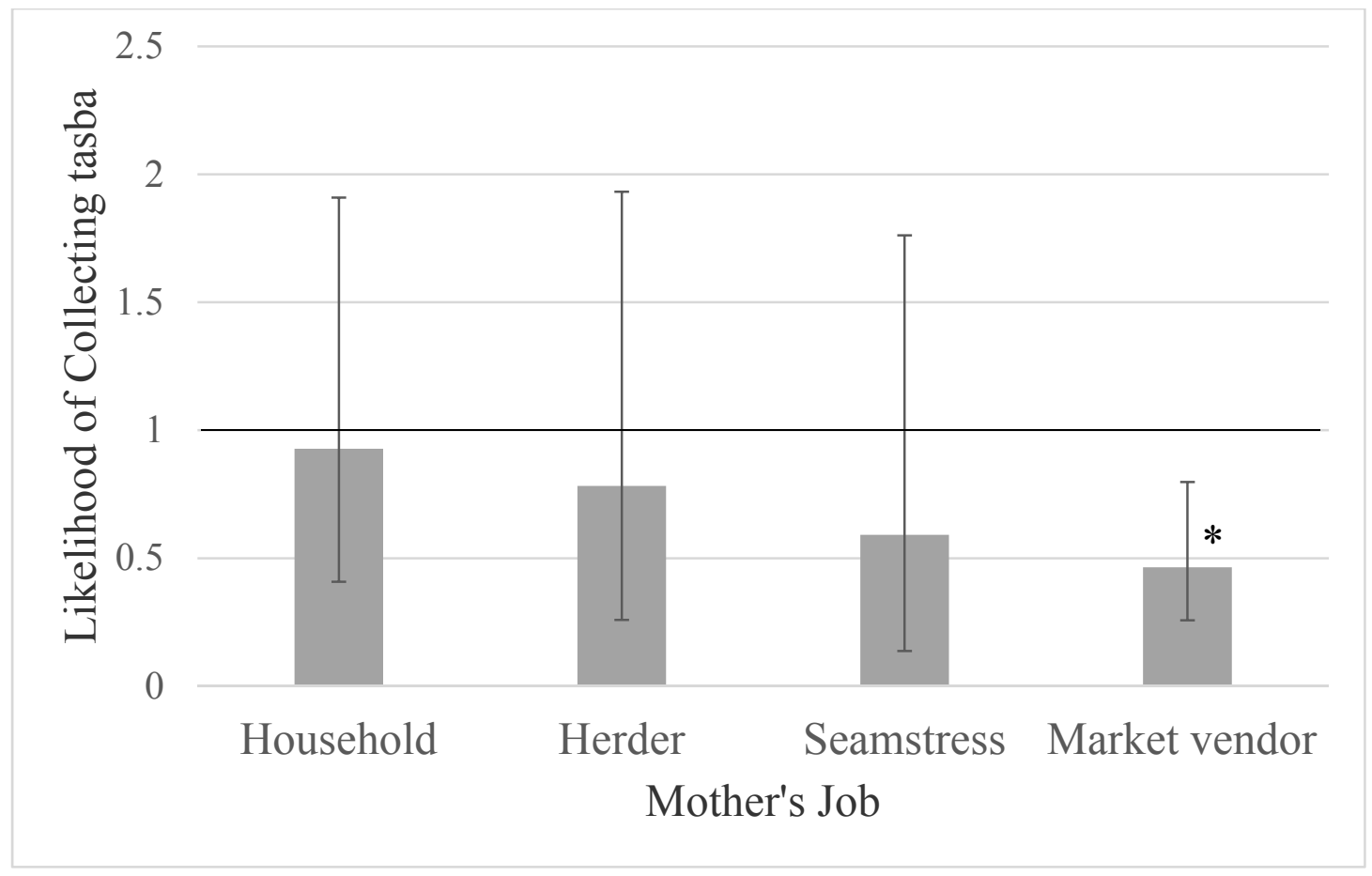

Figure 5.8: Likelihood of households in Sanguéré Paul collecting tasba based mother's job categories compared to subsistence farmers. If error bar includes 1 , there is no significant difference between indicated job and substance farmers' collection patterns. Asterisks indicates significance $\alpha=0.95$.

\subsection{Preserving (Drying) Traditional Vegetables}

The women interviewed indicated that they collect tasba and dry it and save it for the dry season. One key informant mentioned that the tasba collected in the beginning of the year takes a shorter amount of time to dry because there is less moisture in the leaves. Drying times can range from 1 day to 3 days, depending on the "force of the sun". To dry tasba the leaves are removed from the stems and placed on a plastic or metal surface (Figure $5.9 ; 5.10)$. When leaves are adequately dried, they are put in a plastic bag (two if possible) to protect the leaves from moisture and insect pests and are hung from the wall 
or the roof. The leaves must be fully dry before placing them in a plastic bag; humidity can destroy the leaves and affect the taste.

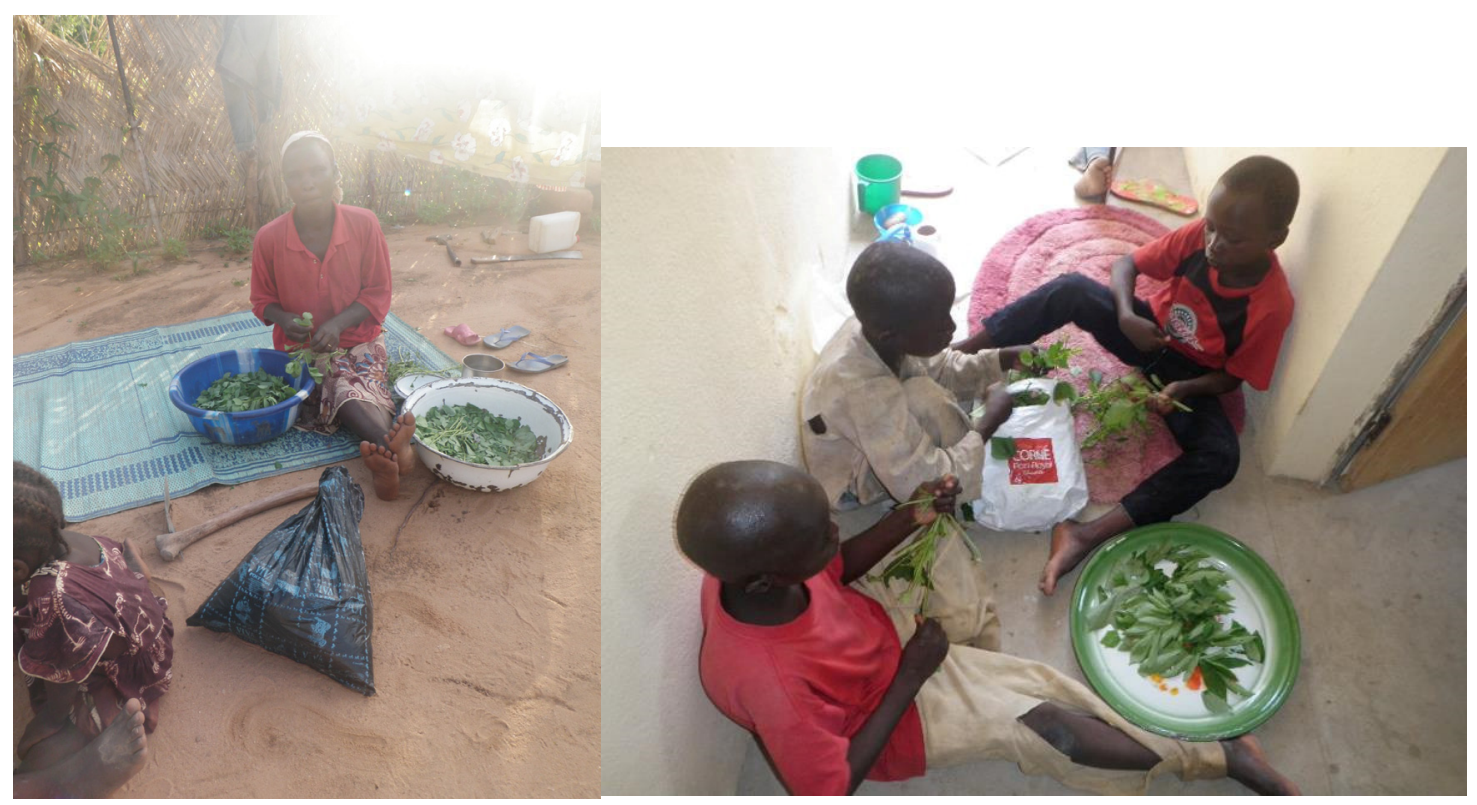

Figure 5.9: Woman (left) and children removing leaves from plants. Photo credit: Mary Snyder

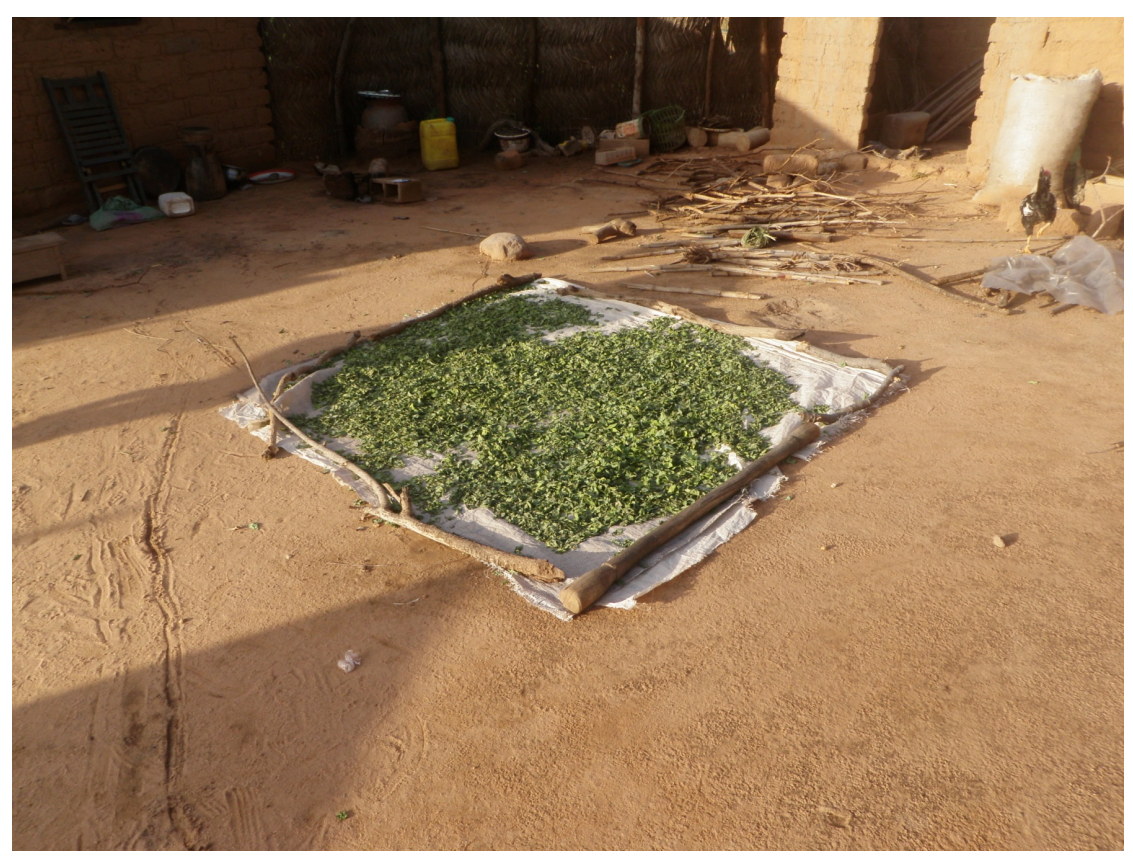

Figure 5.10. Leaves drying in the sun. Photo credit: Mary Snyder 


\subsubsection{Likelihood of Drying Traditional Vegetable Species}

Tasba was the most common species dried. Households were one tenth (0.12) $(\mathrm{p}<0.01), 0.15(\mathrm{p}<0.001)$, and half $(0.46)(\mathrm{p}=0.03)$, as likely to dry folere, laalo and gombo respectively as tasba. There was no significant difference in how likely a family was to dry gubudo rather than tasba $(\mathrm{p}=0.15)$ (Figure 5.11).

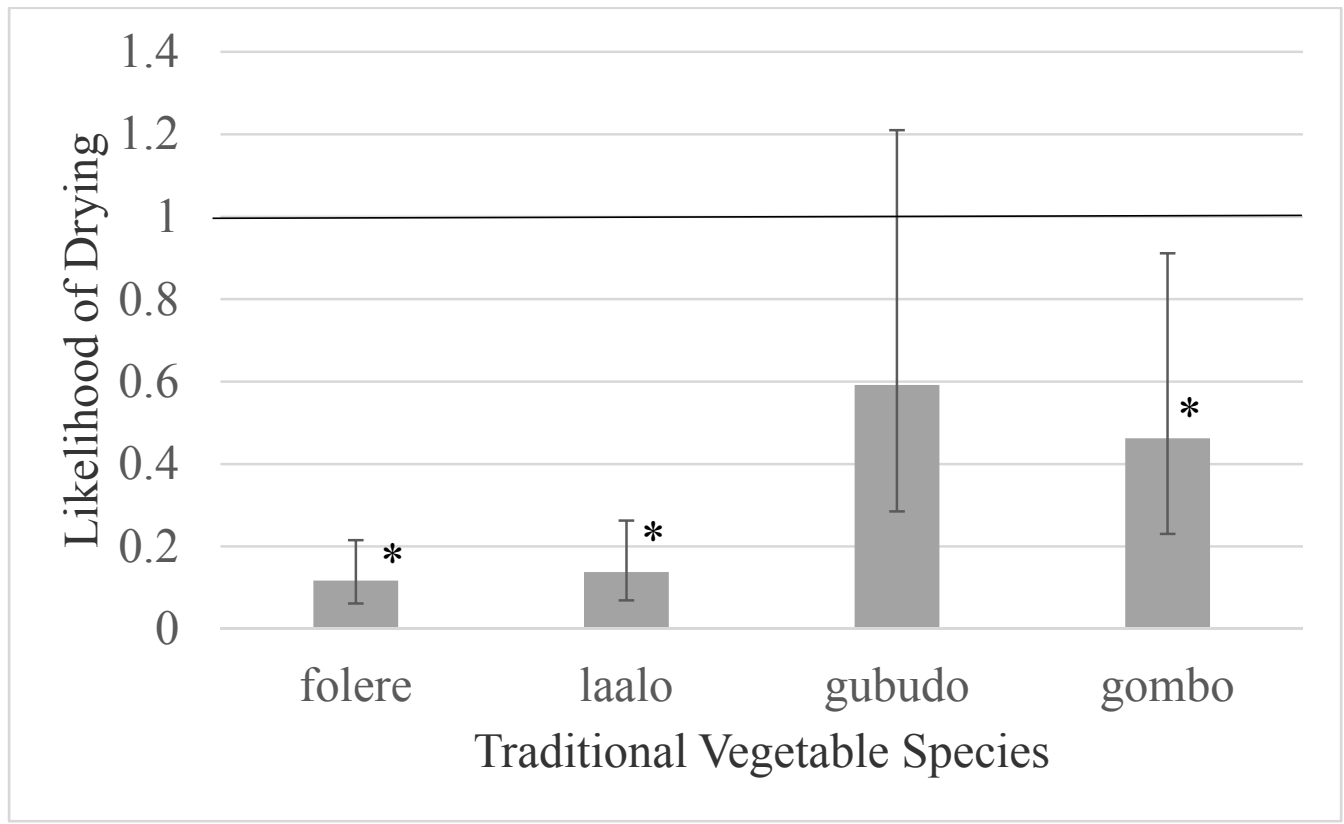

Figure 5.11: Likelihood of drying the four most common traditional vegetables compared to tasba. If error bar includes 1 , there is no significant difference between drying patterns of the indicated vegetable and tasba. Asterisks indicates significance at $\alpha=0.95$

\subsubsection{Likelihood of Drying Based on the Father's Job}

There was no significant difference in likelihood to dry traditional vegetables in households where the father had a job and households where the father was a subsistence farmer $(\mathrm{p}=0.67)$. However, when analyzed by job categories, households where the father worked for the government were 0.17 as likely to dry traditional vegetables as households where the father was a subsistence farmer $(\mathrm{p}=0.03)$. Households where the father worked 
for a private institution were 0.13 as likely to dry traditional vegetables as households where the father was a subsistence farmer $(\mathrm{p}=0.01)$. Households where the father had a village job $(\mathrm{p}=0.18)$, had a government job $(\mathrm{p}=0.15)$ or were herders $(\mathrm{p}=0.67)$ did not dry traditional vegetables more or less than subsistence farmers (Figure 5.12). Households where the father had a job other than subsistence farming did not dry tasba more or less than house households where the father was a subsistence farmer $(\mathrm{p}=0.26)$. Households that had no father present at the house were significantly less likely to dry vegetables than families where the father had a village job $(\mathrm{p}=0.01)$, government job $(\mathrm{p}<0.01)$ or subsistence farmers $(\mathrm{p}<0.01)$.

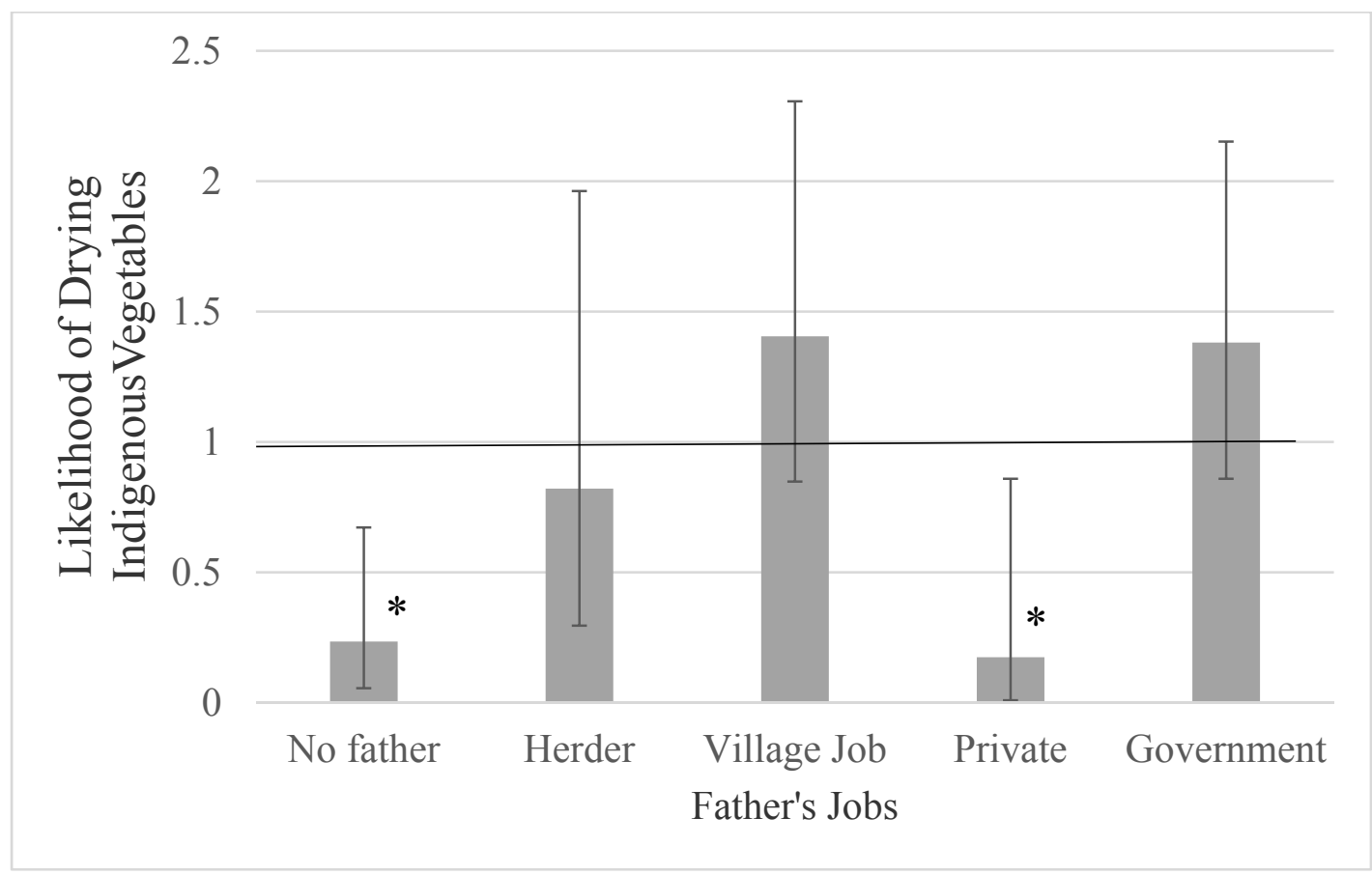

Figure 5.12: Likelihood of households in Sanguéré Paul to dry traditional vegetables for different men's jobs categories compared to subsistence farmers. If error bar includes 1, there is no significant difference between indicated job and substance farmers' collection patterns. Asterisks indicates significance at $\alpha=0.95$. 


\subsubsection{Likelihood of Drying Based on Mother's Job}

Households where the mother had a job other than subsistence farming were half (0.46) times as likely to dry vegetables as households where the mothers only job is subsistence farming $(\mathrm{p}<0.01)$. Households where the mother was a market vendor were $0.44(\mathrm{p}<0.01)$ as likely to dry vegetables as those where the mother was a subsistence farmer. Mothers who stayed at the household where 0.34 as likely to dry vegetables as households where the mother was a subsistence farmer $(\mathrm{p}=0.01)$. Households where the mother was a seamstress or herder were not more or less likely to dry traditional vegetables than households where the mother was a subsistence farmer $(p=0.37$ and $p=$ 0.22 respectively) (Figure 5.13). However, households where the mother had a job other than subsistence farming were 2.4 times as likely to dry tasba specifically than households where the mother was a subsistence farmer $(\mathrm{p}=0.042)$. 


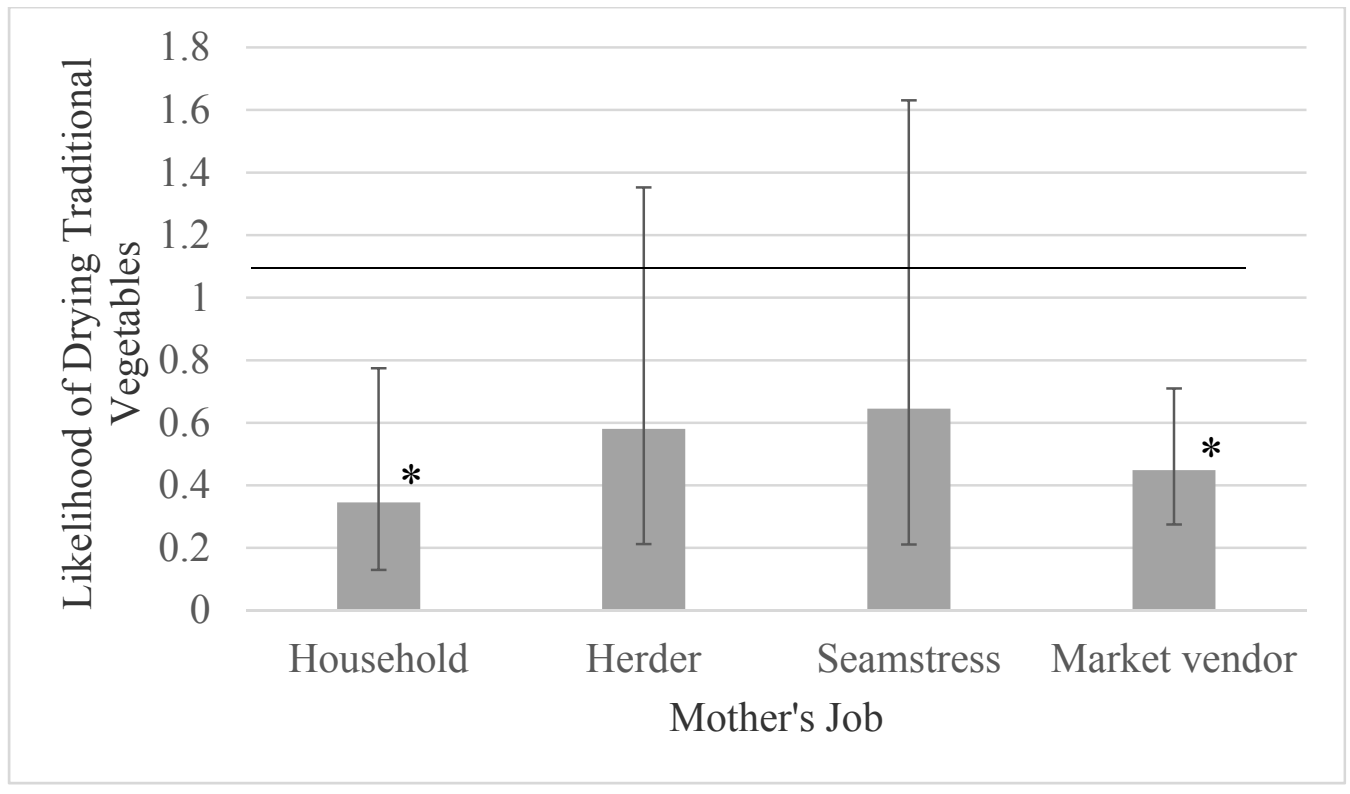

Figure 5.13: Likelihood of households in Sanguéré Paul to dry traditional vegetables for different mother's job categories compared to subsistence farmers. If error bar includes 1 , there is no significant difference between indicated job and substance farmers' collection patterns. Asterisks indicates significance at $\alpha=0.95$.

\subsection{Locations of Collecting Traditional Vegetables and Tasba}

Traditional vegetables were collected from homegardens, fields and en brousse. Tasba was generally collected from en brousse and fields, but it was also traded among neighbors and found in homegardens (likely as a weed).

\subsubsection{Proportion of Vegetable Collection Locations Based on Job type}

The proportion of times traditional vegetables were collected from the three different places for each job title was analyzed. Vegetables were collected from four locations, but collecting from neighbors was left out of the analysis due to infrequency and small sample size. Households where there was no father rarely collected from homegardens, but collected from the other three locations relatively evenly (Figure 5.14). 
Herders most often collected from homegardens and en brousse. Families where the father had a village job collected from all three locations evenly. Households where the father worked for private institutions collected exclusively from homegardens and fields, and never collected from en brousse. Households where the father worked for the government most often collected from en brousse. Households where the father was a subsistence farmer collected from all three locations fairly evenly, but collected most often from homegardens and en brousse.

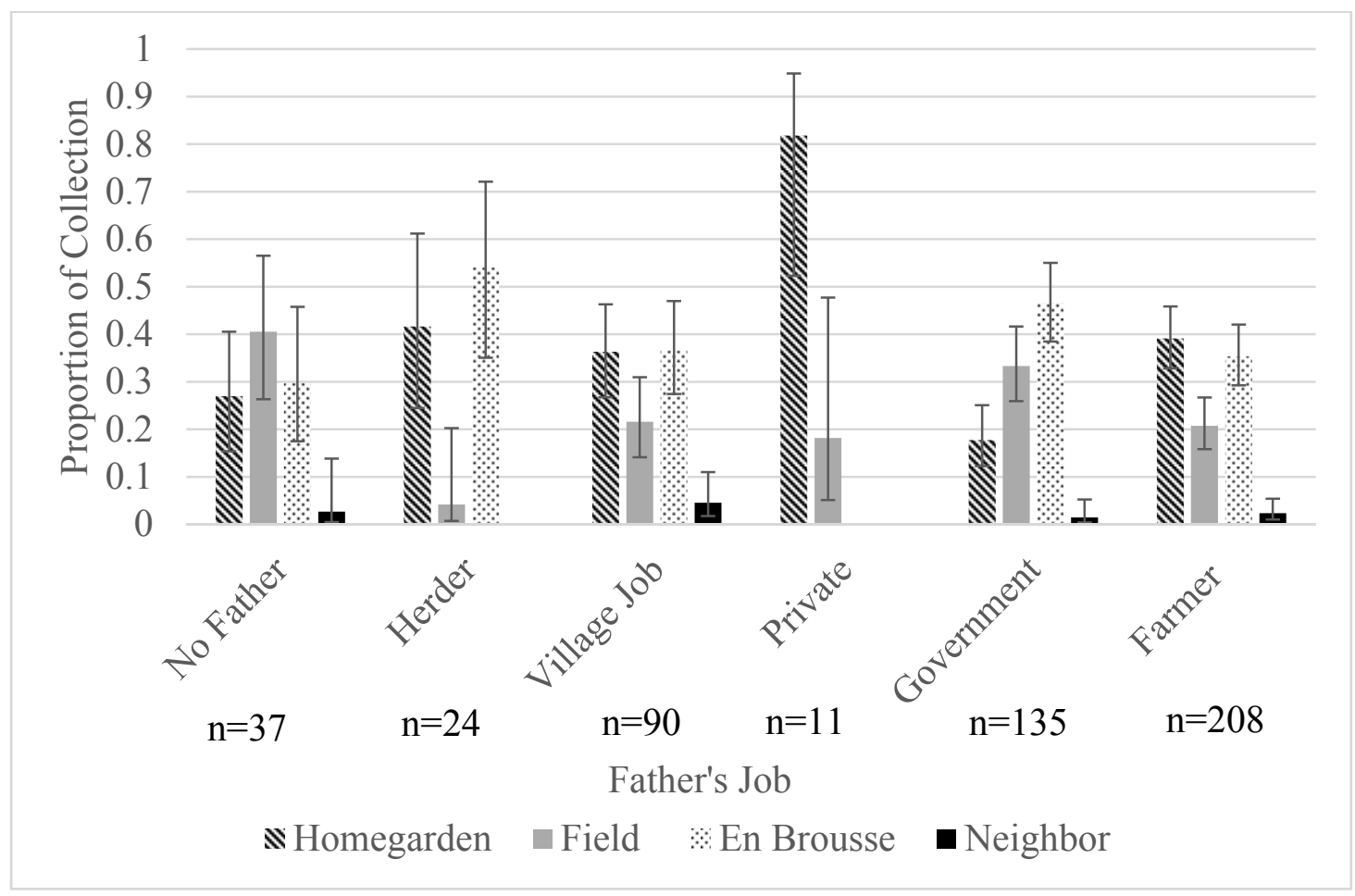

Figure 5.14: Proportion of traditional vegetable collection locations by father's job.

Households where the mother stayed at home most often collected vegetables from homegardens, and herders collected most often from homegardens and en brousse (Figure 5.15). Households where the mother was a seamstress, collected from all three 
locations, but most often homegardens and en brousse. Households where the mother was a market vendor or subsistence farmer collected from all three locations at approximately the same proportion, but most often from homegardens and en brousse.

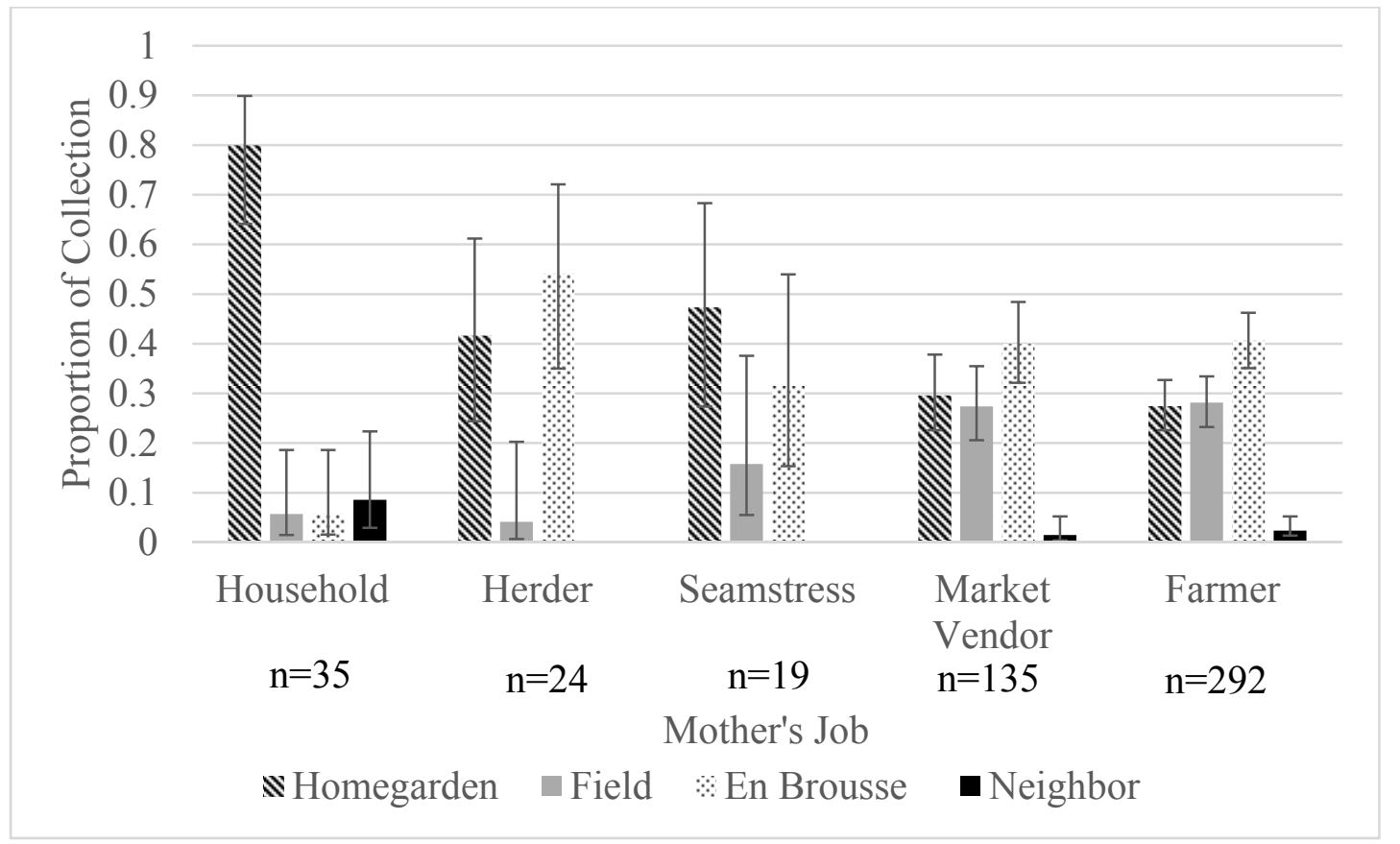

Figure 5.15: Proportion of traditional vegetable collection location by the mother's job.

\subsubsection{Proportion of Tasba Collection Locations Based on Job Type}

Households where there was no father collected tasba most frequently from fields and en brousse and never collected tasba from a homegarden (Figure 5.16). Households where the father was a herder collected tasba exclusively from en brousse and homegardens. Households where the father worked a village job collected tasba from all three locations, most frequently from en brousse. Households where the father worked for a private institution collected tasba exclusively from homegardens. Households 
where the father worked for the government and households where the father worked as a subsistence farmer collected tasba from all three locations but they collected it the most from en brousse.

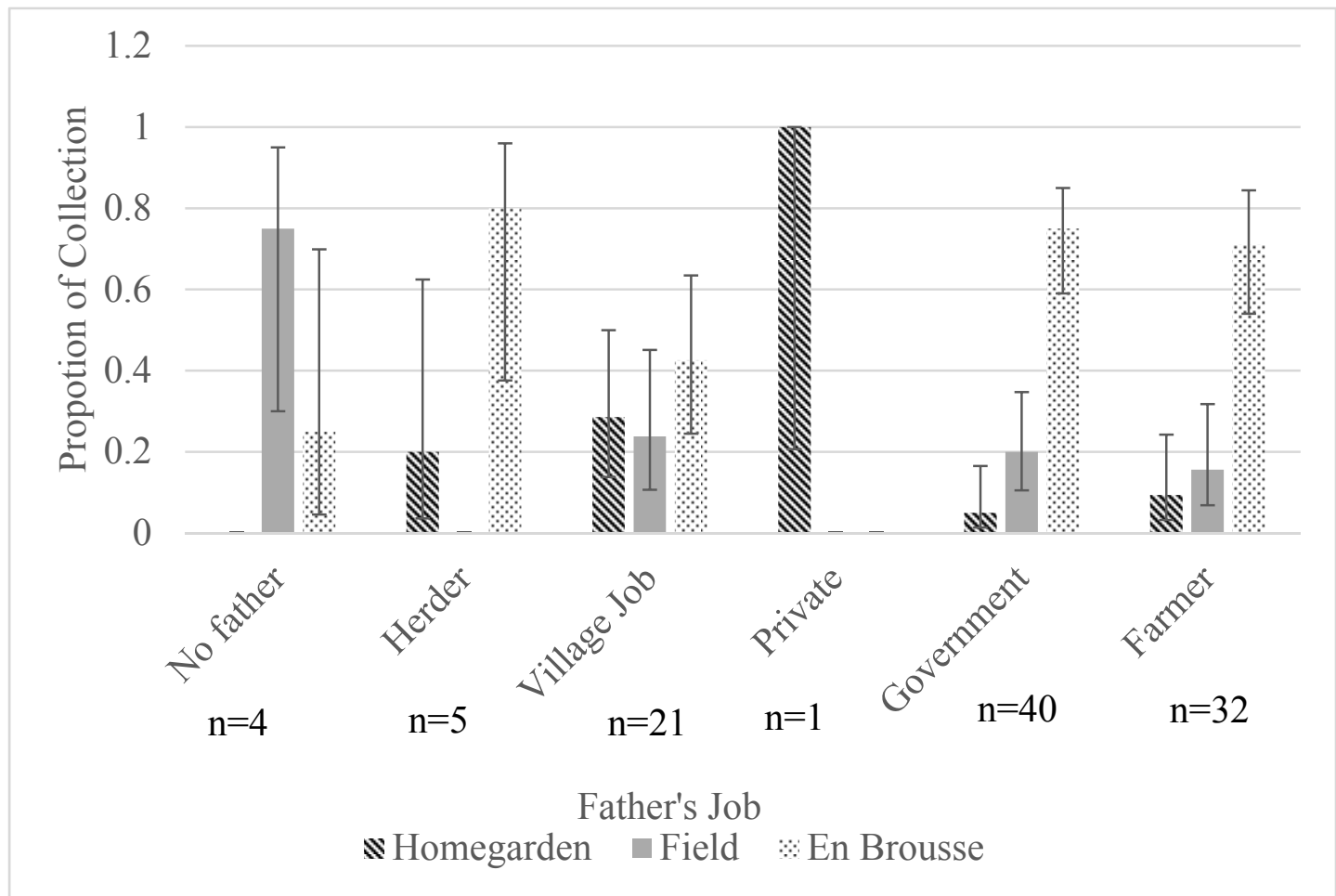

Figure 5.16: Proportion of tasba collection location by the father's job.

Households where the mother was a herder, a seamstress and households where the mother stayed home collected tasba exclusively from homegardens and en brousse, but herders and seamstresses collected more from en brousse and households where the mother stayed home collected more from homegardens (Figure 5.17). Households where the mother was a market vendor or subsistence farmer collected tasba from all three locations, but collected the most from en brousse and least the least from homegardens. 


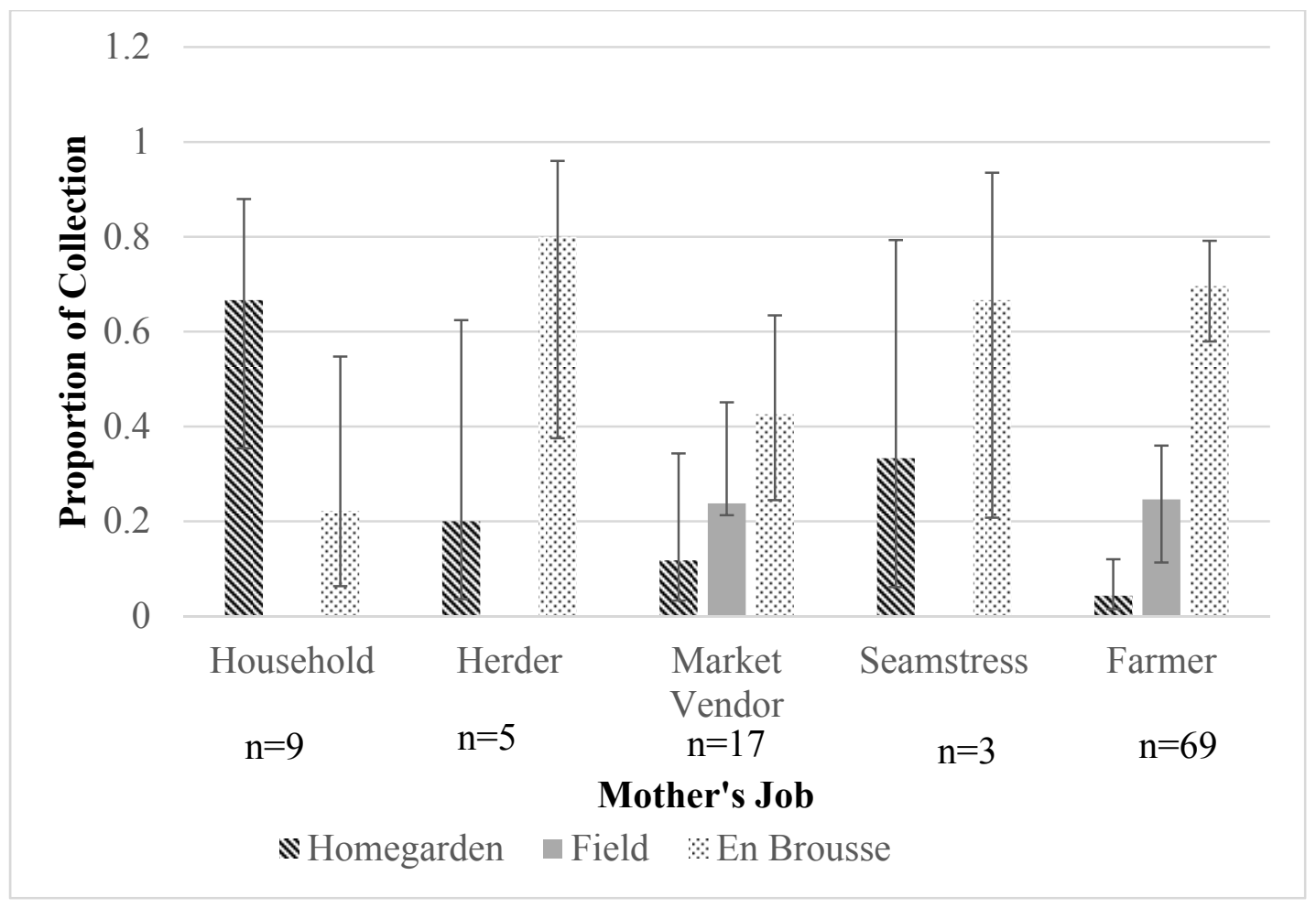

Figure 5.17: Proportion of tasba collection location by the mother's job.

\subsubsection{Likelihood of Collection Locations Based on Job}

Households where the father had a job other than subsistence farming were not more or less likely to collect traditional vegetables at any of the three different locations (en brousse, fields or homegardens) significantly differently $(\mathrm{p}=0.088)$. Households where the mother had a job other than subsistence farming did collect traditional vegetables in the three locations significantly differently $(p=0.028)$. When a mother has a job other than subsistence farming she is 1.71 times more likely to collect traditional vegetables in a homegarden than en brousse and 2.07 times more likely to collect in a homegarden than in a field (Table 5.2). 
Table: 5.2: Likelihood of collecting traditional vegetables at different locations based on if the mother has a job other than subsistence farming. The first row indicates that if a mother has a job she is 1.71 times more likely to collect in a Homegarden than en brousse. The two following columns are read the same way. Asterisks indicates significance at $\alpha=0.95$.

\begin{tabular}{cccc}
\hline & & odds ratio & p value \\
\hline Homegarden & En Brousse & 1.71 & $0.011^{*}$ \\
Homegarden & Field & 2.07 & $0.0024^{*}$ \\
En Brousse & Field & 1.2 & 0.4306 \\
\hline
\end{tabular}

Households where the father had a job other than subsistence farming were not more or less likely to collect tasba at any of the three different locations (en brousse, fields or homegardens) significantly differently $(\mathrm{p}=0.3593)$. Households where the mother had a job other than subsistence farming did collect tasba in the three locations significantly differently $(\mathrm{p}=0.0027)$. When a mother has a job other than subsistence farming she is 8.42 times more likely to collect tasba in a homegarden than en brousse and 14.6 times more likely to collect in a homegarden than in a field (Table 5.3).

Table 5.3: Likelihood of collecting tasba at different locations based on if the mother has a job other than subsistence farming. The first row indicates that if a mother has a job she is 8.42 times more likely to collect in a Homegarden than en brousse. The two following columns are read the same way. Asterisks indicates significance at $\alpha=0.95$.

\begin{tabular}{cccc}
\hline & & odds ratio & p value \\
\hline Homegarden & En Brousse & 8.42 & $0.001^{*}$ \\
Homegarden & Field & 14.6 & $0.0007^{*}$ \\
En Brousse & Field & 1.68 & 0.53 \\
\hline
\end{tabular}




\subsection{Changes of Behavior Throughout the Rainy Season}

Survey week does not have an effect on the collection of traditional vegetables $(p=0.86)$; people are just as likely to collect traditional vegetable at the beginning of the season as they are the end of the season. The same trend appeared when looking at only tasba, the odds ratio was $1(\mathrm{p}=0.86)$. Therefore the survey week did not have a strong effect on collecting tasba.

Survey week had a strong effect on drying tasba. The unit odds ratio was found to be 1.07 , meaning throughout the 20 week survey, each week there was a $7 \%$ increase in the likelihood that the family will dry tasba $(\mathrm{p}=0.04)$. Overall, the households were 3.6 times more likely to dry tasba in week 20 than they were week 1 . This relationship was strong for all traditional vegetables. Survey week has a strong influence on drying traditional vegetables, people are more likely to dry vegetables towards the end of the season $(\mathrm{p}<0.01)$.

\subsection{Results of Field Measurements}

The means of tasba percent cover were significantly different between cultivated (fields) and uncultivated sites $(2.4 \%$ versus $0.5 \%, \alpha=0.05)$. The means of tasba percent cover were also significantly different between shaded and sunny sites $(4.3 \%$ versus $0.3 \%, \alpha=0.05)$. Shaded sites were significantly associated with uncultivated lands, as there were no shaded sites located within cultivated lands $(p=0.052)$ (Table 5.4). 
Table 4.4: Data for Contingency Table comparing sunny and shaded cultivated and Uncultivated Sites $(\mathrm{p}=0.052)$

\begin{tabular}{ccc}
\hline & Sun & Shaded \\
\hline Cultivated Sites & 11 & 0 \\
Uncultivated Sites & 17 & 7 \\
\hline
\end{tabular}




\section{CHAPTER 6: DISCUSSION}

This chapter presents a discussion of the use and local management of the wild edible weed tasba. Every family surveyed was familiar with tasba as a food source; it was harvested at least once by each family surveyed, indicating that tasba is an important wild food source for the community of Sanguéré Paul in northern Cameroon. The management of tasba is part of the larger traditional food system, one which is controlled by women. Modifications and changes in management are influenced by time, proximity and income based on her perspective, preferences and resources available.

\subsection{Limitations of the Study}

The limitations of this study stem from the small sample size as well as the short duration of the study. Although the findings represent the community, a larger sample size and more respondents in the job categories that were poorly represented in the original sample would make the results more robust. The rainy season of 2012 was a higher than average rainfall year which made the nightly survey difficult to complete consistently during heavy rains. This study would be more complete if consumption patterns were recorded during the upcoming dry season, in order to fully understand the role of dried vegetables and sources of fresh vegetables during the dry season. Future work of traditional vegetable use in the dry season would give the complete picture of local management of vegetable species. 


\subsection{Time Saving Activities and Tasba Use}

The amount of time a woman has affects the way she manages food within the household. If a woman is occupied with a job in the market or as a seamstress, she may not have time to go collect vegetables from her field. Market vendors are committed to spending time in the market selling her products (e.g. fish, prepared snacks, condiments, soap, candy and vegetables) and preparing her products for sale. Seamstresses have time commitments involving making and selling clothes. These women may save time by collecting more frequently from homegardens, and therefore can devote more time to other household tasks.

In this study, if a mother had a job, she is 1.71 times more likely to collect vegetables from a homegarden than en brousse, and 2.07 times more likely to collect vegetables from a homegarden than a field (Table 5.2). This trend is more exaggerated when looking at tasba specifically. She is 8.42 times more likely to collect tasba from homegardens than en brousse, and 14.6 times more likely to collect tasba from a homegarden than a field if she has a job other than subsistence farming (Table 5.3). This indicates a shift to collect vegetables closer to the household when a mother has a job. She is still is just as likely to collect traditional vegetables as households where the mother is a subsistence farmer (Figure 5.9), she may not have time to collect en brousse and collect species such as tasba which are located primarily en brousse.

This shift in collection location naturally shifts the change in collected species composition, due to the locations where different vegetables are produced. Households 
where the mother has a job are about half as likely to collect tasba as households where the mother is a subsistence farmer. Subsistence farmers benefit from the areas which tasba grows spontaneously because they are already coming to and from the field and therefore benefits by collecting from fields and en brousse. Therefore they do not have to commit a lot of extra time to forage in the area where tasba is found.

\subsection{Proximity of Collection Locations and Species Composition}

The composition of collected vegetables and collection locations is also based on the proximity of the mother's job and other livelihood activities near where plants grow. These results are closely related to time saving activities because if she is closer to collection locations, she saves time. In this study, if a mother is a subsistence farmer she is more likely to collect tasba (Figure 5.10), and more likely to collect en brousse and in the fields (Table 5.2, 5.3) than households where the mother had a job other than subsistence farming. The subsistence farmer has more of an opportunity to collect en brousse and in the fields, and therefore is more likely to collect in those areas. By working in the fields daily she is closer in proximity to areas where tasba is most commonly found.

If the mother is not going to the field as a subsistence farmer, she will not collect as often from en brousse and in the fields because her daily activities restrict her from going as far from the compound. Her livelihood strategy involves collecting vegetables closer to the household. For example, mothers who stayed at the household collected vegetables from homegardens $80 \%$ of the time compared to subsistence farmers who 
collected from homegardens approximately $25 \%$ of the time, and en brousse $40 \%$ of the time (Figure 5.15). However, if a mother is collecting more often from homegardens, she will not be able to collect species which are found en brousse such as tasba, and therefore households where the mother has a job were half as likely to collect tasba.

Mothers who are herders have a lifestyle and livelihood strategies which are based on herding cows instead of farming as with a subsistence farmer, therefore she rarely collected vegetables from fields and almost exclusively collected from en brousse and her homegarden (Figure 5.15). Because herders have the opportunity to collect en brousse, when mother's jobs are analyzed by categories, they are just as likely to collect tasba as subsistence farmers, compared to households where the mother is a market vendor and may be restricted from going en brousse, and therefore half as likely to collect tasba (Figure 5.10). Although households where the mother has a job other than subsistence farming are not less likely to collect traditional vegetables (Figure 5.9), they are less likely to collect tasba, simply because she is not in the environment where tasba is produced. She likely collects more garden species such as folere or gubudo.

The relationship between a household and the traditional vegetable system also has to do with the proximity between the family to the local food system and the community itself. Higher paying father's jobs (e.g. health center employees, IRAD employees, SODECOTON employees, ministry employees) may move the father out of the community, distancing him from the community and the traditional food system. In this study, when analysis of father's job and tasba collection were analyzed by job 
categories, households where the fathers had high paying jobs which may remove him from the community such as private jobs and government jobs, were significantly less likely to collect traditional vegetables. However, households where the father had a job within the village (e.g. religious leaders, market vendors) the households were not more or less likely to collect traditional vegetables than subsistence farmers (Figure 4.7).

This relationship between job location, household involvement in the local community, and the traditional food system is also seen when comparing mother's jobs to father's jobs. Households where the father has a job were half as likely to collect traditional vegetables, but if the mother had a job, the household was not more or less likely to collect traditional vegetables. Father's jobs often remove the father from the community compared to the mother's jobs which do not remove her from the community. Therefore she is still closely linked to the community, the local economy and the traditional lifestyle. As a woman acquires as job, she remains in the village and continues to manage her household food production, relying on traditional food vegetables.

Although households where the father had a job were less likely to collect traditional vegetables, the likelihood of collecting tasba and likelihood of collection locations were not strongly influenced by the father's job. This further indicates that it is the women who are key players in specific management strategies within the family, and differences and changes and alterations are made based on her job. How reliant a family is on producing their own vegetables may be influenced by how much of the father's 
income is used to purchase vegetables. However, specific livelihood strategies the mother performs and what vegetables she is able to produce are unique to each situation. Each women alters her actions based on what is available, most efficient, easiest and most beneficial to her and her family.

\subsection{Household Income and Food Management Strategies}

A household's income can affect the management of traditional vegetables within the household. When the father has a job other than subsistence farming, houesholds were half as likely to collect traditional vegetables (Figure 5.7). Jobs provide cash income, making the households more financially secure. Households which have jobs and receive income can afford to buy more from markets, as compared to families where the father is a subsistence farmer and excess cash must go towards household expenses such as school fees and medical payment. Families where the father worked for a private industry were the least likely to collect wild vegetables (Figure 5.7). In Cameroon, private jobs are the most secure jobs. Although people who have a job with the government were employed, payment for government jobs was unreliable, making these families more secure than subsistence farmers, but less secure than households where the father works for private institutions.

Shackelton et al. (1998) found that drying vegetables was an "adaptive strategy to cope with increasing environmental uncertainty" which was used more frequently by more vulnerable populations in dryer areas of their study. Drying is an extension of the task of food production, and a livelihood strategy which was used in this study more 
often by poorer households and vulnerable un-employed subsistence farmers who may not have a large cash income to buy vegetable species, particularity in the dry season when there is less agricultural work available. Income can effect whether or not a family dries traditional vegetables because it influences whether or not the family will be secure in the dry season.

Households where the mother was a subsistence farmer were twice as likely to dry traditional vegetables (Figure 5.13) than households where the mother had a job other than subsistence farming, indicating their investment this management activity.

Subsistence farmers dry vegetables to have them available to them in times of uncertainty in the dry season. Households where the mother has a job, particularly market vendors, can depend on the income she makes through selling items in the market and may not be as vulnerable in the dry season. However, the extent to which these dried reserves contribute to food security in the dry season is unknown without a survey of household food choices during the dry season.

\subsection{Seasonal Changes of Tasba Management and Tasba's Importance During the}

\section{"Hungry Season"}

Analysis on changes of behavior throughout the season showed that households were just as likely to collect tasba at the beginning of the season as the end of the season. Each week there was a seven percent increase in how likely households were to dry tasba. At the beginning of the season, households were collecting more day to day, and eating tasba fresh. At the end of the season, when the plants are larger, and other crops are 
available, tasba is dried and saved for the dry season. The "hungry season" occurs at the beginning of the rainy season, when tasba is being collected from day to day. Since tasba is a fast growing and the leaves are eaten (as compared to the fruit of gombo or grain of cereal crops) it can be eaten earlier than other cultivated traditional vegetables and can be foraged to provide food during this "hungry season". Later when other vegetables are available, excess tasba can be dried.

In the interviews, a key informant said that she collects the most tasba in July and August because it is abundant, but it is most often eaten that day and not saved because the plants are small. Others specifically mentioned waiting until the later months in the season when the plants are fully grown to collect, further supporting tasba use throughout the rainy season. Women often associated peak collection times with work tasks, and most women said that they collect the most tasba during the harvest, although during weeding was also mentioned. A key informant indicated that it is important to wait until after tasba has seeded before collecting, and attributed early collection to a decrease in availability.

\subsection{Importance of Tasba and En Brousse Areas in the Traditional Vegetable System}

Households where the mother was a subsistence farmer were most likely to collect tasba (Figure 5.10) and the most likely to collect en brousse (Table 5.3), indicating the importance of tasba as a food source and en brousse for a source of wild foods such as for these households. Non-managed, uncultivated, communal lands are often referred to as important areas for wild food collection (Harris and Mohammad 
2003; McGregor 1994). These communal lands near Sanguéré Paul are too degraded to farms and are often heavily grazed. However the "weedy" nature of tasba allows it to thrive in areas where other plants cannot, and tasba provides a source of free, wild food for subsistence farmers who are able to easily collect it. As important communal land area declines due to increasing population pressure leading to increased agricultural intensity, people depend more upon plants which are cultivated in gardens, and the subsistence farmers who depend on the wild plants may have to change their livelihood strategies for traditional vegetable management if tasba becomes less available (McGregor 1994).

The second most commonly reported place for tasba collection was from fields. Tasba grows well in women's fields due to the low-input nature of their farming practices. In fields where the women are weeding by hand (as opposed to fields where herbicides are used), women have the opportunity to select for specific desirable plants. Men's cash crop production involves high levels of chemical inputs including herbicides, which would decrease the level of tasba (a weed) production in their fields (Martin 1990). Increasing agricultural intensity and increased level of capital inputs could decrease the level of tasba available within fields, as women do not collect from contaminated sites.

In contrast, when agricultural intensification "homogenizes" the landscape, weedy species are favored because they are fast growers and can grow on degraded lands (McGregor 1995). Garoua and the surrounding areas has a high growth rate of people emigrating from the densely populated areas such as the Extreme North seeking 
cultivatable land. This influx of people will inevitably lead to an increase in the agricultural intensity in the area. Since weedy species are favored in these areas of high agricultural intensity, one could expect a natural increase of tasba abundance. However, if land that is currently fallowed or unused is converted to agricultural fields, this agricultural intensification could also lead to a decrease in communal land, the primary area for tasba collection. Careful management of tasba within fields in homegardens may be needed as communal land decreases.

Although households where the mother has a job collect less tasba than households where the mother is a subsistence farmer, they are more likely to dry it. A likely explanation for this is they value tasba enough as a traditional vegetable to dry it and have it available during the dry season, but they are not able to collect as much because they are not en brousse where tasba grows to collect it. Also, households where the mother has a job and potentially a form of income during the dry season may dry tasba as an additional food choice in the dry season and less as a strategy for food security as with subsistence farmers. Conversely, households where the mother is a subsistence farmer are more likely to collect tasba but less likely to dry it, possibly indicating a greater reliance of the fresh tasba during the "hungry season", when other reserves have run out. Also, since subsistence farmers were more likely to dry all vegetables, but less likely to dry tasba, this may indicate the importance of all dried vegetables to these households during the dry season because they are producing and drying species which may be available fresh from gardens in the dry season, but they would not have means to buy them. 


\section{CHAPTER 7: CONCLUSION}

Literature about traditional vegetables often calls for researchers, extension agents and other development workers to document these systems in order to understand the complicated dynamics and traditional knowledge within these systems (Shackleton 2003). This paper documented the use of the plant tasba in the traditional food system in Sanguéré Paul, Cameroon. Studying how one plant works in the system, one piece of the larger picture, shows how these systems are complicated and extensive. Each woman bases her particular strategy of food management based on her personal unique perspective, preferences, and resources, and this strategy is varied based on time, proximity, and income.

Tasba is a weed; it grows quickly and spontaneously, is found in agricultural areas, and considered a nuisance in some agricultural systems. However, the weedy qualities of this species are what also make it useful within to this food system. Since this plant is fast growing, it can be eaten during the "hungry season" when food sources are low, providing important nutrients to the diet which may be lacking at that time. Also, tasba can grow spontaneously in degraded and unused areas where other plants cannot. The weedy characteristics of this crop make this species a valuable species for the community of Sanguéré Paul as trends in land use and climate change will presumably favor this species.

Bharucha and Pretty (2010) noted that "usage [of wild plants] often depends more on natural abundance that socioeconomic factors", and this paper supports that statement. 
Wild plants were used among all socioeconomic groups and were collected from areas where it was most abundant and available to people of certain socioeconomic conditions. Tasba was used the most and managed dynamically among the group of people who were the most closely involved with it. In this case, tasba was utilized most often by women subsistence farmers. Without a form of external income, subsistence farmers are more reliant on producing their food because they may not be able to buy vegetables in the market or during the dry season. They benefit the most from collecting tasba because lives are naturally in closer proximity with the locations where tasba grows, making collecting easy and time efficient.

Changing landscapes will inevitably have an effect on the changing plant community and could affect wild food availability, especially for unmonitored, minimally managed plants that may be under-represented in policy and documentation. In order for a plant to remain a viable and useful part of a food system, it foremost needs to be available to the people who are going to use it. If agricultural intensity leads to diminishing communal lands, more active management may be needed to sustain tasba availability and abundance. This could include cultivation, similar to gubudo or folere where it is planted on the perimeter of fields and in homegardens, or could involve a less extensive version of cultivation by collecting seeds and scattering them in fields to promote growth (Scoones et al. 2004). Often crops come into domestication in food systems in similar ways, through a close relationship with people who nurture and promote favorable wild species, particularly those which thrive in man-made habitats 
(DeWet and Harlan 1975). There is also potential for tasba to become a crop which is intercropped in fields to help improve soil fertility (Becker 1983; Pasternak et al. 2009).

One thing that is clear from this study is that women are at the center of this food system, particularly subsistence farmers. When deciding the future of this plant, women should be addressed in any policy decisions or development programs relating to household food security. Food systems are critical to women; their families' livelihoods depend on it. Tasba is unique within this traditional food system. It contributes to food security by providing variety in the diet and is a low-investment diverse livelihood strategy to aid in times of uncertainty, which is adopted and utilized by subsistence farmers, a vulnerable population. Proper management and land use practices can help tasba remain a part of the traditional system and aid in food security for people of Sanguéré Paul. 


\section{WORKS CITED}

Abasse, T. A., A. Gouzayé, L. Woltering, and D. Pasternak. "The Role of Indigenous Leafy Vegetables on Daily Diet and Rural and Urban Economy of Niger." In I International Conference on Indigenous Vegetables and Legumes. Prospectus for Fighting Poverty, Hunger and Malnutrition 752, pp. 35-40. 2006

Anon,"Peace Corps Welcomes you to Cameroon: A Peace Corps Publication for New Volunteers." Last modified 2008. Accessed February 18, 2013.

http://files.peacecorps.gov/manuals/welcomebooks/cmwb694.pdf.

Awodoyin, R. O., and Sola O. "Use of sicklepod, Senna obtusifolia (L.) Irwin and Barneby, as mulch interplant in cayenne pepper, Capsicum frutescens L., production." Emirates Journal of Food and Agriculture 17, no. 1 (2005).

Balemie, K, and Kebebew F. "Ethnobotanical study of wild edible plants in Derashe and Kucha Districts, South Ethiopia." Journal of Ethnobiology and Ethnomedicine 2, no. 1 (2006): 53.

Becker, B. "The contribution of wild plants to human nutrition in the Ferlo (Northern Senegal)." Agroforestry Systems 1, no. 3 (1983): 257-267.

Beets, W.C. Raising and Sustaining Productivity of Smallholders Farming Systems in the Tropics. AgBe Publishing, Holland. (1990).

Bernard, H. R. Research Methods in Anthropology: Qualitative and Quantitative Approaches (2nd Ed). Walnut Creek: Altamira, 1995.

Bharucha, Z, and J. Pretty. "The roles and values of wild foods in agricultural systems." Philosophical Transactions of the Royal Society B: Biological Sciences 365, no. 1554 (2010): 2913-2926.

Binggeli, P. updated. Crop Protection Compendium-Senna obtusifolia (1.L Irwin and Barneby. (2005).

Campbell, B. M., M. K. Luckert, and I. Scoones. "Local-level valuation of savanna resources: a case study from Zimbabwe." Economic Botany 51, no. 1 (1997): 59-77.

Cerdan, C., R. Ndjouenkeu, and K Mbayhoudel. "Increasing the value of food crops: Impact of small-scale processing activities on the economic development of Central African savannahs." Cahiers Agricultures 13, no. 1 (2004): 85-90.

CIA (Central intelligence Agency). The World Factbook: Cameroon https://www.cia.gov/library/publications/the-world-factbook/geos/cm.html (accessed January 24, 2013) 
Cocks, M. L., L. Bangay, C. M. Shackleton, and F. K. Wiersum. "'Rich man poor man'inter-household and community factors influencing the use of wild plant resources amongst rural households in South Africa." The International Journal of Sustainable Development \& World Ecology15, no. 3 (2008): 198-210.

Cruz-Garcia, G. S., and L. L. Price. "Weeds as important vegetables for farmers." Acta Societatis Botanicorum Poloniae 81, no. 4 (2012): 397-403.

Daubenmire, R. "A Canopy-Cooerage Method ol V egetational Anal. ysis." Northwest Science 50 (1959): 431.

De Haan, L., and A. Zoomers. "Exploring the frontier of livelihoods research." Development and Change 36, no. 1 (2005): 27-47.

Delang, C. "Not just minor forest products: The economic rationale for the consumption of wild food plants by subsistence farmers." Ecological Economics 59, no. 1 (2006): 6473.

De Wet, J. MJ, and J. R. Harlan. "Weeds and domesticates: evolution in the man-made habitat." Economic Botany 29, no. 2 (1975): 99-108.

Dirar, Hamid A. "Kawal, meat substitute from fermented Cassia obtusifolia leaves." Economic Botany 38, no. 3 (1984): 342-349.

Dunlop, E. A., J. C. Wilson, and A. P. Mackey. "The potential geographic distribution of the invasive weed Senna obtusifolia in Australia." Weed research 46, no. 5 (2006): 404413.

Duponnois, R., C. Plenchette, J. Thioulouse, and P. Cadet. "The mycorrhizal soil infectivity and arbuscular mycorrhizal fungal spore communities in soils of different aged fallows in Senegal." Applied Soil Ecology 17, no. 3 (2001): 239-251.

El Hadj, Meriem, Ozzie Abaye, Amadou Kodio, and Moussa KeYta. "1 4 Dry Season Feed Supplements: the Potential Role of Cassia tora." Conflict, Social Capital and Managing Natural Resources: A West African Case Study (2005): 195.

Emmanuel Neba, N. "Triggers and Processes Of Desertification In The Dry Lands Of North Cameroon." Global Journal of Human Social Science Research 10, no. 3 (2010).

FAO (2007). Country Pasture/Forage Resource Profiles. http://www.fao.org/ag/AGP/AGPC/doc/Counprof/cameroon/cameroon.htm. February 19, 2013.

FAO (2011). The Role of Women in Agriculture Rome: FAO. http://www.fao.org/docrep/013/am307e/am307e00.pdf. February 13, 2013. 
FAO (2013). GIEWS Country Briefs: Food Security Snapshot. http://www.fao.org/giews/countrybrief/country.jsp?code=CMR April 9, 2013.

Fon, D. E.. "Access to Arable Land by Rural Women in Cameroon." Tropicultura 29, no. 2 (2011): 65-69.

Gockowski, J., Julie M. Mbah, and T.F. Moulende. "African traditional leafy vegetables and the urban and peri-urban poor." Food policy 28, no. 3 (2003): 221-235.

Gregory, P. J., J. SI Ingram, and M. Brklacich. "Climate change and food security." Philosophical Transactions of the Royal Society B: Biological Sciences 360, no. 1463 (2005): 2139-2148.

Guest, Greg, Arwen Bunce, and Laura Johnson. "How many interviews are enough? An experiment with data saturation and variability." Field methods 18, no. 1 (2006): 59-82.

Hansen, K. F. "The politics of personal relations: beyond neopatrimonial practices in northern Cameroon." Africa 73, no. 02 (2003): 202-225.

Hargreaves, J. R., L. A. Morison, J. SS Gear, J. C. Kim, M. B. Makhubele, J. DH Porter, C. Watts, and P. M. Pronyk. "Assessing household wealth in health studies in developing countries: a comparison of participatory wealth ranking and survey techniques from rural South Africa." Emerging themes in epidemiology 4, no. 1 (2007): 4.

Harris, Frances MA, and Salisu Mohammed. "Relying on nature: wild foods in northern Nigeria." AMBIO: A Journal of the Human Environment 32, no. 1 (2003): 24-29.

High, C., and C. M. Shackleton. "The comparative value of wild and domestic plants in home gardens of a South African rural village." Agroforestry systems 48, no. 2 (2000): $141-156$

Holm, L., J. Doll, E. Holm, Juan V. Pancho, and James P. Herberger. World weeds: natural histories and distribution. Wiley, 1997.

Holm, L., J. V. Pancho, J. P. Herberger, and Donald L. Plucknett. A geographical atlas of world weeds. John Wiley and Sons., 1979

(IFRC). International Federation of Red Cross and Red Crescent Societies Disaster relief emergency fund (dref) Cameroon: Floods in the north and far north regions. (2012, September 06). Retrieved from http://www.ifrc.org/docs/Appeals/12/MDRCM014.pdf

Institut National de la Statistique. Chapitre4 : Caracteristiques de la Population. Annuaire Statistique du Cameroun. 2011 
Iyebi-Mandjeki, O. "A l'écoute du marché: les mutations de l'agriculture maraîchère au nord du Cameroun." D. Barreteau, R. Dognin et C. von Graffenried (éds.), L'homme et le milieu végétal dans le bassin du lac Tchad, Paris, Ed. de l'ORSTOM (1997): 187-193.

Jenkins, M. W., and B. Scott. "Behavioral indicators of household decision-making and demand for sanitation and potential gains from social marketing in Ghana." Social science \& medicine 64, no. 12 (2007): 2427-2442.

JMP, Version 7. SAS Institute Inc., Cary, NC, 1989-2007

Kenga, R., M. M'Biandoun, A. Njoya, M. Havard, and E. Vall. "Analysis of constraints to agricultural production in the Sudan-sahelian zone of Cameroon using a diagnostic survey." In Savanes africaines: des espaces en mutation, des acteurs face à de nouveaux défis. Actes du colloque, Garoua, Cameroun. 2003.

Kuhnlein, H. V., and O. Receveur. "Dietary change and traditional food systems of indigenous peoples." Annual Review of Nutrition 16, no. 1 (1996): 417-442.

LimLi, C., S. Edwards, and N. El-Hage Scialabba. Climate change and food systems resilience in sub-saharan Africa. Food and agriculture organization of the United nations (FAO), 2011.

Lodhi, A. Y. "The language situation in Africa today." Nordic Journal of African Studies 2, no. 1 (1993): 79-86.

Lynch, S. G. "Income distribution, poverty, and consumer preferences in Cameroon." $\mathrm{PhD}$ diss., Cornell University, 1991.

Martin, J. "L'expérimentation de produits herbicides du Nord Cameroon: résultats récents et perspectives de développement." Coton et fibres tropicales 45, no. 4 (1990): 309-321.

Mayaka, T. B. "Wildlife co-management in the Bénoué National Park-Complex, Cameroon: A bumpy road to institutional development." World Development 30, no. 11 (2002): 2001-2016.

Mahyao, A., C. Kouame, E. Agbo, J. N'zi, L. Fondio, and P. Van Damme. "Socioeconomic Importance of Uran Markets Supply Chains of indigenous Leafy Vegetables in Cote d'Ivoire" In International Symposium on Underutilized Plants for Food Security, Nutrition, Income and Sustainable Development 806, pp. 489-496. 2008.

McGregor, J. "Gathered produce in Zimbabwe's communal areas changing resource availability and use." Ecology of Food and Nutrition 33, no. 3 (1995): 163-193.

MINPAT (Ministeere du Plan et de l'Administration Territoriale) "Declaration de la Politique Nationale de Population.” Yaounde, Cameroon. (1993) 
Modi, M., A. Modi, and S. Hendriks. "Potential role for wild vegetables in household food security: a preliminary case study in KwaZulu-Natal, South Africa." African Journal of Food, Agriculture, Nutrition and Development 6, no. 1 (2006): 1-13.

Molua, E. L. "Climatic trends in Cameroon: implications for agricultural management." Climate Research 30, no. 3 (2006): 255-262.

Molua, E L., and C. M. Lambi. "Climate, hydrology and water resources in Cameroon." CEEPA DP33, University of Pretoria, South Africa(2006)

Molua, E.t L., and C. M. Lambi. "The economic impact of climate change on agriculture in Cameroon." (2007).

Moritz, M., P. Scholte, and S. Kari. "The demise of the nomadic contract: arrangements and rangelands under pressure in the Far North of Cameroon." Nomadic Peoples 6, no. 1 (2002): 124-143.

Murray, D. S., D. L. Thurlow, and G. A. Buchanan. "Sicklepod in the Southeast." Weeds Today 7 (1976): 12-14.

Nana P. D., and M. Havard. "Management advice for family farms: an extension process to help farmers of North Cameroon meet up challenges of professionalization." (2002).

Noer, C.. Fulfulde-Francais-English Trilingual Dictionary. n.d.

Parsons, W. T., and E. Cuthbertson. Noxious weeds of Australia. CSIRO, 2001.

Pasternak, D., L. Woltering, A. Nikiema, D. Senbeto, D. Fatondji, and J. Ndjeunga. "Domestication of Senna obtusifolia, an important leafy vegetable for the Sahel." In I International Conference on Indigenous Vegetables and Legumes. Prospectus for Fighting Poverty, Hunger and Malnutrition 752, pp. 299-302. 2006.

Pasternak, D., D. Senbeto, A. Nikiema, S. Kumar, D. Fatondji, L. Woltering, A. Ratnadass, and J. Ndjeunga. "Bioreclamation of degraded African lands with women empowerment." Chronica Hortic 49 (2009): 24-27.

Radosevich, S. R., J. S. Holt, and C. Ghersa. Weed ecology: implications for management. Wiley, 1997.

Saito, K. A., H. Mekonnen, and D. Spurling. Raising the productivity of women farmers in Sub-Saharan Africa. Vol. 230. World Bank Publications, 1994. Chicago

Saito, K. A., and C.J. Weidemann, Agricultural extension for women farmers in Africa. Vol. 103. World Bank Publications, 1990.

Scoones, I., M. Melnyk, and J. N. Pretty. "Wild Foods in Agricultural Systems." The Overstory Book: Cultivating Connections with Trees (2004): 44 
Shackleton, C. M. "The prevalence of use and value of wild edible herbs in South Africa." South African journal of science 99, no. 1 \& 2 (2003): 23-25.

Shackleton, C. M., and S. E. Shackleton. "Household wealth status and natural resource use in the Kat River valley, South Africa." Ecological Economics 57, no. 2 (2006): 306317.

Shackleton, S. E., C. M. Dzerefos, C. M. Shackleton, and F. R. Mathabela. "Use and trading of wild edible herbs in the central lowveld savanna region, South Africa." Economic Botany 52, no. 3 (1998): 251-259.

Shackleton, S. E., C. M. Shackleton, T. R. Netshiluvhi, B. S. Geach, A. Ballance, and D. HK Fairbanks. "Use patterns and value of savanna resources in three rural villages in South Africa." Economic Botany 56, no. 2 (2002): 130-146.

Shava, Soul. "Research on indigenous knowledge and its application: A case of wild food plants of Zimbabwe"." Southern African Journal of Environmental Education 22 (2005): 73-86.

Sudi, I. Y., Ksgbiya, D. M., Muluh, E. K., \& Clement, A. Nutritional and phytochemical screening of Senna obtusifolia indigenous to Mubi, Nigeria. Advances in Applied Science Research, 3 (2011):432-437

Tabuti, J. R. S. "Status of non-cultivated food plants in Bulamogi County, Uganda." African Journal of Ecology 45 (2007): 96-101.

Thrupp, L.A.. "Linking agricultural biodiversity and food security: the valuable role of agrobiodiversity for sustainable agriculture." International Affairs76, no. 2 (2000): 283297.

Tingem, M., M. Rivington, G. Bellocchi, S. Azam-Ali, and J. Colls. "Effects of climate change on crop production in Cameroon."Climate Research 36, no. 1 (2008): 65.

Transparency International: Archive site , "The Corruption Perceptions Index (1998)." Accessed February 6, 2013.

Transparency International, "Corruption by country/territory." Last modified 2012. UNICEF,. West and Central Africa: Cameroon.

UNICEF (Humanitarian Action fund For Children). 2011.

http://www.unicef.org/hac2011/files/HAC2011_4pager_Cameroon_rev1.pdf (accessed February, 6 2013). Accessed February 18, 2013. http://www.transparency.org/country

US State Department, "International Religious Freedom Report: BUREAU OF DEMOCRACY, HUMAN RIGHTS, AND LABOR." Last modified 2005. Accessed March 18, 2013. http://www.state.gov/j/drl/rls/irf/2005/51454.htm 
Vainio-Mattila, K. "Wild vegetables used by the Sambaa in the Usambara Mountains, NE Tanzania." In Annales Botanici Fennici, vol. 37, no. 1, pp. 57-68. Helsinki: Societas Biologica Fennica Vanamo, 2000.

Vieyra-Odilon, Leticia, and Heike Vibrans. "Weeds as crops: The value of maize field weeds in the valley of Toluca, Mexico." Economic Botany 55, no. 3 (2001): 426-443.

XE Currency Converter, "Central African CFA Franc BEAC- USD Exchange rates." Last modified 2013. Accessed March 26, 2013. (http://www.xe.com/currencyconverter/convert/?Amount=1\&From=XAF\&To=USD.)

Yang, Ray-Yu, and Gudrun B. Keding. "Nutritional contributions of important African indigenous vegetables." African Indigenous Vegetables in Urban Agriculture. (2009): 105-143.

Yengoh, Genesis T. "Determinants of yield differences in small-scale food crop farming systems in Cameroon." Agriculture \& Food Security 1, no. 1 (2012): 19.

Zinyama, L. M., T. Matiza, and D. J. Campbell. "The use of wild foods during periods of food shortage in rural Zimbabwe." Ecology of Food and Nutrition 24, no. 4 (1990): 251265.

\section{Appendix A: Copyright Permission}

Figure 2.1

Unless a copyright is indicated, information on the Central Intelligence Agency Web site is in the public domain and may be reproduced, published or otherwise used without the Central Intelligence Agency's permission. We request only that the Central Intelligence Agency be cited as the source of the information and that any photo credits or bylines be 
similarly credited to the photographer or author or Central Intelligence Agency, as appropriate.

If a copyright is indicated on a photo, graphic, or any other material, permission to copy these materials must be obtained from the original source.

This copyright notice does not pertain to information at Web sites other than the Central Intelligence Agency Web site.

Online: https://www.cia.gov/library/publications/the-world-factbook $/ \mathrm{geos} / \mathrm{cm} . \mathrm{html}$

Accessed: February 13, 2013

Figure 2.2

Content on www.fao.org, its affiliated websites and specific pages (collectively "the FAO website") is protected by copyright. To ensure wide dissemination of its information, FAO is committed to making its content freely available and encourages the use, reproduction and dissemination of the text, multimedia and data products presented. Except where otherwise indicated, content may be copied, printed and downloaded for private study, research and teaching purposes, or for use in non-commercial products or services, provided that appropriate acknowledgement of FAO as the source and copyright holder is given and that FAO's endorsement of users' views, products or services is not stated or implied in any way. FAO encourages unrestricted use of news releases provided on the FAO website, and no formal permission is required to reproduce these materials.

Figure 3.5

From: Trevor Taylor $<$ ttaylorpccam@gmail.com>

To: $\quad$ Mary Snyder < marys623@gmail.com>

Date: Wed, Mar 13, 2013 at 1:42 PM

I release the following photos of Millet and Cotton to Mary Snyder under the Creative Commons Attribution-NonCommercial 3.0 Unported license:

CIMG6978

CIMG6979 
P1010446

P1010856

P1010859

P1010861

Thanks,

Trevor Taylor

Figure 3.6 and Figure 3.7

from: Meghan Pollak<meghanpollak@gmail.com>

to: Mary Snyder < marys623@gmail.com>

date: Wed, Mar 13, 2013 at 3:20 PM

Hi Mary,

I give you full permission to use my photos, videos and any other documents needed for your thesis.

Meghan Pollak

Appendix B: Household survey 


\begin{tabular}{|c|c|c|c|c|c|c|c|c|c|c|c|c|}
\hline \multicolumn{8}{|c|}{ Name of family } & \multirow{2}{*}{\multicolumn{3}{|c|}{ CONSUMPTION }} & \multirow[b]{3}{*}{\begin{tabular}{|l} 
Daily \\
activity(s)
\end{tabular}} & \multirow[b]{3}{*}{ Notes } \\
\hline & \multicolumn{7}{|c|}{ COLLECTION } & & & & & \\
\hline Date & \begin{tabular}{|l}
$\begin{array}{l}\text { species } \\
\text { collected* }\end{array}$ \\
\end{tabular} & \begin{tabular}{|l} 
tasba? \\
$\mathrm{y} / \mathrm{n}$
\end{tabular} & where** & \begin{tabular}{|l} 
dried? \\
$\mathrm{y} / \mathrm{n}$
\end{tabular} & $\begin{array}{l}\text { quantity } \\
\text { collected }\end{array}$ & $\begin{array}{l}\text { onsumed } \\
\text { same day? } \\
(\mathrm{y} / \mathrm{n})\end{array}$ & $\begin{array}{l}\text { who } \\
\text { collected? }\end{array}$ & $\begin{array}{l}\begin{array}{l}\text { species } \\
\text { consumed }\end{array} \\
\end{array}$ & $\begin{array}{l}\text { Bought } \\
\text { (y/n)(price) }\end{array}$ & Prep notes & & \\
\hline & & & & & & & & & & & & \\
\hline & & & & & & & & & & & & \\
\hline & & & & & & & & & & & & \\
\hline & & & & & & & & & & & & \\
\hline & & & & & & & & & & & & \\
\hline & & & & & & & & & & & & \\
\hline & & & & & & & & & & & & \\
\hline & & & & & & & & & & & & \\
\hline & & & & & & & & & & & & \\
\hline & & & & & & & & & & & & \\
\hline & & & & & & & & & & & & \\
\hline & & & & & & & & & & & & \\
\hline & & & & & & & & & & & & \\
\hline & & & & & & & & & & & & \\
\hline & & & & & & & & & & & & \\
\hline & & & & & & & & & & & & \\
\hline & & & & OLLECTI & $\mathrm{ION}$ & & & & ONSUMPTI & & & \\
\hline Date & $\begin{array}{l}\begin{array}{l}\text { species } \\
\text { collected* }\end{array} \\
\text { colle }\end{array}$ & \begin{tabular}{|l|} 
tasba? \\
$\mathrm{y} / \mathrm{n}$
\end{tabular} & where** & $\begin{array}{l}\text { dried? } \\
y / n\end{array}$ & $\begin{array}{l}\text { quantity } \\
\text { collected }\end{array}$ & $\begin{array}{l}\text { Consumed } \\
\text { same day? } \\
(y / n)\end{array}$ & $\begin{array}{l}\text { who } \\
\text { collected? }\end{array}$ & $\begin{array}{l}\text { species } \\
\text { consumed }\end{array}$ & $\begin{array}{l}\text { Bought } \\
\text { (y/n)(price) }\end{array}$ & Prep notes & \begin{tabular}{|l} 
daily \\
activity(s)
\end{tabular} & Notes \\
\hline & & & & & & & & & & & & \\
\hline & & & & & & & & & & & & \\
\hline & & & & & & & & & & & & \\
\hline & & & & & & & & & & & & \\
\hline & & & & & & & & & & & & \\
\hline & & & & & & & & & & & & \\
\hline & & & & & & & & & & & & \\
\hline & & & & & & & & & & & & \\
\hline & & & & & & & & & & & & \\
\hline & & & & & & & & & & & & \\
\hline & & & & & & & & & & & & \\
\hline & & & & & & & & & & & & \\
\hline & & & & & & & & & & & & \\
\hline & & & & & & & & & & & & \\
\hline & & & & & & & & & & & & \\
\hline & & & & & & & & & & & & \\
\hline & & & & & & & & & & & & \\
\hline & & & & & & & & & & & & \\
\hline
\end{tabular}

\section{Appendix C: Interview Questions}


1. Do you have a homegarden? What do you plant in it? (Est-ce-que vous avez un jardin de la maison? Qu'est-ce que vous plantez dans votre jardin?)

2. Did you plant any species in your fields? (Avez-vous planter des espèces dans votre champ?)

3. What sauce do you prepare most often? Why? (Quelle sauce [haako] vous préparez-vous le plus souvent? Pourquoi?)

4. When weeding or planting do you collect from inside the fields? Do you save sauce species? (Quand vous elaborate, est-ce-que vous gardez les herbs a à l'intérieur des champs?)

5. Who collects? Do men? (Qui amener les herbes? Les hommes?)

6. How do you prepare tasba? Are there alternative ways? (Comment préparez-vous Tasba? Y at-il d'autres façons?)

7. Do you collect from "en brousse"? (Est-ce-que vous amener les herbes de la brousse?)

8. Do you preserve leaves? Why? (Ne vous conservez les herbes [haako]? Pourquoi?

9. Do you sell things you collected? Do you sell things you have dried? (Vendezvous des choses que vous avez recueillies? Vendez-vous des choses que vous avez séché?)

10. Do you eat tasba? 10. Mangez-vous Tasba?

11. Do you collect tasba? (Amenez-vous Tasba?)

12. When do you eat it most often? (Lorsque le mangez-vous le plus souvent?)

13. What other vegetables do you consume? (Que d'autres légumes mangez-vous?)

14. Did you eat tasba when you were young? Do you eat more or less now? (Avezvous mangé Tasba quand vous étiez jeune? Mangez-vous plus ou moins maintenant?)

15. Are there other uses for tasba? (Y at-il d'autres utilisations pour Tasba?)

16. Where do you look for tasba? (Où dois-vous chercher les Tasba?)

17. Do you find tasba with other plants? (Ne trouvez-vous Tasba avec d'autres plantes?)

18. Does the tasba at the beginning of the year taste different than the tasba collected at the end of the year? (Est-ce que l'Tasba au début de l'année différente de celle goût du Tasba recueillies à la fin de l'année?)

19. Does tasba taste different after it is dried? (Est-ce que le goût différent après Tasba il est séché?)

20. Is tasba sold in markets? Fresh? Dried? During the dry season? (Tasba est vendu sur les marchés? Fresh? Séché? Pendant la saison sèches)

21. What are the prices during these different times? When is it most expensive? (Quels sont les prix au cours de ces différentes périodes? Quand est-il plus cher?) 22. When you bring a lot of tasba? (22. Lorsque vous apportera beaucoup de Tasba?) 
23. Which leave did you bring the most this year? Why? (Quel congé avez-vous apporté le plus cette année? Pourquoi?) 


\section{Appendix D: Logistic Regression Using JMP}

FJOBhitmiss vs S0hitmiss

\begin{tabular}{|c|c|c|c|c|c|}
\hline \multicolumn{6}{|c|}{ Odds Ratios for FjoBHIT/miss } \\
\hline Level1 & /Level2 & Odds Ratio & Prob $>$ Chisq & Lower $95 \%$ & Upper $95 \%$ \\
\hline & hit & 1.7480932 & $0.0030^{*}$ & 1.2064007 & 2.5629295 \\
\hline hit & miss & 0.5720519 & $0.0030^{*}$ & 0.3901785 & 0.828912 \\
\hline
\end{tabular}

Fjobjmp vs s0hitmiss

\begin{tabular}{llrrrrr}
\hline \multicolumn{6}{l}{ Odds Ratios for FJOBjmp } \\
\hline Level1 & /Level2 & Odds Ratio & Prob>Chisq & Lower $95 \%$ & Upper $95 \%$ \\
1 & 0 & 0.972973 & 0.9550 & 0.3780213 & 2.5694244 \\
2 & 0 & 1.1056511 & 0.7853 & 0.5283687 & 2.2492546 \\
2 & 1 & 1.1363636 & 0.7662 & 0.4748092 & 2.5777834 \\
3 & 0 & 0.3716216 & 0.0547 & 0.1321866 & 1.0201549 \\
3 & 1 & 0.3819444 & 0.0837 & 0.1235174 & 1.136032 \\
3 & 2 & 0.3361111 & $0.0195^{*}$ & 0.1332823 & 0.8370554 \\
4 & 0 & 1.0945946 & 0.7958 & 0.54134 & 2.1345509 \\
4 & 1 & 1.125 & 0.7758 & 0.4836745 & 2.461164 \\
4 & 2 & 0.99 & 0.9694 & 0.5887851 & 1.6506026 \\
4 & 3 & 2.9454545 & $0.0170^{\star}$ & 1.2167089 & 7.2067783 \\
5 & 0 & 1.7539989 & 0.1120 & 0.8728918 & 3.3985667 \\
5 & 1 & 1.8027211 & 0.1621 & 0.7789982 & 3.9220586 \\
5 & 2 & 1.5863946 & 0.0763 & 0.9518551 & 2.6233865 \\
5 & 3 & 4.7198516 & $0.0007^{\star}$ & 1.9595427 & 11.494864 \\
5 & 4 & 1.6024187 & $0.0398^{*}$ & 1.0222431 & 2.5148689 \\
0 & 1 & 1.0277778 & 0.9550 & 0.3891922 & 2.6453539 \\
0 & 2 & 0.9044444 & 0.7853 & 0.4445917 & 1.8926179 \\
1 & 2 & 0.88 & 0.7662 & 0.3879302 & 2.1061091 \\
0 & 3 & 2.6909091 & 0.0547 & 0.9802433 & 7.5650649 \\
1 & 3 & 2.6181818 & 0.0837 & 0.8802569 & 8.0960235 \\
2 & 3 & 2.9752066 & $0.0195^{\star}$ & 1.1946641 & 7.5028729 \\
0 & 4 & 0.9135802 & 0.7958 & 0.4684826 & 1.8472678 \\
1 & 4 & 0.8888889 & 0.7758 & 0.4063118 & 2.0675062 \\
2 & 4 & 1.010101 & 0.9694 & 0.6058393 & 1.6984125 \\
3 & 4 & 0.3395062 & $0.0170^{\star}$ & 0.1387583 & 0.8218893 \\
0 & 5 & 0.5701258 & 0.1120 & 0.2942417 & 1.1456173 \\
1 & 5 & 0.554717 & 0.1621 & 0.2549681 & 1.2836999 \\
2 & 5 & 0.6303602 & 0.0763 & 0.3811867 & 1.0505801 \\
3 & 5 & 0.2118711 & $0.0007^{\star}$ & 0.0869954 & 0.5103231 \\
4 & 5 & 0.6240566 & $0.0398^{*}$ & 0.397635 & 0.9782409
\end{tabular}


Fjobhitmiss vs s1hitmiss

\begin{tabular}{llrrrrr}
\hline Odds Ratios for FjoBHIT/miss \\
\begin{tabular}{llrlrr}
\hline Level1 & /Level2 & Odds Ratio & Prob>Chisq & Lower 95\% & Upper $95 \%$ \\
miss & hit & 0.6809767 & 0.0887 & 0.4297901 & 1.0588667 \\
hit & miss & 1.468479 & 0.0887 & 0.9444059 & 2.3267171
\end{tabular}
\end{tabular}

Fjobhjmp vs s1hitmiss

\begin{tabular}{llrrrrr}
\hline \multicolumn{6}{l}{ Odds Ratios for FJOBjmp } \\
\hline Level1 & /Level2 & Odds Ratio & Prob>Chisq & Lower $95 \%$ & Upper 95\% \\
1 & 0 & 2.0689655 & 0.3048 & 0.5085012 & 8.9560764 \\
2 & 0 & 2.4705882 & 0.0884 & 0.8814493 & 8.8170757 \\
2 & 1 & 1.1941176 & 0.7395 & 0.4409156 & 3.8184726 \\
3 & 0 & 0.5454545 & 0.5783 & 0.0270563 & 3.9576366 \\
3 & 1 & 0.2636364 & 0.1873 & 0.0132623 & 1.7905651 \\
3 & 2 & 0.2207792 & 0.0768 & 0.0120092 & 1.1469646 \\
4 & 0 & 3.3103448 & $0.0137^{\star}$ & 1.2519897 & 11.440517 \\
4 & 1 & 1.6 & 0.3430 & 0.6266841 & 4.9348741 \\
4 & 2 & 1.3399015 & 0.3233 & 0.7526831 & 2.4410177 \\
4 & 3 & 6.0689655 & $0.0240^{\star}$ & 1.2147604 & 110.26694 \\
5 & 0 & 1.6768559 & 0.3240 & 0.6283368 & 5.8215438 \\
5 & 1 & 0.8104803 & 0.6914 & 0.3144815 & 2.5125029 \\
5 & 2 & 0.6787274 & 0.2089 & 0.3753965 & 1.2481085 \\
5 & 3 & 3.0742358 & 0.2037 & 0.6116491 & 55.950499 \\
5 & 4 & 0.5065502 & $0.0086^{\star}$ & 0.3028123 & 0.8412435 \\
0 & 1 & 0.4833333 & 0.3048 & 0.111656 & 1.9665638 \\
0 & 2 & 0.4047619 & 0.0884 & 0.1134163 & 1.1344952 \\
1 & 2 & 0.8374384 & 0.7395 & 0.2618848 & 2.2680077 \\
0 & 3 & 1.8333333 & 0.5783 & 0.2526761 & 36.959907 \\
1 & 3 & 3.7931034 & 0.1873 & 0.5584829 & 75.401786 \\
2 & 3 & 4.5294118 & 0.0768 & 0.8718665 & 83.269603 \\
0 & 4 & 0.3020833 & $0.0137^{\star}$ & 0.0874086 & 0.7987286 \\
1 & 4 & 0.625 & 0.3430 & 0.2026394 & 1.5957003 \\
2 & 4 & 0.7463235 & 0.3233 & 0.4096652 & 1.3285804 \\
3 & 4 & 0.1647727 & $0.0240^{*}$ & 0.0090689 & 0.8232076 \\
0 & 5 & 0.5963542 & 0.3240 & 0.1717757 & 1.5915031 \\
1 & 5 & 1.2338362 & 0.6914 & 0.3980095 & 3.1798376 \\
2 & 5 & 1.4733456 & 0.2089 & 0.8012124 & 2.6638498 \\
3 & 5 & 0.3252841 & 0.2037 & 0.0178729 & 1.6349244 \\
4 & 5 & 1.9741379 & $0.0086^{\star}$ & 1.1887165 & 3.302376
\end{tabular}


Mjobhit/miss vs s0 hit/miss

\section{Odds Ratios for mjob hit/miss}

$\begin{array}{llrrrr}\text { Level1 } & \text { Level2 } & \text { Odds Ratio } & \text { Prob>Chisq } & \text { Lower 95\% } & \text { Upper 95\% } \\ \text { miss } & \text { hit } & 1.3411945 & 0.0997 & 0.9454963 & 1.9025405 \\ \text { hit } & \text { miss } & 0.745604 & 0.0997 & 0.525613 & 1.0576456\end{array}$

Mjob vs s0 hit/miss

\begin{tabular}{|c|c|c|c|c|c|}
\hline \multicolumn{6}{|c|}{ Odds Ratios for Mjobjmp } \\
\hline Level1 & /Level2 & Odds Ratio & Prob $>$ Chisq & Lower $95 \%$ & Upper 95\% \\
\hline 2 & 1 & 1.2342857 & 0.6566 & 0.4915504 & 3.2097544 \\
\hline 3 & 1 & 1.3959184 & 0.5240 & 0.50765 & 4.1289571 \\
\hline 3 & 2 & 1.1309524 & 0.8319 & 0.3644858 & 3.6423899 \\
\hline 4 & 1 & 1.4464286 & 0.2759 & 0.7393807 & 2.7682026 \\
\hline 4 & 2 & 1.171875 & 0.7025 & 0.502974 & 2.5694608 \\
\hline 4 & 3 & 1.0361842 & 0.9402 & 0.3847041 & 2.5217771 \\
\hline 5 & 1 & 1.7700997 & 0.0768 & 0.9385151 & 3.2460224 \\
\hline 5 & 2 & 1.4341085 & 0.3727 & 0.6330679 & 3.0359576 \\
\hline 5 & 3 & 1.2680539 & 0.6106 & 0.4819498 & 2.9918873 \\
\hline 5 & 4 & 1.2237726 & 0.3339 & 0.810452 & 1.8338686 \\
\hline 1 & 2 & 0.8101852 & 0.6566 & 0.3115503 & 2.0343796 \\
\hline 1 & 3 & 0.7163743 & 0.5240 & 0.2421919 & 1.969861 \\
\hline 2 & 3 & 0.8842105 & 0.8319 & 0.274545 & 2.7435911 \\
\hline 1 & 4 & 0.691358 & 0.2759 & 0.3612452 & 1.3524833 \\
\hline 2 & 4 & 0.8533333 & 0.7025 & 0.3891867 & 1.9881743 \\
\hline 3 & 4 & 0.9650794 & 0.9402 & 0.3965458 & 2.5994007 \\
\hline 1 & 5 & 0.5649399 & 0.0768 & 0.3080693 & 1.0655129 \\
\hline 2 & 5 & 0.6972973 & 0.3727 & 0.3293854 & 1.5796095 \\
\hline 3 & 5 & 0.78861 & 0.6106 & 0.3342372 & 2.0749049 \\
\hline 4 & 5 & 0.8171453 & 0.3339 & 0.5452953 & 1.2338794 \\
\hline
\end{tabular}

Mjob hit/miss vs s1hitmiss

\begin{tabular}{|c|c|c|c|c|c|}
\hline \multicolumn{6}{|c|}{ Odds Ratios for mjob hit/miss } \\
\hline & /Level2 & Odds Ratio & Prob>Chisq & Lower 95\% & Upper 95\% \\
\hline & hit & 1.6987408 & $0.0167^{\star}$ & 1.0992181 & 2.6688234 \\
\hline hit & miss & 0.5886713 & $0.0167^{\star}$ & 0.374697 & 0.9097376 \\
\hline
\end{tabular}


Mjobjmp vs s1hit/miss

\begin{tabular}{|c|c|c|c|c|c|}
\hline \multicolumn{6}{|c|}{ Odds Ratios for Mjobjmp } \\
\hline Level1 & /Level2 & Odds Ratio & Prob $>$ Chisq & Lower $95 \%$ & Upper $95 \%$ \\
\hline 2 & 1 & 0.8429119 & 0.7771 & 0.2386823 & 2.698472 \\
\hline 3 & 1 & 0.6376812 & 0.5182 & 0.131923 & 2.38028 \\
\hline 3 & 2 & 0.7565217 & 0.7190 & 0.1431061 & 3.4141781 \\
\hline 4 & 1 & 0.5006693 & 0.1321 & 0.2128261 & 1.2451984 \\
\hline 4 & 2 & 0.5939759 & 0.3588 & 0.2152413 & 1.9172351 \\
\hline 4 & 3 & 0.7851406 & 0.7219 & 0.239748 & 3.5443363 \\
\hline 5 & 1 & 1.0777423 & 0.8465 & 0.5238313 & 2.4503319 \\
\hline 5 & 2 & 1.2785942 & 0.6160 & 0.5176613 & 3.861165 \\
\hline 5 & 3 & 1.6900958 & 0.3749 & 0.5675896 & 7.2635322 \\
\hline 5 & 4 & 2.1526029 & $0.0048^{*}$ & 1.2530447 & 3.8893944 \\
\hline 1 & 2 & 1.1863636 & 0.7771 & 0.3705801 & 4.1896689 \\
\hline 1 & 3 & 1.5681818 & 0.5182 & 0.4201186 & 7.5801795 \\
\hline 2 & 3 & 1.3218391 & 0.7190 & 0.2928963 & 6.9878225 \\
\hline 1 & 4 & 1.9973262 & 0.1321 & 0.8030849 & 4.6986727 \\
\hline 2 & 4 & 1.68357 & 0.3588 & 0.5215845 & 4.6459476 \\
\hline 3 & 4 & 1.2736573 & 0.7219 & 0.2821403 & 4.1710459 \\
\hline 1 & 5 & 0.9278656 & 0.8465 & 0.408108 & 1.9090116 \\
\hline 2 & 5 & 0.7821089 & 0.6160 & 0.2589892 & 1.9317649 \\
\hline 3 & 5 & 0.5916824 & 0.3749 & 0.1376741 & 1.7618364 \\
\hline 4 & 5 & 0.4645539 & $0.0048^{*}$ & 0.2571094 & 0.7980561 \\
\hline
\end{tabular}

Fjobhit/miss vs dried

\begin{tabular}{|c|c|c|c|c|c|}
\hline \multicolumn{6}{|c|}{ Odds Ratios for FjoBHIT/miss } \\
\hline & & Odds Ratio & Prob $>$ Chisq & Lower $95 \%$ & \\
\hline & hit & & & & \\
\hline hit & miss & 1.0851282 & 0.6716 & 0.7454381 & 1.5911515 \\
\hline
\end{tabular}


Fjobvsjmp vs dried hit/miss

\begin{tabular}{|lrrrrr|}
\hline \multicolumn{6}{l}{ Odds Ratios for FJOBjmp } \\
\hline Level1 & /Level2 & Odds Ratio & Prob $>$ Chisq & Lower $95 \%$ & Upper $95 \%$ \\
1 & 0 & 3.5 & 0.0820 & 0.8541972 & 17.611369 \\
2 & 0 & 5.9888889 & $0.0006^{*}$ & 2.0137537 & 25.774418 \\
2 & 1 & 1.7111111 & 0.2594 & 0.6863012 & 4.9014903 \\
3 & 0 & 0.7424242 & 0.7968 & 0.0356369 & 6.1698524 \\
3 & 1 & 0.2121212 & 0.1072 & 0.0108151 & 1.3689179 \\
3 & 2 & 0.1239669 & $0.0073^{\star}$ & 0.0067927 & 0.6281939 \\
4 & 0 & 5.8848039 & $0.0004^{*}$ & 2.0361209 & 24.955766 \\
4 & 1 & 1.6813725 & 0.2595 & 0.6965698 & 4.7110499 \\
4 & 2 & 0.9826203 & 0.9469 & 0.5884648 & 1.6541071 \\
4 & 3 & 7.9264706 & $0.0068^{*}$ & 1.5967621 & 143.74049 \\
5 & 0 & 4.2608696 & $0.0046^{*}$ & 1.4878407 & 17.9816 \\
5 & 1 & 1.2173913 & 0.6738 & 0.5096228 & 3.3859389 \\
5 & 2 & 0.7114625 & 0.1843 & 0.433553 & 1.1786566 \\
5 & 3 & 5.7391304 & $0.0282^{*}$ & 1.1637898 & 103.85958 \\
5 & 4 & 0.7240461 & 0.1540 & 0.4647335 & 1.129282 \\
0 & 1 & 0.2857143 & 0.0820 & 0.0567815 & 1.1706899 \\
0 & 2 & 0.1669759 & $0.0006^{*}$ & 0.0387982 & 0.4965851 \\
1 & 2 & 0.5844156 & 0.2594 & 0.2040196 & 1.4570863 \\
0 & 3 & 1.3469388 & 0.7968 & 0.1620784 & 28.060811 \\
1 & 3 & 4.7142857 & 0.1072 & 0.730504 & 92.463566 \\
2 & 3 & 8.0666667 & $0.0073^{*}$ & 1.5918653 & 147.21616 \\
0 & 4 & 0.1699292 & $0.0004^{*}$ & 0.0400709 & 0.49113 \\
1 & 4 & 0.5947522 & 0.2595 & 0.2122669 & 1.4356064 \\
2 & 4 & 1.0176871 & 0.9469 & 0.6045558 & 1.6993368 \\
3 & 4 & 0.1261596 & $0.0068^{*}$ & 0.006957 & 0.6262674 \\
0 & 5 & 0.2346939 & $0.0046^{*}$ & 0.0556124 & 0.672115 \\
1 & 5 & 0.8214286 & 0.6738 & 0.2953391 & 1.9622356 \\
2 & 5 & 1.4055556 & 0.1843 & 0.8484236 & 2.3065231 \\
3 & 5 & 0.1742424 & $0.0282^{*}$ & 0.0096284 & 0.8592617 \\
4 & 5 & 1.3811275 & 0.1540 & 0.8855184 & 2.151771
\end{tabular}

Mjob hit/miss vs dried hit/miss

\begin{tabular}{|c|c|c|c|c|c|}
\hline \multicolumn{6}{|c|}{ Odds Ratios for mjob hit/miss } \\
\hline & ILevel2 & Odds Ratio & Prob $>$ Chisq & Lower $95 \%$ & Upper 95\% \\
\hline & hit & 2.1721262 & $<.0001^{*}$ & 1.4733149 & 3.2478604 \\
\hline & miss & 0.4603784 & $<.0001^{*}$ & 0.307895 & 0.6787415 \\
\hline
\end{tabular}


Mjobjmp vs dried hit/miss

\begin{tabular}{llrrrr}
\hline \multicolumn{6}{l}{ Odds Ratios for Mjobjmp } \\
\hline \multicolumn{7}{l}{ Level1 } & /Level2 & Odds Ratio & Prob>Chisq & Lower $95 \%$ & Upper $95 \%$ \\
2 & 1 & 1.6785714 & 0.4085 & 0.4820038 & 5.8597086 \\
3 & 1 & 1.8650794 & 0.3500 & 0.4892871 & 6.878262 \\
3 & 2 & 1.1111111 & 0.8753 & 0.2855634 & 4.1782562 \\
4 & 1 & 1.2972399 & 0.5821 & 0.5336648 & 3.6492688 \\
4 & 2 & 0.7728238 & 0.6108 & 0.3069588 & 2.2238878 \\
4 & 3 & 0.6955414 & 0.5134 & 0.2562737 & 2.2248921 \\
5 & 1 & 2.8918757 & $0.0081^{\star}$ & 1.2915009 & 7.7272772 \\
5 & 2 & 1.7228196 & 0.2187 & 0.7393414 & 4.7124144 \\
5 & 3 & 1.5505376 & 0.3721 & 0.6132253 & 4.7389861 \\
5 & 4 & 2.2292528 & $0.0005^{\star}$ & 1.4085101 & 3.636075 \\
1 & 2 & 0.5957447 & 0.4085 & 0.170657 & 2.0746726 \\
1 & 3 & 0.5361702 & 0.3500 & 0.1453856 & 2.04379 \\
2 & 3 & 0.9 & 0.8753 & 0.2393343 & 3.5018495 \\
1 & 4 & 0.7708674 & 0.5821 & 0.2740275 & 1.8738356 \\
2 & 4 & 1.293956 & 0.6108 & 0.449663 & 3.2577666 \\
3 & 4 & 1.4377289 & 0.5134 & 0.44946 & 3.9020781 \\
1 & 5 & 0.3457963 & $0.0081^{\star}$ & 0.1294117 & 0.7742929 \\
2 & 5 & 0.5804438 & 0.2187 & 0.2122054 & 1.3525552 \\
3 & 5 & 0.6449376 & 0.3721 & 0.2110156 & 1.6307221 \\
4 & 5 & 0.4485808 & $0.0005^{\star}$ & 0.2750218 & 0.7099701
\end{tabular}


Location verses mjobhit/miss

\begin{tabular}{|c|c|c|c|c|c|}
\hline \multicolumn{6}{|c|}{ Odds Ratios for Location } \\
\hline Level1 & /Level2 & Odds Ratio & Prob $>$ Chisq & Lower 95\% & Upper $95 \%$ \\
\hline Field & En Brousse & 0.8289157 & 0.4306 & 0.5171311 & 1.3200623 \\
\hline Homegarden & En Brousse & 1.7185185 & $0.0108^{*}$ & 1.1328921 & 2.616332 \\
\hline Homegarden & Field & 2.0732127 & $0.0024^{*}$ & 1.2921105 & 3.356718 \\
\hline Neighbor & En Brousse & 1 & 1.0000 & 0.292882 & 3.1110042 \\
\hline Neighbor & Field & 1.2063953 & 0.7561 & 0.3466252 & 3.8415987 \\
\hline Neighbor & Homegarden & 0.5818966 & 0.3528 & 0.1698646 & 1.8164723 \\
\hline No Collection & En Brousse & 1.2 & 0.8155 & 0.2311518 & 5.5862445 \\
\hline No Collection & Field & 1.4476744 & 0.6415 & 0.2749958 & 6.850829 \\
\hline No Collection & Homegarden & 0.6982759 & 0.6430 & 0.1341903 & 3.258628 \\
\hline No Collection & Neighbor & 1.2 & 0.8485 & 0.173206 & 7.9696587 \\
\hline En Brousse & Field & 1.2063953 & 0.4306 & 0.75754 & 1.9337455 \\
\hline En Brousse & Homegarden & 0.5818966 & $0.0108^{*}$ & 0.3822145 & 0.8826966 \\
\hline Field & Homegarden & 0.4823432 & $0.0024^{*}$ & 0.29791 & 0.7739276 \\
\hline En Brousse & Neighbor & 1 & 1.0000 & 0.3214396 & 3.4143439 \\
\hline Field & Neighbor & 0.8289157 & 0.7561 & 0.2603083 & 2.8849604 \\
\hline Homegarden & Neighbor & 1.7185185 & 0.3528 & 0.5505176 & 5.8870423 \\
\hline En Brousse & No Collection & 0.8333333 & 0.8155 & 0.1790111 & 4.3261611 \\
\hline Field & No Collection & 0.6907631 & 0.6415 & 0.1459677 & 3.636419 \\
\hline Homegarden & No Collection & 1.4320988 & 0.6430 & 0.3068776 & 7.4521061 \\
\hline & & & & 01254750 & \\
\hline
\end{tabular}


Fjob hit/miss vs location

\begin{tabular}{|c|c|c|c|c|c|}
\hline \multicolumn{6}{|c|}{ Odds Ratios for Location } \\
\hline Level1 & /Level2 & Odds Ratio & Prob $>$ Chisq & Lower $95 \%$ & Upper $95 \%$ \\
\hline Field & En Brousse & 1.1647727 & 0.5206 & 0.7323512 & 1.8635117 \\
\hline Homegarden & En Brousse & 0.6400602 & $0.0359^{*}$ & 0.420629 & 0.9711802 \\
\hline Homegarden & Field & 0.5495151 & $0.0127^{*}$ & 0.3401535 & 0.8807468 \\
\hline Neighbor & En Brousse & 0.7291667 & 0.5851 & 0.2336259 & 2.3431208 \\
\hline Neighbor & Field & 0.6260163 & 0.4285 & 0.1962098 & 2.0525338 \\
\hline Neighbor & Homegarden & 1.1392157 & 0.8212 & 0.3637924 & 3.6736301 \\
\hline No Collection & En Brousse & 0.46875 & 0.3270 & 0.0902796 & 2.181681 \\
\hline No Collection & Field & 0.402439 & 0.2446 & 0.0764346 & 1.9022548 \\
\hline No Collection & Homegarden & 0.7323529 & 0.6878 & 0.1407443 & 3.4175885 \\
\hline No Collection & Neighbor & 0.6428571 & 0.6388 & 0.0924612 & 4.1034894 \\
\hline En Brousse & Field & 0.8585366 & 0.5206 & 0.5366212 & 1.3654651 \\
\hline En Brousse & Homegarden & 1.5623529 & $0.0359^{*}$ & 1.029675 & 2.3773918 \\
\hline Field & Homegarden & 1.8197861 & $0.0127^{\star}$ & 1.1354001 & 2.9398494 \\
\hline En Brousse & Neighbor & 1.3714286 & 0.5851 & 0.4267812 & 4.2803474 \\
\hline Field & Neighbor & 1.5974026 & 0.4285 & 0.4872027 & 5.0965866 \\
\hline Homegarden & Neighbor & 0.8777969 & 0.8212 & 0.2722103 & 2.7488203 \\
\hline En Brousse & No Collection & 2.1333333 & 0.3270 & 0.4583622 & 11.076705 \\
\hline Field & No Collection & 2.4848485 & 0.2446 & 0.5256919 & 13.083079 \\
\hline Homegarden & No Collection & 1.3654618 & 0.6878 & 0.292604 & 7.1050834 \\
\hline Neighbor & No Collection & 1.5555556 & 0.6388 & 0.243695 & 10.815351 \\
\hline
\end{tabular}

